
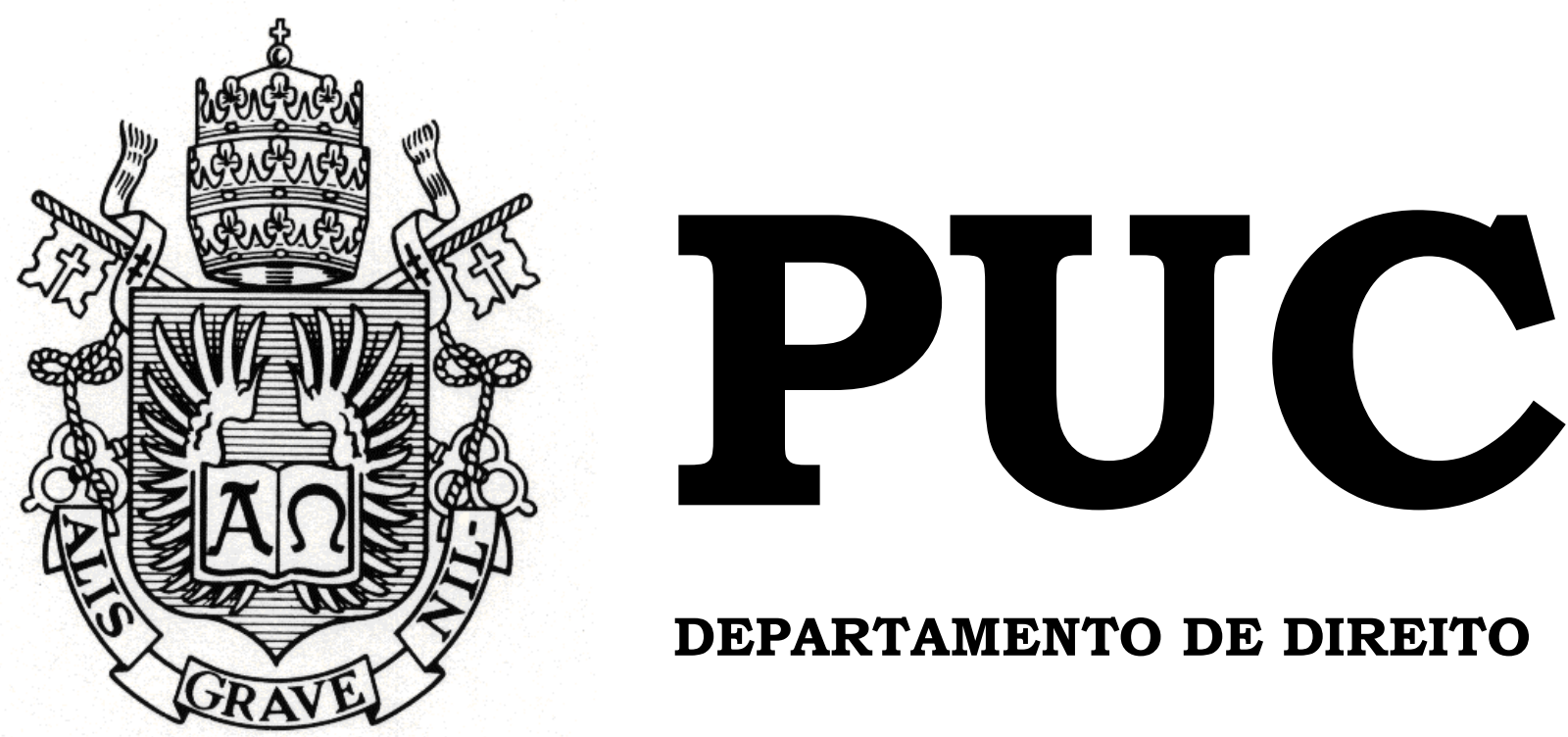

DEPARTAMENTO DE DIREITO

\title{
MERCADO DE CAPITAIS NO SÉCULO XXI - OS CRIPTOATIVOS E O INITIAL COIN OFFERING
}

\author{
Por
}

MURILO DEBOSSAM DE BARROS E AZEVEDO

ORIENTADOR: Luiz Claudio Salles Cristófaro COORIENTADOR: Francisco Antunes Maciel Mussnich

\section{1}

PONTIFÍCIA UNIVERSIDADE CATÓLICA DO RIO DE JANEIRO

RUA MARQUÊS DE SÃO VICENTE, 225 - CEP 22451-900

$$
\text { RIO DE JANEIRO - BRASIL }
$$




\title{
MERCADO DE CAPITAIS NO SÉCULO XXI - OS CRIPTOATIVOS E O INITIAL COIN OFFERING
}

por

\section{MURILO DEBOSSAM DE BARROS E AZEVEDO}

\author{
Monografia apresentada ao \\ Departamento de Direito da \\ Pontifícia Universidade Católica do \\ Rio de Janeiro (PUC-Rio) como \\ requisito parcial para a obtenção do \\ Título de Bacharel em Direito.
}

Orientador: Luiz Claudio Salles Cristófaro Coorientador: Francisco Antunes Maciel Mussnich 


\section{AGRADECIMENTOS}

Aos meus pais, por todo apoio incondicional e ensinamentos que sempre me deram.

Aos meus amigos, por sempre estarem ao meu lado nos momentos mais difíceis e pela compreensão da minha ausência.

Adicionalmente, gostaria de agradecer ao escritório Barbosa, Raimundo, Gontijo e Câmara Advogados, por ter sido meu berço de direito societário e terem me acolhido como uma família.

Por fim, aos meus professores e orientadores Luiz Claudio Cristófaro e Francisco Mussnich, por toda disponibilidade, paciência e serem minhas fontes de inspiração e admiração. 


\section{RESUMO}

AZEVEDO, Murilo Debossam de Barros e. Mercado de Capitais no Século XXI - Criptoativos e o Initial Coin Offering. Rio de Janeiro: 2019. 89 p. Monografia de final de curso. Departamento de Direito da Pontifícia Universidade Católica do Rio de Janeiro - PUC-Rio.

O presente trabalho tem como objetivo analisar a constituição dos Criptoativos e o seu enquadramento dentro da esfera jurídica, a fim de comparar com os sistemas de investimento atuais e com os conceitos jurídicos trabalhados dentro das operações financeiras. Além disso, serão examinadas instituições regulatórias, brasileiras e de outros países, e seus comunicados sobre o tema com o propósito de ponderar o entendimento que está sendo construído e tentar compreender as formas que esse novo ativo poderá ser trabalho na atualidade e no futuro.

Palavras-Chave: Direito Societário - Mercado de Capitais - Valor Mobiliário - Criptoativos - Criptomoedas - Cryptocurrency - Cryptoassets - Sandbox - Initial Coin Offering - Tokenized Asset Offering - Oferta Pública de Aquisição de Ações - Initial Public Offering. 


\section{SUMÁRIO}

INTRODUÇÃ̂ ...................................................................................6

CAPÍTULO 1- CARACTERÍSTICAS DOS CRIPTOATIVOS..............9

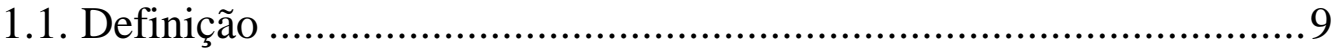

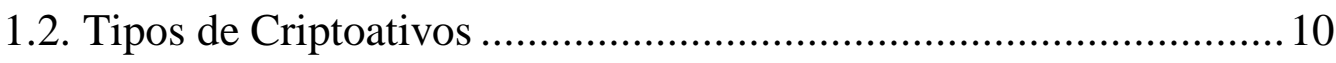

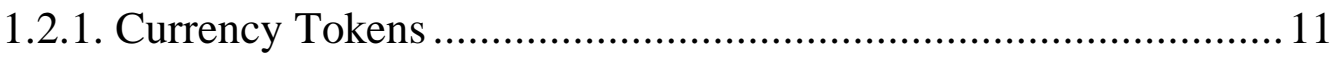

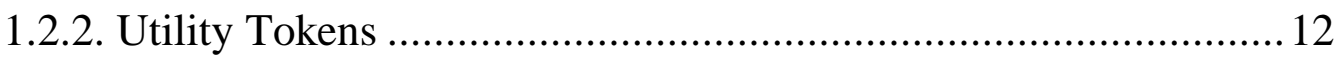

1.2.3. SecuritiesTokens / EquityTokens ............................................... 14

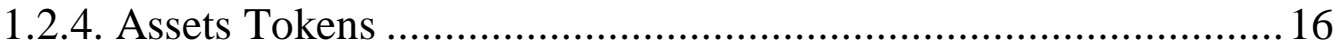

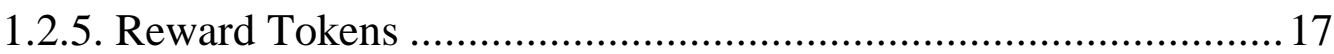

CAPÍTULO 2 - CONCEITOS JURÍDICOS .............................................19

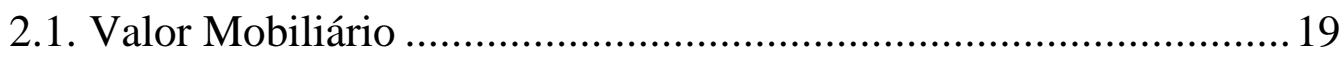

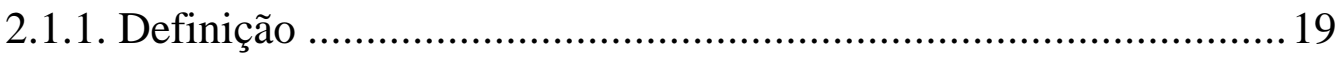

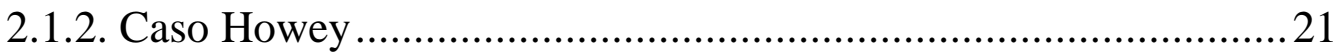

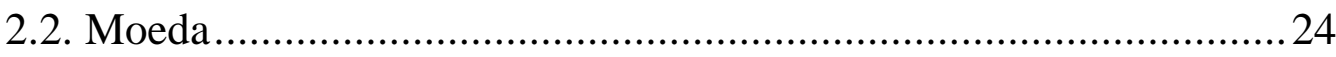

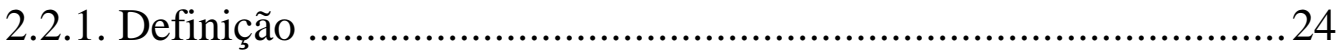

CAPÍTULO 3 - TIPOS DE MERCADO _...........................................28

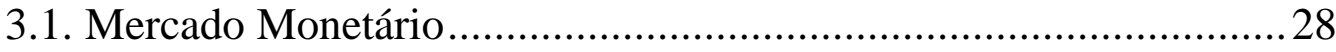

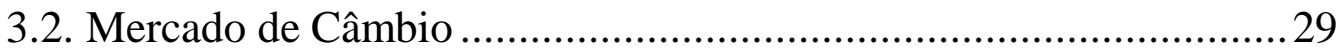

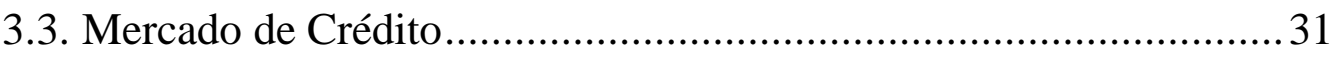

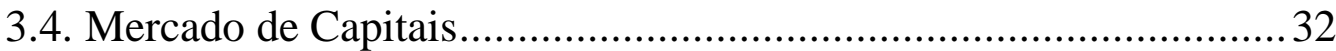

CAPÍTULO 4 - CONCEITUAÇÃO DO I.C.O. COM SUAS SEMELHANÇAS E DIFERENÇAS COM O I.P.O..................................36

4.1. Definição ...............................................................................................36

CAPÍTULO 5 - Entidades Reguladoras e Fiscalizadoras do Brasil .....45

5.1. Comissão de Valores Mobiliários ......................................................45

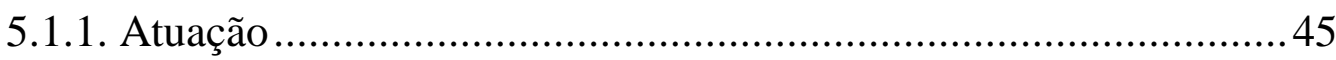

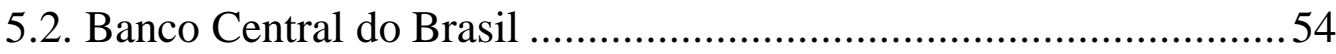

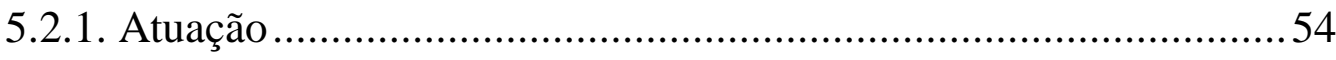




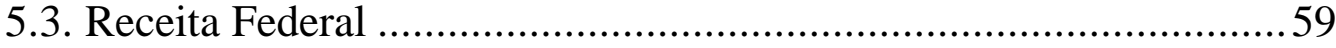

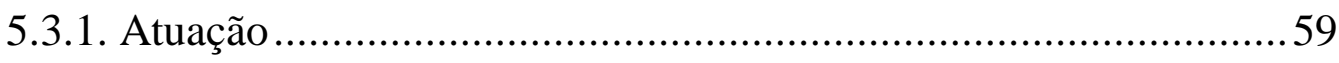

CAPÍTULO 6 - DIRETRIZES DE INSTITUIÇÕES REGULADORAS INTERNACIONAIS ........................................................................63

6.1. Securities and Exchange Commission ......................................6 63

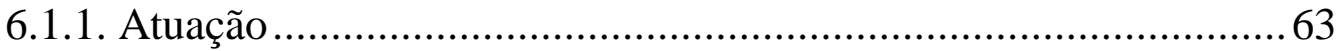

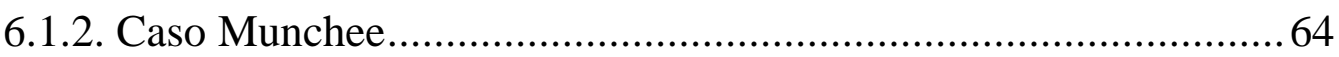

6.2. Malta Financial Services Authority ......................................... 72

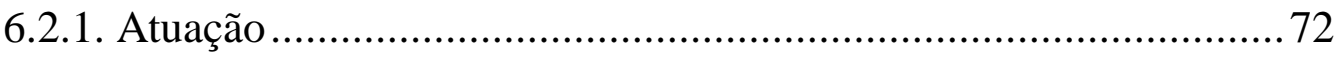

6.3. China Securities Regulatory Commission ................................ 75

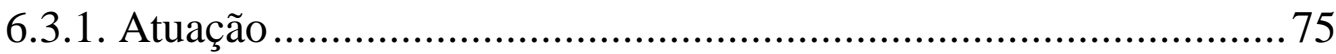

CONCLUSÃO

REFERÊNCIAS BIBLIOGRÁFICAS...............................................8 80 


\section{INTRODUÇÃO}

Desde a criação da Amsterdam Stock Exchange em $1602^{1}$, fundada pela Companhia das Índias Orientais, o conceito de ações e ativos foi se ampliando com o passar do tempo. Tal bolsa de valores foi constituída primeiramente como forma de captação de dinheiro pela então criada sociedade anônima holandesa para poder exercer seus projetos de trocas comerciais marítimas através das grandes navegações. O que mostra que desde o início o mercado de capitais tem como objetivo de financiar a atividade econômica, ao tornar atrativa uma forma de poupança que pode conferir rendimento ao dinheiro aportado por meio de uma valorização futura em longo prazo.

Como é definido pela Luciana Dias em sua recente obra²:

O mercado de capitais, segmento integrante do mercado financeiro, tem por função econômica essencial possibilitar a transferência de recursos de sujeitos superavitários para sujeitos deficitários. Esse mercado se instrumentaliza por uma série de mecanismos jurídicos, bastante distintos entre si, cuja principal característica é o fato de que os agentes superavitários que transferem seus recursos para os agentes deficitários o fazem de forma direta, sem a interposição de uma instituição bancária.

Contudo, como ocorre a regulação dos investimentos quando feitos em bolsas de valores? Entende-se como regulação o emprego dos instrumentos legais necessários à implementação de objetivos de política econômica social ${ }^{3}$.

\footnotetext{
${ }^{1}$ Considerada como a bolsa de valores mais antiga do mundo a emitir ações. Conforme trata PETRAM, Lodewijk. The World's First Stock Exchange: How the Amsterdam Market for Duscht East India Company Shares Became a Modern Securities Market, 1602-1200. RICHARDS, Lynne. (Trad.). ISBN 9780231163781. Columbia University Press, 2014.

${ }_{2}^{2}$ PINHEIRO, Armando Castelar et al. Direito e economia: diálogos. Rio de Janeiro: FGV Editora, 2019. p. 441.

${ }^{3}$ HERTOG, Johan Den. General Theories of Regulation. In: BOUDEWIJN BOUCKAERT, Gerrit de Geest (Eds.). Enciclopedia of Law and Economics, v. 3. Cheltenham: Edward Elgar Publishing Limited, 2001. p. 223.
} 
Como explica o ilustre professor Nelson Eizirik em sua obra ${ }^{4}$ :

A regulação de determinada atividade importa o estabelecimento de limites à atuação dos agentes econômicos, que inexistem quando o mercado é inteiramente livre. Com efeito, num modelo puro de economia de livre mercado, a ordem jurídica não estabelece uma regulação da conduta dos participantes, restringindose a disciplinar os direitos de propriedade e as relações contratuais, sem, porém, limitar o direito do proprietário de usar o bem, ou estabelecer exigências com relação ao conteúdo dos contratos (preços mínimos ou cláusulas obrigatórias).

No Brasil, o primeiro passo para regulamentação foi dado com a promulgação da Lei 4.595/1964, que criou o Conselho Monetário Nacional ("CMN") e o Banco Central, e da Lei 4.728/65, que criou o sistema de mercado de capitais. A partir dessas normas, resultou, pela primeira vez, num controle institucional sobre as instituições financeiras e foram estabelecias medidas para disciplinar e fortalecer o mercado de capitais no país, com regras para emissão de novas ações, proibição de mercado paralelo, regulação da bolsa de valores e de outros agentes intermediadores ${ }^{5}$.

Porém, o quadro de mercado de capitais brasileiro permaneceu estagnado. Só em 1976 foi possível obter o começo da formação desse mercado com a introdução das leis: 6.404/76, a nova lei das sociedades anônimas que visava modernizar as regras que regiam as companhias, e a lei 6.385/76, Lei de Mercado de Capitais, que constituiu a Comissão de Valores Mobiliários, órgão encarregado da disciplina do mercado destinado exclusivamente a regulamentar e desenvolver o mercado de capitais, fiscalizar a Bolsa de Valores e as companhias abertas ${ }^{6}$.

E até os dias atuais, os ativos do mercado de capitais continuam constantemente em evolução, desafiando os doutrinadores e os agentes

\footnotetext{
${ }^{4}$ EIZIRIK, Nelson et al. Mercado de Capitais - regime jurídico. $3^{\text {a }}$ ed. rev. e amp., Rio de Janeiro: Renovar, 2011. p. 35.

${ }^{5}$ Conforme disposto no artigo de Jorge Hilário Gouvêa Vieira, no livro Lei das S.A. em seus 40 anos.

${ }^{6}$ COMISSÃO DE VALORES MOBILIÁRIOS. História do Mercado de Capitais. Disponível em: $<$ https://www.investidor.gov.br/menu/Menu_Academico/O_Mercado_de_valores_mobiliarios_bra sileiro/Historia_Mercado-Capitais.html>. Acesso em: 06 jun. 2019.
} 
públicos na forma como são vistos e regulados. Recentemente, contrária a toda legislação regulatória e portando um víeis político libertário, alguns indivíduos começaram a elaborar um método para fugir dos intermediadores financeiros e do "excessivo controle estatal".

Tais indivíduos se organizaram em basicamente dois movimentos, os Cypherpunks e os Crypto-anarchits, ambos basicamente detinham aversão à possibilidade de as agências nacionais conseguirem "espionar" todas as suas informações e seus demais dados e transferência bancária. Nesse sentido, foram criadas as primeiras formas de ativos e dinheiros digitais atrelados à tecnologia de criptografia ${ }^{7}$.

$\mathrm{Na}$ época, foi criado um produto conhecido como "Digicash", um prelúdio da ideia que posteriormente ficou conhecida através da criptomoeda chamada Bitcoin $^{8}$.

Esta moeda digital surge como uma espécie de garantidor do direito de privacidade pretendido pelos movimentos libertários, com o objetivo de contrapor ao sistema financeiro atual, que demanda uma série de informações pessoais para concretizar a operação com a justificativa de regular "excessos do mercado" e "estimular a economia"9.

\footnotetext{
${ }^{7}$ Cryptography is a method of protecting information and communications through the use of codes so that only those for whom the information is intended can read and process it. The pre-fix "crypt" means "hidden" or "vault" and the suffix "graphy" stands for "writing.". Disponível em: <https://searchsecurity.techtarget.com/definition/cryptography>. Acesso em: 06 jun. 2019.

8 Curso de Bitcoin and Cryptocurrencies da BerkeleyX: CS198.1. Disponível em: $<$ https://courses.edx.org/courses/course-

v1:BerkeleyX+CS198.1x+3T2018/courseware/9aab1c6ab2ff46d9a2696895ac71f176/97414bbf219 9433799b8e87aa60fc8b0/1?activate_block_id=blockv1\%3ABerkeleyX\%2BCS198.1x\%2B3T2018\%2Btype\%40vertical\%2Bblock\%4017b784dd3caf4 ac6908ca14a3f193f59>. Acesso em: 06 jun. 2019.

${ }^{9}$ REVOREDO, Tatiana Trícia de Paiva. Criptomoedas: cenário global e tendências. Disponível em: <https://www.jota.info/paywall?redirect_to=//www.jota.info/opiniao-e analise/artigos/criptomoedas-cenario-global-e-tendencias-25102017>. Acesso em: 06 jun. 2019.
} 


\title{
CAPÍTULO 1- CARACTERÍSTICAS DOS CRIPTOATIVOS
}

\subsection{Definição}

Ao abordar o tema, é importante estar ciente da sua volatilidade tanto na definiçãa quanto na aplicação da matéria, já que até o presente momento não há uma pacificação sobre a sua exata caracterização. A Comissão de Valores Mobiliários (“CVM") já se posicionou ${ }^{10}$ a respeito desta matéria e emitiu esclarecimento na seguinte forma:

\begin{abstract}
Os criptoativos são ativos virtuais, protegidos por criptografia, presentes exclusivamente em registros digitais, cujas operações são executadas e armazenadas em uma rede de computadores. [...] $\mathrm{O}$ funcionamento dos criptoativos se baseia em uma tecnologia de registro descentralizado, um tipo de contabilidade ou livro-razão distribuído em uma rede ponto a ponto de computadores espalhados ao redor do mundo. Toda transação realizada é divulgada para a rede, e somente será aceita após um complexo sistema de validação e de uma espécie de consenso da maioria dos participantes da rede. Com isso, as operações são praticamente irreversíveis, por exemplo: se um proprietário tenta reutilizar ativos já negociados (o chamado "gasto duplo"), a rede de computadores rejeitaria a transação, característica essa que eliminaria a necessidade de um intermediário.
\end{abstract}

$\mathrm{Na}$ elaboração dos Criptoativos e, consequentemente, na sua distribuição são emitidos os tokens. O termo token possui alguns diferentes significados e usos, mas em âmbito geral é uma espécie de "ficha" de um bem ou de uma particular unidade. Os tokens podem representar basicamente quaisquer ativos que são fungíveis e negociáveis, de commodities para pontos de fidelidade para uniformizar outros Criptoativos $^{11}$.

A fim de inseri-lo na esfera jurídica, constata-se uma tarefa um tanto quanto árdua em caracterizar a natureza jurídica dos Criptoativos, visto que a percepção jurídico-econômica da espécie pode apresentar alterações devido a sua funcionalidade. Contudo, a princípio, pode-se constatar que os

\footnotetext{
${ }^{10}$ COMISSÃO DE VALORES MOBILIÁRIOS. Criptoativos. Série Alertas, Maio 2018. p. 2.

11 MASTERTHECRYPTO. Moedas, Tokens \&Altcoins: Qual é a diferença? Disponível em: $\langle$ https://masterthecrypto.com/differences-between-cryptocurrency-coins-and-tokens/?lang=pt $>$. Acesso em: 17 mar. 2019.
} 
Criptoativos são uma espécie de bem jurídico, como leciona o professor

Caio Mario da Silva Pereira em seu livro Instituições de Direito Civil, Volume $\mathrm{I}^{12}$ :

São bens jurídicos, antes de tudo, os de natureza patrimonial. Tudo que se pode integrar no nosso patrimônio é um bem, e é objeto de direito subjetivo. São os bens econômicos. [...] Dizendo que são objeto dos direitos os bens jurídicos, empregamos a expressão em sentido amplo ou genérico, para compreender tudo que pode ser objeto da relação jurídica, sem distinção da materialidade ou da patrimonialidade. Cuidando especificamente dos bens como o ativo do patrimônio, podemos defini-los como elementos de riqueza suscetível de apropriação.

Assim, possuindo como ponto de partida o referido enquadramento dos Criptoativos como um bem a ser tutelado pelo direto, o trabalho introduzirá os tipos mais comuns em que são emitidos.

\subsection{Tipos de Criptoativos}

Como acima citado, inerente a sua forma de utilização, os tokens foram caracterizados em diferentes tipos e fontes mais específicas. Há uma diversidade imensurável de Criptoativos, visto que se trata de uma forma descentralizada e livre de empreendimento e investimento.

Dentre os diferentes tipos de Criptoativos destacam-se ${ }^{13}$ :

\footnotetext{
${ }^{12}$ PEREIRA, Caio Mário da Silva. Instituições de direito civil: introdução ao direito civil: teoria geral de direito civil. rev. e atual. MORAES, Maria Celina Bodin de. $32^{\mathrm{a}}$ ed. Rio de Janeiro: Forense, 2019.

${ }^{13}$ Para os tipos de Criptoativos apresentados, foram utilizados as seguintes fontes:

ICOSCORING. Types of tokens. The four mistakes beginner crypto-investors make. Disponível em: <https://medium.com/swlh/types-of-tokens-the-four-mistakes-beginner-crypto-investorsmake-a76b53be5406>. Acesso em: 19 mar. 2019.

CLAYTON, Chairman Jay. Statement on Cryptocurrencies and Initial Coin Offerings. Disponível em: <https://www.sec.gov/news/public-statement/statement-clayton-2017-12-11>. Acesso em: 19 mar. 2019.

SWISS FINANCIAL MARKET SUPERVISORY AUTHOTIRY. FINMA publishes ICO guidelines. Disponível em: <https://www.finma.ch/en/news/2018/02/20180216-mm-icowegleitung/>. Acesso em: 19 mar. 2019.

MEDIAPEDIA. The Various types of Crypto Tokens. Disponível em: <https://medium.com/@medipedia/the-various-types-of-crypto-tokens-26bab8f6622c>. Acesso em: 19 mar. 2019.

COIN CRUNCH. Guide to Crypto Token Types. Disponível em: <https://hackernoon.com/guideto-crypto-token-types-6ce04edaba72>. Acesso em: 19 mar. 2019.
} 


\subsubsection{Currency Tokens}

Também conhecidos como altcoins, ou especialmente no Brasil criptomoeda ${ }^{14}$, as Currency Tokens (Fichas de moedas) são o tipo mais conhecido de Criptoativo. A Securities and Exchange Commission (" $\underline{E E C "),}$ a instituição regulamentadora de ativos e valores mobiliários dos Estados Unidos, já se pronunciou a respeito dessa questão na seguinte forma:

Cryptocurrencies. Speaking broadly, cryptocurrencies purport to be items of inherent value (similar, for instance, to cash or gold) that are designed to enable purchases, sales and other financial transactions. They are intended to provide many of the same functions as long-established currencies such as the U.S. dollar, euro or Japanese yen but do not have the backing of a government or other body. Although the design and maintenance of cryptocurrencies differ, proponents of cryptocurrencies highlight various potential benefits and features of them, including (1) the ability to make transfers without an intermediary and without geographic limitation, (2) finality of settlement, (3) lower transaction costs compared to other forms of payment and (4) the ability to publicly verify transactions. Other often-touted features of cryptocurrencies include personal anonymity and the absence of government regulation or oversight. Critics of cryptocurrencies note that these features may facilitate illicit trading and financial transactions, and that some of the purported beneficial features may not prove to be available in practice.

It has been asserted that cryptocurrencies are not securities and that the offer and sale of cryptocurrencies are beyond the SEC's jurisdiction. Whether that assertion proves correct with respect to any digital asset that is labeled as a cryptocurrency will depend on the characteristics and use of that particular asset. In any event, it is clear that, just as the SEC has a sharp focus on how U.S. dollar, euro and Japanese yen transactions affect our securities markets, we have the same interests and responsibilities with respect to cryptocurrencies. This extends, for example, to securities firms and other market participants that allow payments to be made in cryptocurrencies, set up structures to invest in or hold cryptocurrencies, or extend credit to customers to purchase or hold cryptocurrencies.

Pode-se perceber que a característica que distingue esse tipo de Criptoativo dos outros tipos é a sua finalidade de apenas transacionar como

WILMOTH, Josiah. 3 Types of ICO Tokens. Disponível em: <https://strategiccoin.com/3-typesico-tokens/>. Acesso em: 19 mar. 2019.

WILMOTH, Josiah. The Difference Between Utility Tokens and Equity Tokens. Disponível em: <https://strategiccoin.com/difference-utility-tokens-equity-tokens/>. Acesso em: 19 mar. 2019.

BARROSI-FILHO, M; SZTAJN, R. Natureza Jurídica da Moeda e Desafios da Moeda Virtual. São Paulo: Justitia, v. 204/205/206, p.251-268, Jan./Dec. 2013-2014-2015.

14 O nome vem sendo debatido graças as características necessárias para ser caracterizado juridicamente e economicamente como "moeda". Tal questão vai ser mais aprofundada neste trabalho na parte de conceituação de moeda. 
um método de troca em um determinado sistema ou plataforma, importante destacar também que este token não fornece nenhum direito político, direito econômico ou qualquer forma de remuneração para o seu titular, distinguindo-se, a princípio, do conceito de valor mobiliário.

Muito se tem discutido a respeito da funcionalidade dos Currencies Tokens, já que o seu exemplo mais notório, o Bitcoin, mesmo que tenha como idealização ser considerado apenas como uma espécie de moeda virtual, um método de pagamento e reserva de bem online (muito semelhante a plataformas de realização de pagamentos como o PayPal, por exemplo), fora comumente utilizado internacionalmente como uma espécie de investimento.

Essa utilização gerou alguns transtornos para os órgãos reguladores, proporcionando uma confusão a respeito da sua natureza e classificação para regulamentá-lo, e para os investidores, que não possuíam grandes informações sobre o produto e só adquiriram o bem com o objetivo de lucro apresentado na sua valorização, não tinham qualquer instituição a quem pudessem recorrer em casos de fraudes e demais golpes que explodiram junto com a ascensão desses Criptoativos.

\subsubsection{Utility Tokens}

Utility Tokens (fichas de serviço) têm o propósito de conferir ao possuidor do Criptoativo um acesso a um sistema, networking ou plataforma com o objetivo de utilizar um bem ou um serviço específico disponível. Muitas vezes se assemelha como uma espécie de sistema de uso, e pode ser utilizado como uma espécie de moeda de troca dentro dessas plataformas.

A exemplo de ilustração, pode-se comparar informalmente a definição e utilização dos Utility Tokens como os "tickets de festa junina", 
que tem como forma de utilização a troca e utilização de bens e serviços dentro de um espaço já pré-selecionado.

\section{A Swiss Financial Market Supervisory Authority ("FINMA"), a} autoridade de supervisão do mercado financeiro da Suíça, caracterizou esses específicos tokens da seguinte forma:

Utility tokens are tokens which are intended to provide digital access to an application or service [...] These tokens do not qualify as securities only if their sole purpose is to confer digital access rights to an application or service and if the utility token can already be used in this way at the point of issue. If a utility token functions solely or partially as an investment in economic terms, FINMA will treat such tokens as securities (i.e. in the same way as asset tokens).

E, assim como a FINMA, a SEC comenta com víeis semelhante:

Certain market professionals have attempted to highlight utility characteristics of their proposed initial coin offerings in an effort to claim that their proposed tokens or coins are not securities. Many of these assertions appear to elevate form over substance. Merely calling a token a "utility" token or structuring it to provide some utility does not prevent the token from being a security. Tokens and offerings that incorporate features and marketing efforts that emphasize the potential for profits based on the entrepreneurial or managerial efforts of others continue to contain the hallmarks of a security under U.S. law. On this and other points where the application of expertise and judgment is expected, I believe that gatekeepers and others, including securities lawyers, accountants and consultants, need to focus on their responsibilities. I urge you to be guided by the principal motivation for our registration, offering process and disclosure requirements: investor protection and, in particular, the protection of our Main Street investors.

Embora os Utility Tokens tenham sido moldados para efetuar uma espécie de ficha de entrada para determinadas plataformas e como método de troca de bens e serviços, houve inúmeros casos em que fora utilizado também como uma espécie de investimento. Em alguns casos, usaram do nome de "Utility Token" como uma tentativa de "esconder" sua forma de valor mobiliário. Contudo, tanto aqui no Brasil quanto nos órgãos reguladores dos demais países, não há um vínculo do nome com a caracterização ou não de conceito de valor mobiliário. 
Pode ser citado como exemplo de ficha de serviço o Ethereum, que é uma plataforma descentralizada que executa smartcontracts ${ }^{15}$, aplicativos que são executados exatamente como programados, sem qualquer possibilidade de tempo de inatividade, censura, fraude ou interferência de terceiros ${ }^{16}$.

No Brasil houve o caso do NiobiumCoin ${ }^{17}$, que apesar de possuir características de Criptomoeda, também se enquadra como uma Utility Token.

\subsubsection{SecuritiesTokens / EquityTokens}

Os Securities Tokens têm como projeto funcionarem da mesma forma que um valor mobiliário ou que uma security. São uma espécie de ativos negociáveis como obrigações, débitos, debêntures, ações, garantias ou até mesmo imóveis. Também chamados de Equity Tokens, tais Criptoativos atuam como uma espécie de ação ou parte proporcional de uma companhia, que é fornecida ao comprador através de uma oferta pública por parte da respectiva companhia ou por uma transação por parte de algum player no mercado.

\footnotetext{
15 "A smart contract is a piece of code that facilitates, verifies, or enforce the negotiation or execution of a digital contract. For us to reach consensus, a trusted entity must run this code. After all, we need to trust that digital contract is enforced correctly. Like a traditional contract, it carries a set of conditions that must be fulfilled, or terms that must be executed on. The difference is that the execution and enforcement is done through carefully designed algorithms, not through law." Definição tirada de: BerkeleyX: CS198.1x. Ethereum\& Smart Contracts: Enabling a Decentralized Future. Bitcoin and Cryptocurrencies. Disponível em:

$<$ https://courses.edx.org/courses/course-

v1:BerkeleyX+CS198.1x+3T2018/courseware/ff59f66fd88246d992d5d001dd4820a8/8244efc217 974454ba060eced4bld83c/3?activate_block_id=block-

v1\%3ABerkeleyX\%2BCS198.1x\%2B3T2018\%2Btype\%40vertical\%2Bblock\%40496d2eb3deb24

72aaaac0e4421a862dd>. Acesso em: 20 mar. 2019.

16 ETHEREUM. What is Ethereum? Disponível em: <https://www.ethereum.org/beginners/>. Acesso em: 21 mar. 2019.

${ }_{17}$ NiobiumCoin trata-se do criptoativo utilizado como meio de troca na Bolsa de Valores de Moedas Virtuais Empresariais de São Paulo, que possui um funcionamento semelhante à Bolsa de Valores de Valores Mobiliários só que voltada para Criptoativos. Tal questão vai ser melhor abordada no decorrer do trabalho. Disponível em: 〈https://www.niobiumcoin.io/>. Acesso em: 21 mai. 2019.
} 
Ao comprar uma Security Token de uma companhia ou de um projeto, o comprador obterá certos direitos juntamente com a participação de ações da referida companhia ou projeto.

Os Equity Tokens são diferentes dos já mencionados Utility Tokens, pois são limitados por leis federais específicas e por regras de negociação de ações de cada país, já que eles são, desde a sua concepção, um bem que almeja se enquadrar como um valor mobiliário. Podem ser acessados fora da plataforma da qual fazem parte, e seu valor pode aumentar ou diminuir de acordo com o desempenho do projeto, de maneira semelhante às ações, o que não acontece com os Utility Tokens ${ }^{18}$.

O exemplo mais famoso de Security Tokens é o Polymath, que tratase tanto de um Criptoativo que possui características semelhantes a um valor mobiliário, a uma security, podendo ser adquirida como uma participação da própria Companhia Polymath ${ }^{19}$, como também possui a utilização de uma plataforma semelhante a uma Bolsa de Valores aberta 24 (vinte e quatro) horas por dia, todos os dias da semana, em que pode-se negociar diversas outras Securities Tokens no seu sistema de blockchain $^{20}$ com as suas fichas.

No Brasil houve o caso do Kria ${ }^{21}$, que após a publicação da Instrução da CVM $n^{\circ} 588^{22}$, tentou enquadrar sua Oferta Inicial a partir da

\footnotetext{
${ }^{18}$ MEDIAPEDIA. The Various types of Crypto Tokens. Acesso em: 23 mar. 2019.

HENRIQUE, Matheus. $O$ que são as securities tokens e porque o mercado está tão interessado nelas?. Disponível em: 〈https://guiadobitcoin.com.br/que-sao-security-tokens/>. Acesso em: 24 mar. 2019.

${ }^{19}$ POLYMATH. Disponível em: <https://polymath.network/>. Acesso em: 24 mar. 2019.

${ }^{20}$ KHATWANI, Sudhir. A look at the top 5 Securities Tokens Issuance Plataforms. Disponível em: <https://coinsutra.com/security-tokens-platform/>. Acesso em: 24 mar. 2019.

${ }^{21} \mathrm{Kria}$, antiga Broota, trata-se de um projeto em que os criadores planejaram negociar o I.C.O. da Kria nos padrões da Instrução da $\mathrm{CVM} \mathrm{n}^{\circ} 588$ que regula as plataformas de crowdfunding. Conforme publicado, a Kria pretende emitir 25 (vinte e cinco) mil títulos de dívidas conversíveis em ações preferenciais que serão emitidos na forma de tokens (ERC-20). A startup pretende captar, dessa forma, uma quantia de $\mathrm{R} \$ 1,2$ milhão na operação. Foi dada autorização para sua operação, contudo, não foi relatado sua operação. Tais informações foram retiradas dos:

COINTIMES. $O$ primeiro Security Token Offering do Brasil. Disponível em: $<$ https://cointimes.com.br/o-primeiro-security-token-offering-do-brasil/>. Acesso em: 26 mar. 2019.

KRIA. Disponível em: <https://www.kria.vc/startups/kria>. Acesso em: 26 mar. 2019.

COMISSÃO DE VALORES MOBILIÁRIOS. Relatório Semestral Janeiro-Junho 2018. Disponível em:
} 
regulamentação do crowdfunding, que estão expostos no blockchain ethereum juntamente com diversos outros Criptoativos semelhantes.

\title{
1.2.4. Assets Tokens
}

A característica principal que distinguem os Assets Tokens do resto dos Criptoativos é que esse token possui uma espécie de lastro. Durante o processo de "tokenização", o usuário poderá comprar uma parte de um ativo, um bem do mundo real usando o Criptoativo, e nunca precisar tomar posse do bem pessoalmente. Um exemplo a ser citado seria o ouro, que através da plataforma online pode se comprar certa quantidade de Assets Tokens que corresponderá nas exatas proporções da sua parcela em ouro ${ }^{23}$.

Importante destacar que a FINMA utiliza a nomenclatura dos Assets Tokens para classificar como uma espécie de Securities Tokens, não os classificando somente como uma ação, mas como todo e qualquer dívida de uma Companhia, como está exposto nos Guidelines do site do órgão na seguinte forma ${ }^{24}$ :

\begin{abstract}
Asset tokens: Asset tokens represent assets such as a debt or equity claim on the issuer. Asset tokens promise, for example, a share in future company earnings or future capital flows. In terms of their economic function, therefore, these tokens are analogous to equities, bonds or derivatives. Tokens which enable physical assets to be traded on the blockchain also fall into this category. The individual token classifications are not mutually exclusive. Asset and utility tokens can also be classified as payment tokens (referred to as hybrid tokens). In these cases, the requirements are cumulative; in other words, the tokens are deemed to be both securities and means of payment. [...]
\end{abstract}

FINMA treats asset tokens as securities. Asset tokens constitute securities within the meaning of Article 2 let. $b$ FMIA ${ }^{25}$ if they represent an uncertificated security

<http://www.cvm.gov.br/export/sites/cvm/menu/acesso_informacao/planos/sbr/Relatorio_semestra 1_janeirojunho_2018.pdf>. Acesso em: 26 mar. 2019.

22 Instrução da CVM n 588 que dispõe sobre a oferta pública de distribuição de valores mobiliários de emissão de sociedades empresárias de pequeno porte realizada com dispensa de registro por meio de plataforma eletrônica de investimento participativo.

${ }^{23}$ COIN CRUNCH. Guide to Crypto Token Types. Acesso em: 26 mar. 2019.

24 SWISS FINANCIAL MARKET SUPERVISORY AUTHOTIRY. FINMA publishes ICO guidelines. Acesso em: 28 mar. 2019.

${ }^{25}$ FMIA é a sigla para Financial Market InfrastructureAct. Lei suíça que entrou em vigor em $1^{\circ}$ de janeiro de 2016 que aborda essencialmente sobre a regulamentação das infraestruturas do mercado 
and the tokens are standardised and suitable for mass standardised trading. An asset token also qualifies as a security if it represents a derivative (i.e. the value of the conferred claim depends on an underlying asset) and the token is standardised and suitable for mass standardised trading. In the case of the prefinancing and pre-sale phases of an ICO which confer claims to acquire tokens in the future, these claims will also be treated as securities (i.e. in the same way as asset tokens) if they are standardised and suitable for mass standardised trading.

Como exemplo de Assets Tokens temos o caso da "Petro", um Criptoativo emitido pelo Estado da Venezuela, que é lastreada pela reserva de barris de petróleo do país, com a possibilidade de trocar os seus tokens por commodities venezuelanos (os produtos finais), pagar impostos, ou comprar bens e serviços de uso particular dentro do território da Venezuela ou no exterior ${ }^{26}$. No Brasil temos o caso da BTG Pactual, um banco de investimento brasileiro, que lançou em fevereiro do ano de 2019 um Asset Token, o ReitBZ (RBZ), um token com lastro em imóveis ${ }^{27}$.

\subsubsection{Reward Tokens}

Por último, temos os Rewards Tokens, esses tokens se distinguem por não possuírem um real valor atrelados a eles. Foram concebidos como uma forma de premiação de usuários que fazem parte de um sistema ou plataforma, com a possibilidade de troca por bens ou serviços dentro do marketplace (a plataforma desses Criptoativos).

Como exemplo, destacam-se o Sugar Reward e o Gym Reward, tipos de Reward Tokens que podem ser adquiridos através da participação de sua respectiva plataforma ou sistema, comentando nas salas de bate-papo, ou

financeiro e da negociação de derivativos de acordo com os padrões internacionais e das mudanças nas condições de mercado. Informações dispostas pelo. DEPARTAMENTO FEDERAL DE FINANÇAS DA SUÍÇA. Disponível em:

<https://www.efd.admin.ch/efd/en/home/themen/wirtschaft--waehrung--

finanzplatz/finanzmarktpolitik/financial-market-infrastructure-act--fmia-.html>. Acesso em: 22 mai. 2019.

${ }^{26}$ SUPERINTENDENCIA NACIONAL DE CRIPTOACTIVOS Y ACTIVIDADES CONEXAS. Petro. Hacia la revolucion digital económica. Disponível em: <https://petro.gob.ve/files/petrowhitepaper.pdf>. Acesso em: 29 mar. 2019.

27 TAUHATA, Sérgio. BTG Pactual lança criptoativo lastreado em imóveis. Disponível em: $<$ https://www.valor.com.br/financas/6130683/btg-pactual-lanca-criptoativo-lastreado-emimoveis>. Acesso em: 22 mai. 2019. 
usando as funções próprias do aplicativo. Dessa forma, através da utilização do seu aplicativo, o usuário é premiado com o respectivo token que poderá trocar por melhorias no próprio aplicativo, por bens e serviços, por algum bônus ou prêmios temporários oferecidos ${ }^{28}$.

Como pode ser percebido, ao tratar de Criptoativos, há inúmeros casos em que as classificações expostas mesclam umas com as outras, o que possibilita a criação de diversos Criptoativos híbridos. Para fins desse trabalho serão considerados dois principais tipos de tokens: “(i) tokens que concedem acesso a um serviço, plataforma ou projeto da empresa, nos moldes de uma licença de uso ou de crédito para consumir um bem ou serviço; e (ii) tokens que conferem aos investidores direito de participação em resultados do empreendimento, remuneração pré-fixada sobre o capital investido, ou ainda voto em assembleias que determinam o direcionamento dos negócios do emissor"29. Devido às semelhanças em suas finalidades, e o já abordado pela FINMA, o Security Token também será tratado como Asset Token.

Tais referidos tipos de tokens são as espécies de Criptoativos que estão sendo discutidas, estudadas e reguladas pelas autoridades de valor mobiliário ao redor do mundo, que são os já mencionados Utility Tokens e Security Token. Contudo, graças ao seu renome e notoriedade, este trabalho também irá expor matérias pertinentes aos Currencies Tokens.

\footnotetext{
28 Tais informações foram retiradas do site dos próprios tokens: SCOTT, Doug. Sweet Appoints Crypto Expert Max Keiser to Economic Advisory Role. Disponível em: <https://brands.sweet.io/2018/06/11/max-keiser-joins-sweet/>. Acesso em: 1 abr. 2019. GYMREWARDS. Disponível em: 〈https://www.gymrewards.io/>. Acesso em: 1 abr. 2019.

${ }^{29}$ COMISSÃO DE VALORES MOBILIÁRIOS. Criptoativos. Série Alertas, Maio 2018. p. 4.
} 


\section{CAPÍTULO 2 - CONCEITOS JURÍDICOS}

\subsection{Valor Mobiliário}

\subsubsection{Definição}

No intuito de classificar os Criptoativos como matéria de regulamentação dos órgãos e instituições competentes, é preciso primeiramente demarcar a esfera jurídica a ser enquadrada na realidade fática do bem a ser exercido.

Como muito se tem discutido a respeito da CVM e demais autoridades internacionais em regular a oferta pública e a comercialização dos Criptoativos, é importante perceber se estes tokens se enquadram no conceito de valor mobiliário.

Conceituar o que é valor mobiliário não é uma tarefa simples. Dada a natureza e especificidade própria de cada valor mobiliário, visto que se apropriam de direitos distintos e características díspares ${ }^{30}$. Contudo, é de suma importância para fins de delimitação da aplicação da Lei $\mathrm{n}^{\circ}$ 6.385/1976 (Dispõe sobre o mercado de valores mobiliários e criação da Comissão de Valores Mobiliários) e da regulamentação imposta pela CVM.

Conforme Alfredo Lamy Filho e José Luiz Bulhões Pedreira esclarecem na sua obra ${ }^{31}$ :

Os títulos compreendidos no conceito de valor mobiliário têm em comum a função de servirem como instrumentos de investimento de capital financeiro com o fim de obter renda e são "títulos de massa": não são emitidos singularmente, mas em conjuntos de diversos títulos que conferem os mesmos direitos e são fungíveis - no sentido de que podem ser trocados uns pelos outros porque têm igual valor.

\footnotetext{
${ }^{30}$ EIZIRIK, 2011, p. 46.

${ }^{31}$ LAMY FILHO, Alfredo; PEDREIRA, José Luiz Bulhões. Direito das Companhias. v. I. Rio de Janeiro: Forense, 2009. p. 365.
} 
Já na definição de Nelson Eizirik, há a demarcação de aspectos fundamentais para poder conceituar valor mobiliário ${ }^{32}$ :

Primeiramente, eles não possuem um valor intrínseco, isto é, não tem valor em si [...] Em segundo lugar, os valores mobiliários não são bens produzidos ou fabricados para serem usados ou consumidos, mas são emitidos e depois ofertados aos investidores, que podem negociá-los no mercado secundário a preços variáveis e por número indeterminado de vezes. Em terceiro lugar, embora tenham em comum a aptidão a circular publicamente em massa devido à sua natureza fungível, os ativos considerados valores mobiliários possuem características díspares entre si, por atribuírem a seus titulares diferentes direitos e, também, por serem utilizados para diversas finalidades.

Dessa forma, nota-se que não há um conceito certo e definido de o que seja um valor mobiliário, mas sim uma delimitação de certas características que enquadram o bem a ser classificado como um valor mobiliário.

Pode ser dito que isto é uma característica que o Brasil se inspirou no direito norte-americano, diferente como é dado na tradição europeia continental em que usualmente opta por definir o que é um valor mobiliário. Como Ary Oswaldo Mattos Filho diferencia em seu $\operatorname{artigo~}^{33}$, nos Estados Unidos optou-se por listar, à exaustão, os títulos que preencham a condição de valor mobiliário. Dessa forma, não há no sistema legal brasileiro um conceito específico do que seja valor mobiliário, mas sim há um rol exemplificativo disposto no artigo $2^{\circ}$ da Lei $n^{\circ} 6.385 / 76^{34}$, com a possibilidade de aumentar futuramente o elenco. Para fins desse trabalho, será explorado mais especificamente o inciso IX do artigo supracitado.

\footnotetext{
${ }^{32}$ EIZIRIK, 2011, p. 25.

${ }^{33}$ MATTOS FILHO, Ary Oswaldo. O conceito de valor mobiliário. RAE-Revista de administração de empresas, $\mathrm{n}^{\circ} 2$, 1985. p. 31.

${ }^{34}$ Disposto no Artigo $2^{\circ}$ da Lei 6.385/1976: Art. $2^{\circ}$ - São valores mobiliários sujeitos ao regime desta Lei: I- as ações, debêntures e bônus de subscrição; II- os cupons, direitos, recibos de subscrição e certificados de desdobramento relativos aos valores mobiliários referidos no inciso II; III- os certificados de depósito de valores mobiliários; IV- as cédulas de debêntures; V- as cotas de fundos de investimento em valores mobiliários ou de clubes de investimento em quaisquer ativos; VI- as notas comerciais; VII- os contratos futuros, de opções e outros derivativos, cujos ativos subjacentes sejam valores mobiliários; VIII- outros contratos derivativos, independentemente dos ativos subjacentes; e IX- quando ofertados publicamente, quaisquer outros títulos ou contratos de investimento coletivo, que gerem direito de participação, de parceria ou de remuneração, inclusive resultante de prestação de serviços, cujos rendimentos advêm do esforço do empreendedor ou de terceiros.
} 
A inclusão do referido inciso se deu pela Lei 10.198/2001, oriunda da Medida Provisória 1.637/1998, que estabeleceu um conceito de contrato de investimento coletivo ${ }^{35}$ no rol do artigo $2^{\circ}$ da Lei $6.385 / 1976$ que compõe os tipos de valores mobiliários regulados pela CVM, o que forneceu para o órgão regulador uma classificação mais ampla e genérica, podendo enquadrar em sua fiscalização possíveis novos empreendimentos privados que fossem surgindo nesse sentido.

Já que no mercado brasileiro na época milhares de investidores foram prejudicados por ofertas de investimento coletivo realizadas de maneira informal, sem registro, com promessas de elevados ganhos em troca da aplicação em empreendimentos privados, e tiveram que arcar com vultuosos prejuízos quando tais empreendimentos se mostraram incapazes de distribuir os ganhos prometidos ${ }^{36}$.

\subsubsection{Caso Howey}

Tal inclusão na lei foi inspirada no caso incorrido nos Estados Unidos da SEC v. W.J. HoweyCo., julgado pela Suprema Corte Americana em 1946, sendo um caso com bastante peso pois foi o primeiro a julgar contratos de investimento coletivos e classificá-los como valores mobiliários (securities no caso da legislação norte americana).

O caso se deu pois o W.J. Howey Company e a Howey-in-the-Hills Service, Inc., ambas as empresas sediadas na Flórida sob controle e gerenciamento comuns e diretos, realizaram uma oferta de um

\footnotetext{
35 Contrato de investimento coletivo é utilizado como sinônimo de valor mobiliário, servindo como uma forma mais abrangente de definição dos referidos instrumentos. Como está exposto na Instrução da CVM no 296, de 18 de dezembro de 1998 (...) Art. $2^{\circ}$ Constituem valores mobiliários, sujeitos ao regime da Lei $\mathrm{n}^{\circ} 6.385$, de 7 de dezembro de 1976, quando ofertados publicamente, contratos de investimento coletivo, que gerem direito de participação, de parceria ou de remuneração, inclusive resultante de prestação de serviços, cujos rendimentos advêm do esforço do empreendedor ou de terceiros.

${ }^{36}$ PARENTE, Norma Jossen. Mercado de Capitais. In: CARVALHOSA, Modesto. (Coord.). Coleção tratado de direito empresarial. v. 6. São Paulo: Editora Revista dos Tribunais, 2016. p. $225-226$.
} 
empreendimento de frutas cítricas juntamente com um contrato para cultivar, comercializar e remeter os recursos líquidos para o investidor.

Para cada cliente em potencial foi proposto um contrato de venda de terrenos e um contrato de serviços, depois de ter sido informado de que não é viável investir em um bosque a menos que sejam feitos acordos de serviço. Enquanto o comprador é livre para fazer acordos com outras empresas de serviços, a superioridade do serviço da Howey-in-the-Hills Service, Inc. era enfatizada, dessa forma, captavam ambos os contratos.

O Contrato de vendas de terras com a Howey Company previa um preço de compra uniforme por acre ou fração, variando em quantidade apenas de acordo com o número de anos que a parcela particular foi plantada com árvores cítricas. Após o pagamento integral do preço de compra, o terreno era encaminhado ao comprador por escritura de garantia. As compras geralmente eram feitas em faixas estreitas de terra organizadas de modo que um acre consistia de uma fileira de 48 árvores. Durante o período entre $1^{\circ}$ de fevereiro de 1941 e 31 de maio de 1943, 31 das 42 pessoas que estabeleceram o acordo adquiriram menos de 5 acres cada. A participação média dessas 31 pessoas foi de 1,33 acres, e foram feitas vendas de apenas 0,$65 ; 0,7$ e 0,73 de um acre.

Tais contratos de serviços possuíam uma duração de 10 anos, sem opção de cancelamento, dessa forma, fornecia à Howey-in-the-Hills Service, Inc. uma participação de arrendamento e uma posse "completa" da área. Sem o consentimento do grupo Howey, o proprietário ou comprador não tinha sequer o direito de entrada para comercializar a safra plantada. Notase, portanto, que todos os produtos são agrupados pelas empresas correspondentes, e fazem negócios sob seus próprios nomes.

A $S E C$ instituiu uma liminar contra essas empresas para impedir que usassem o sistema de correios e os meios disponíveis no comércio interestadual na oferta e venda de valores mobiliários não registrados, em violação do $\$ 5$ (a) do Title15ofthe United States Code Act §77e(a). O 
tribunal distrital indeferiu a liminar, e o Fifith Circuit Court of Appeals manteve a decisão.

O pedido liminar somente foi concedido na Suprema Corte Americana, que alegaram que a decisão do Fifth Circuit of Appeals conflitava com outras decisões federais e estaduais, e que foi introduzido um teste novo e injustificado nos termos da lei que a $S E C$ considerou administrativamente impraticável.

Tais transações foram definidas como um contrato de investimento coletivo. As empresas, pelo entendimento da Suprema Corte Americana, ofereceram algo mais do que juros simples em terra, e algo diferente de uma venda de um lote de terra de uma fazenda ou pomar com serviços de gerenciamento. Eles estavam oferecendo uma oportunidade de contribuir com dinheiro e compartilhar os lucros de uma grande empresa de frutas cítricas administrada e parcialmente de propriedade do grupo Howey.

A Suprema Corte Americana entendeu que as pessoas que compraram tal investimento não foram com o desejo de ocupar as terras ofertadas ou de desenvolvê-las, elas foram atraídas única e exclusivamente pelas perspectivas de retorno do investimento. Suas respectivas ações neste investimento foram evidenciadas por contratos de compra e venda de terras e escrituras de garantia, que serviram como um método conveniente para determinar as ações alocáveis dos lucros dos investidores. A transferência resultante de direitos na terra foi puramente incidental.

Assim, ficou proibida a oferta, bem como a venda, de valores mobiliários não registrados. Foi criado para esse caso um teste para determinar se certas transações se qualificam como contratos de investimento coletivo para serem consideradas como securities e sujeitas a requisitos de divulgação e registro na $S E C^{37}$.

37 U.S. SUPREME COURT. SEC v. Howey Co., 328 U.S. 293 (1946). Disponível em: <https://supreme.justia.com/cases/federal/us/328/293/\#F1>. Acesso em: 2 abr. 2019. 
O Howey Test, assim como ficou denominado o teste criado pela Suprema Corte Americana, estabeleceu os seguintes critérios para que um investimento seja considerado como uma security: (i) it must be an investment of money; (ii) expectation of profit; (iii) in a common enterprise; and (iv) with the profit to be generated by a third party, through the efforts of the promoter ${ }^{38}$.

E com essa ideia, conforme já mencionado, foi incluído o inciso IX no artigo $2^{\circ}$ da Lei 6.385/1976, propondo que os contratos de investimento coletivo constassem como uma espécie de valores mobiliários de forma mais ampla e genérica, para que a legislação consiga acompanhar a dinâmica evolução do mercado, como ocorreu nos casos do Boi Gordo, dos Condo-hoteis, do Crowdfunding, e agora, mais recentemente, como está sendo analisado pela CVM no caso dos Criptoativos.

\subsection{Moeda}

\subsubsection{Definição}

Em se tratando da outra classificação mais utilizada de Criptoativo que será exposta nesse trabalho, destacam-se as criptocurrencies, ou criptomoedas, nome que ficou popularmente conhecido no Brasil. Nessa classificação, o caso mais emblemático é o já referido Bitcoin, o primeiro token a ter sua funcionalidade equiparada a uma moeda.

Como relatou o Ministro Eros Grau em Recurso Extraordinário ${ }^{39}$ : A funcionalidade do conceito de moeda revela-se em sua utilização no plano das relações jurídicas. $\mathrm{O}$ instrumento monetário válido é padrão de valor,

CORNELL LAW SCHOOL. U.S. Supreme Court. Securities and Exchange Comission v. W. J. Howey CO. et al. Disponível em: <https://www.law.cornell.edu/supremecourt/text/328/293>. Acesso em: 2 abr. 2019.

${ }^{38}$ DALE, Oliver. What is the Howey Test \& How Does it Relate to ICOs \& Cryptocurrency? Disponível em: <https://blockonomi.com/howey-test/>. Acesso em: 3 abr. 2019.

${ }^{39}$ BRASIL. RE 478.410. Rel. Min. Eros Grau, Tribunal Pleno, DJe 14/5/2010. 
enquanto instrumento de pagamento sendo dotado de poder liberatório: sua entrega ao credor libera o devedor.

Para estabelecer um método comparativo, pode-se delimitar o conceito de moeda a partir de três importantes funções, como explica Paul $\operatorname{Hugon}^{40}$ : (i) função de bem intermediário de troca; (ii) função como instrumento de reserva de valor; e (iii) função de unidade de conta.

A partir dessas referidas funções nota-se que as criptomoedas se enquadram em duas das três funções destacadas. Mesmo que não seja sua utilização mais comum entre os titulares de tais bens, as criptomoedas foram originalmente pensadas como um método de intermediação de troca, um método de resolução de obrigações de compra e venda. Nesse caso, podem ser citados marcas e estabelecimentos famosos que aceitaram a utilização das moedas digitais para compra de produtos, como é o caso do time de futebol espanhol Real Madrid, que através de uma parceria com a empresa espanhola 13Tickets (um site espanhol destinado à compra de ingressos de eventos turísticos no país), foi o primeiro a aceitar criptomoedas, no caso o Bitcoin, como forma de pagamento ${ }^{41}$.

As Cryptocurrencies como instrumento de reserva de valor possuem ligação direta com a função anterior. Trata-se de um método de armazenamento de riqueza, de bens patrimoniais, e, dessa forma, constituem forma válida de referida função.

Contudo, em relação à função de unidade de conta ocorre uma inadequação. As moedas por se tratarem de uma forma líquida dos bens em qualquer economia em que estão inseridas, precisam ser facilmente convertidas em um valor próprio, sendo possível a conversão direta e imediata para outras moedas. Esse caso não acontece com o Bitcoin e as

\footnotetext{
${ }^{40}$ HUGON, Paul. Introdução à Análise e às políticas Monetárias e à Moeda no Brasil. São Paulo: Pioneira, 1967.

${ }^{41}$ UMPIERES, Rodrigo Tolotti. Real Madrid se torna o primeiro time de futebol do mundo a aceitar Bitcoin. Disponível em:

<https://www.infomoney.com.br/mercados/bitcoin/noticia/7189013/real-madrid-torna-primeirotime-futebol-mundo-aceitar-bitcoin>. Acesso em: 04 abr. 2019.
} 
outras criptomoedas em geral. Por serem altamente voláteis e não terem nenhum meio de expressão de valor, já que sua unidade de conta reporta-se diretamente a uma moeda corrente conhecida, que em grande parte trata-se do dólar norte-americano o objeto dessa comparação ${ }^{42}$.

Dessa forma, não há como caracterizar as Cryptocurrencies como moeda, mesmo que cumpram duas das funções clássicas da moeda, há uma descaracterização do papel econômico do ativo como moeda por não ser possível a sua quantificação. Com variações frequentes e elevadas nos preços, há uma sujeição do ativo a riscos elevados.

Da maneira que está sendo posto, trata-se apenas de um método de troca, cuja função primordial é evitar custos que os agentes privados incorreriam se utilizassem bancos e/ou instituições financeiras como intermediários ${ }^{43}$.

Ademais, dentro do mesmo contexto, há ainda a concepção dos meios de pagamentos. Dada a aparente rejeição do enquadramento dos cryptocurrencies como moeda, poderia melhor defini-los como um método de pagamento como as emissoras de cartão de crédito, ou plataformas de pagamento online como a empresa PayPal?

Nelson Abrão conceitua o modelo de cartão de crédito como:

[...] podemos chegar a conceituar o cartão de crédito como um documento comprobatório cujo titular goza de um crédito determinado perante certa instituição financeira, o qual o credencia a efetuar compras de bens e serviços a prazo e saques de dinheiro a título de mútuo.

Essas operações se efetuam em observância a um feixe de contratos[... $]^{44}$.

Estes, por sua vez, de dividem de duas formas:

\footnotetext{
${ }^{42}$ BARROSI-FILHO; SZTAJN, 2015, p. 251-268.

${ }^{43}$ Ibid., p. 266.

${ }^{44}$ ABRÃ̃, Nelson. Direito Bancário. 17ª ed. São Paulo: Saraiva Educação, 2018. p. 204.
} 
I - Os de credenciamento não são propriamente cartões de crédito, na acepção que tem hoje o instituto, de vez que habilitam seu titular a aquisições a prazo apenas em determinadas empresa, que é a própria emissora.

II - Os cartões de crédito verdadeiros ou stricto sensu credenciam seu portador à compra de bens e serviços numa pluralidade de empresas filiadas ao sistema ${ }^{45}$.

Assim, ao tentar comparar a funcionalidade das criptomoedas como um cartão de crédito, mesmo que haja aproximação das funcionalidades de ambos os sistemas, há um conceito importante envolvido que define a distinção: o estabelecimento da obrigação.

Ao constituir o sistema de cartão de crédito, ou as plataformas de pagamento online, há, em linhas gerais, um vínculo jurídico entre o titular e o emissor do cartão. No qual o emissor do cartão de crédito contrai a prestação a ser paga pela compra e venda e o titular do cartão se obriga a pagar os débitos contraídos.

Tal sistematização não é estabelecida ao se tratar dos Criptoativos, já que não há a inclusão de intermediadores nas operações de compra e venda realizadas.

Constata-se, dessa forma, um método de pagamento puro e simples, através de um bem jurídico incorpóreo (dada a sua natureza digital), assemelhando-se a uma espécie de permuta, visto o não enquadramento dos tokens como moeda.

\footnotetext{
${ }^{45}$ ABRÃO, 2018, p. 209.
} 


\title{
CAPÍTULO 3 - TIPOS DE MERCADO
}

Após analisar os conceitos e classificações básicas em questão e relatar que os Criptoativos, até o momento, dificilmente se enquadrariam nos pontos anteriormente levantados, salvo alguns casos específicos, visto que constam requisitos necessários para sua validação, passa-se a analisar a possível disposição nos tipos de mercado existentes a fim de conseguir captar o meio de negociação aplicável a essa forma de ativo dentro do Sistema Financeiro Nacional.

\subsection{Mercado Monetário}

Trata-se de um sistema de transferência de recursos a curtíssimo prazo, com o financiamento dos desencaixes momentâneos das instituições financeiras e as necessidades de política monetária e rolagem de dívida do governo, por meio do Banco Central. É um mercado utilizado basicamente para controlar a liquidez da economia nacional, no qual o Banco Central intervém para condução da Política Monetária do país ${ }^{46}$.

Segue abaixo a exemplificação desse mercado dada pela CVM em um de seus livros de programa de treinamento de professores ${ }^{47}$ :

\begin{abstract}
Resumidamente, se o volume de dinheiro estiver maior do que o desejado pela política governamental, o Banco Central intervém vendendo títulos e retirando moeda do mercado, reduzindo, assim, a liquidez da economia. Ao contrário, caso observe que a quantidade de recursos está inferior à desejada, o Banco Central intervém comprando títulos e injetando moeda no mercado, restaurando a liquidez desejada.
\end{abstract}

Percebe-se então que os Criptoativos não fariam parte desse mercado inicialmente, já que se trata de uma comercialização de títulos e moeda nacional de um determinado país. A não ser que se tenha validado um

\footnotetext{
${ }^{46}$ COMISSÃO DE VALORES MOBILIÁRIOS. O mercado de valores mobiliários brasileiro. $3^{\mathrm{a}}$ ed. Rio de Janeiro, 2014. p. 32.

${ }^{47}$ Ibid., p. 32.
} 
determinado token como moeda corrente ou título público do país isso não seria estabelecido.

Assim, é um mercado pouco estimado e de pouquíssima chance de inserção, já que a ideia concebida na criação dos Criptoativos, desde a emissão do Bitcoin, seria uma moeda desvalorizada e desregulada ${ }^{48}$, dessa forma, não se enquadra no referido sistema de mercado apontado.

\subsection{Mercado de Câmbio}

É o mercado onde ocorre transferência entre moedas estrangeiras e moeda nacional. Como está classificado no site do Banco Central ${ }^{49}$, câmbio é a operação de troca de moeda de um país pela moeda de outro. Por exemplo, quando um turista brasileiro viaja para o exterior e precisa de moeda do país que irá visitar, o agente autorizado pelo Banco Central a operar no mercado de câmbio recebe do turista brasileiro a moeda nacional e realiza a transferência na proporção correspondente da moeda estrangeira.

O mercado de câmbio no Brasil é o ambiente onde se realizam as operações de câmbio ente os agentes e instituições autorizadas pelo Banco Central a operar a transferência de moedas. É compreendida dentro dessa esfera de comercialização a compra e venda de moeda estrangeira, as operações em moeda nacional entre residentes e domiciliados no Brasil ou residentes e domiciliados, ou com sede caso seja pessoa jurídica, no exterior. As operações também podem ser realizadas através do ouro como instrumento cambial, sendo obrigatória a presença de um intermediário das instituições autorizadas a operar no mercado de câmbio, seja diretamente ou por meio de seus respectivos correspondentes. Estão dispostas nesse mercado ainda as operações relativas aos recebimentos, pagamentos e

\footnotetext{
48 NAKAMOTO, Satoshi. Bitcoin: A Peer-to-Peer Eletronic Cash System. Disponível em: <www.bitcoin.org>. Acesso em: 09 abr. 2019.

49 BANCO CENTRAL DO BRASIL. FAQ - Câmbio - Mercado de câmbio - definições. Disponível em:

<www.bcb.gov.br/acessoinformacao/legado?url=https:\%2F\%2Fwww.bcb.gov.br\%2Fpre\%2Fbc_at ende\%2Fport\%2Fmerccam.asp>. Acesso em: 10 abr. 2019.
} 
transferência do e para o exterior mediante a utilização de cartões de uso internacional.

As instituições financeiras ${ }^{50}$ autorizadas pelo Banco Central a operar no mercado de câmbio são: bancos múltiplos; bancos comerciais; caixas econômicas; bancos de investimento; bancos de desenvolvimento; bancos de câmbio propriamente ditos; agências de fomento; sociedades de crédito, financiamento e investimento; sociedades corretoras de títulos e valores mobiliários; sociedades distribuidoras de títulos e valores mobiliários e sociedades corretoras de câmbio ${ }^{51}$.

Dessa forma, seria um segmento de mercado em que o Criptoativo também não se enquadraria, a não ser que seja considerada futuramente como uma moeda e que as exchanges ${ }^{52}$ (local onde ocorrem as transferência

${ }^{50}$ Artigo 17 da Lei 4.494, de 31 de dezembro de 1964. Dispõe sobre a Política e as Instituições Monetárias, Bancárias e Creditícias, Cria o Conselho Monetário Nacional e dá outras providências: "Art. 17. Consideram-se instituições financeiras, para os efeitos da legislação em vigor, as pessoas jurídicas públicas ou privadas, que tenham como atividade principal ou acessória a coleta, intermediação ou aplicação de recursos financeiros próprios ou de terceiros, em moeda nacional ou estrangeira, e a custódia de valor de propriedade de terceiros. Parágrafo único. Para os efeitos desta lei e da legislação em vigor, equiparam-se às instituições financeiras as pessoas físicas que exerçam qualquer das atividades referidas neste artigo, de forma permanente ou eventual."

Nos termos do Artigo $1^{\circ}$ da Lei 7.492/86, que trata dos crimes contra o sistema financeiro nacional, define instituição financeira da seguinte forma:“Art. $1^{\circ}$ - Considera-se instituição financeira, para efeito desta lei, a pessoa jurídica de direito público ou privado, que tenha como atividade principal ou acessória, cumulativamente ou não, a captação, intermediação ou aplicação de recursos financeiros de terceiros, em moeda nacional ou estrangeira, ou a custódia, emissão, distribuição, negociação, intermediação ou administração de valores mobiliários. Parágrafo único. Equipara-se à instituição financeira: I- a pessoa jurídica que capte ou administre seguros, câmbios, consórcio, capitalização ou qualquer tipo de poupança, ou recursos de terceiros. II- a pessoa natural que exerça quaisquer das atividades referidas neste artigo, ainda que de forma eventual."

Importante relatar que as instituições financeiras também integram o sistema de distribuição de valores mobiliários, assim, de certa maneira, equipara as instituições financeiras com as corretoras e distribuidoras, conforme disposto no artigo $5^{\circ}$ da Lei $\mathrm{n}^{\circ}$ 4.728/76: "Art. 5 - O sistema de distribuição de títulos ou valores mobiliários no mercado de capitais será constituído: I - das Bolsas de Valores e das sociedades corretoras que sejam seus membros; II - das instituições financeiras autorizadas a operar no mercado de capitais; III - das sociedades ou empresas que tenham por objeto a subscrição de títulos para revenda, ou sua distribuição no mercado, e que sejam autorizadas a funcionar nos termos do art. 11; IV - das sociedades ou empresas que tenham por objeto atividade de intermediação na distribuição de títulos ou valores mobiliários, e que estejam registradas nos termos do art. 12."

${ }^{51}$ BANCO CENTRAL DO BRASIL. FAQ - Câmbio - Mercado de câmbio - definições. Acesso em: 10 abr. 2019.

${ }^{52}$ Exchanges são plataformas digitais que possuem um conceito similar a uma corretora de valores do mercado financeiro tradicional, um local centralizador cheiro de diferentes moedas, podendo haver transação de criptoativos. Tem como finalidade conectar pessoas que desejam vender e comprar criptoativos, assegurando que cada um receba o que foi negociado. Tais "corretoras" também costumam cobrar taxas e organizar as negociações em livros abertos As exchanges de 
e operações dos Criptoativos.) tornassem instituições autorizadas pelo Banco Central.

\subsection{Mercado de Crédito}

O sistema financeiro no qual é estabelecido método de financiamento entre instituições financeiras que captam recursos dos agentes superavitários e emprestam a pessoas físicas ou jurídicas, ocorrendo a remuneração das instituições financeiras através da diferença entre o custo de captação e o que é cobrado dos tomadores de crédito, diferença conhecida como spread.

Geralmente são ações de curto e médio prazo, com finalidade de abastecer o consumo ou capital de giro das empresas. São formalizadas através de contratos, como por exemplo o cheque especial e a conta garantia.

O mercado de crédito é uma forma bastante utilizada de captação de recursos. Entretanto, graças ao seu custo elevado das intermediações tornase, em grande parte, um meio de suprir as necessidades de financiamento dos agentes do mercado quando a quantia desejada for elevada.

Assim como os outros tipos anteriores elencados, os Criptoativos também não se enquadram nesse segmento de mercado financeiro. Visto que não se trata de uma instituição bancária, financeira que tem como objeto, finalidade a realização de empréstimos ou afins.

Nota-se, portanto, que os Criptoativos não se enquadram a nenhum dos segmentos do sistema financeiro apresentados. Em grande parte se dá pela sua natureza que foi criada, como também pelo próprio conceito da

criptoativos não são intermediários obrigatórios nesse referido mercado, são apenas facilitadores para os agentes que estão envolvidos.

Tal definição foi encontrada no: Exchanges de criptomoedas: o que é e como escolher?. Acesso em: 11 abr. 2019. 
intermediação presente nessas operações, ponto chave que os Criptoativos, em sua extensa maioria, tem como objetivo eliminar tal necessidade.

\subsection{Mercado de Capitais}

Por fim, encontra-se o mercado de capitais. Como é definido por Nelson Eizirik ${ }^{53}$ :

A função econômica essencial do mercado de capitais é a de permitir às empresas, mediante a emissão pública de seus valores mobiliários, a captação de recursos não exigíveis para o financiamento de seus projetos de investimento ou mesmo para alongar o prazo de suas dívidas; como não se tratam de empréstimos, a companhia não está obrigada a devolver os recursos aos investidores (exceto no caso de debêntures ou de commercialpapers, que também integram o mercado de capitais), mas, isto sim, a remunerá-los, sob a forma de dividendos, caso apresente lucros em suas demonstrações financeiras. Daí decorre a natureza do mercado de capitais como mercado "de risco", uma vez que os investidores não têm qualquer garantia quanto ao retorno de seus investimentos, que dependerá dos resultados do empreendimento econômico desenvolvido pela companhia. Embora as ações continuam investimento de risco, são, usualmente, dotadas de liquidez, isto é, podem ser rapidamente transformadas em dinheiro, particularmente quando admitidas à negociação em bolsa de valores.

Diversamente do que ocorre no mercado de crédito, no mercado de capitais, a mobilização da poupança é realizada diretamente entre a unidade econômica deficitária - a entidade emissora - e a unidade econômica superavitária - o investidor. Inexiste, no caso, intermediação financeira, pois os recursos fluem diretamente dos adquirentes dos valores mobiliários para as empresas que os emitem. Tratando-se de emissão pública de valores mobiliários, é obrigatória a presença de uma instituição financeira underwriter, cuja atuação, porém, não se confunde com aquela desempenhada quando capta recursos ou concede crédito; o underwirter, com efeito, não importa em intermediação financeira, mas em participação, ainda que com garantia firme de subscrição dos títulos, no processo de colocação pública dos títulos.

Como apontado pelo professor, o mercado de capitais é marcado pelo dinamismo e liquidez das suas aplicações. Tal segmento de mercado encontra-se sujeito a supervisão e fiscalização da Comissão de Valores Mobiliários, no que diz respeito a títulos de emissão das sociedades anônimas e fundos de investimento, sendo regulado segundo a Lei ${ }^{\circ}$ 6.385/76.

\footnotetext{
${ }^{53}$ EIZIRIK, 2011, p. 8.
} 
Estão presente nesse mercado dois segmentos: o mercado primário e o mercado secundário.

O mercado primário destina-se à colocação original dos títulos emitidos pelas sociedades através das emissões públicas de novos valores mobiliários. É no mercado primário que se atende à finalidade principal do mercado de capitais, visto que há a captação de recursos de terceiros de forma pública, sendo canalizados diretamente para as entidades emissoras, que poderão utilizá-los em seus próprios projetos de investimento.

No mercado secundário, diferentemente, não há o ingresso de recursos para as companhias emissoras, visto que não ocorre a emissão de novos títulos, mas sim a comercialização e transferência de títulos já existentes pelos investidores. A sua função consiste em conferir liquidez aos ativos comercializados, possibilitando a sua transferência de forma mais dinâmica.

As operações de valores mobiliários podem ocorrer em diversas plataformas, a mais usual é a Bolsa de Valores, sendo comercializados na de Futuros e Mercadorias, no Novo Mercado, ou no "mercado de balcão". Vale ressaltar também que não é vedado a opção de os investidores comprarem e venderem diretamente os valores mobiliários que possuam, ou seja, fora da Bolsa de Valores ou do mercado de balcão, sem a participação de qualquer intermediário financeiro. Tais operações são denominadas como privadas, já que são realizadas fora do mercado de capitais.

As bolsas são entidades que permitem a centralização das operações no mercado secundário através de sistema de pregão, que também pode ser estabelecido por meio eletrônico, como dita a Instrução CVM n ${ }^{\circ} 380$, de 23 de dezembro de $2002^{54}$. Atuam como corporações auto reguladoras, na medida em que regulam a conduta das instituições que nelas operam.

\footnotetext{
${ }^{54}$ A negociação poderá também se fazer através de sistema eletrônico, inclusive "por meio da rede mundial de computadores" (Instrução da CVM nº 380, 23 de 12 de 2002).
} 
Por sua vez, no mercado de balcão está constituído o conjunto das operações de mercado secundário realizadas fora da Bolsa de Valores, porém com a intermediação de instituições financeiras. A Lei $\mathrm{n}^{\circ}$ 6.385/1976, em seu artigo $2^{\circ}$, $\S 3^{\circ}$, inciso $I^{55}$, faz a distinção do mercado de balcão "organizado" para o "não organizado", isto é, no primeiro modelo, que está disciplinado na Instrução CVM no 461, de 23 de outubro de 2007, há uma entidade com finalidade específica de manter um sistema adequado de negociações onde são centralizadas as operações de títulos e valores mobiliários, enquanto que no segundo não há maior transparência dos negócios realizados com a intermediação de instituições financeiras ${ }^{56}$.

E como isso se enquadra para os Criptoativos? Poderiam se adequar aos critérios requeridos por tal mercado? Como foi visto anteriormente, há um tipo de token que possue finalidade semelhante a dos valores mobiliários. Dessa forma, terá que se adequar a legislações especializadas vigentes e serem regulado e fiscalizado por órgãos e instituições competentes.

Contudo, como enquadrar os procedimentos da emissão de Criptoativos com o mercado de capitais? A forma inicial que se constata para eles são os I.C.O. (Initial Coin Offering) ${ }^{57}$, uma forma semelhante aos I.P.O. (Initial Public Offering) ${ }^{58}$ e com as Ofertas Públicas de Aquisição de Ações (O.P.A.), existindo também a forma de mineração ${ }^{59}$ dos Criptoativos,

\footnotetext{
55 Art. $2^{\circ}$ São valores mobiliários sujeitos ao regime desta Lei(...) $\S 3^{\circ}$ Compete à Comissão de Valores Mobiliários expedir normas para a execução do disposto neste artigo, podendo:(...) IVestabelecer padrões de cláusulas e condições que devam ser adotadas nos títulos ou contratos de investimento, destinados à negociação em bolsa ou balcão, organizado ou não, e recusar a admissão ao mercado da emissão que não satisfaça a esses padrões.

${ }^{56}$ EIZIRIK, Nelson et al. Mercado de Capitais - regime jurídico. $3^{\text {a }}$ ed. rev. e amp., Rio de Janeiro: Renovar, 2011.

${ }^{57}$ I.C.O será abordado mais detalhadamente no capítulo seguinte.

${ }^{58}$ I.P.O - InitialPublicOffer, refere-se às ofertas mediantes as quais uma companhia fechada acessa o mercado pela primeira vez, promovendo a distribuição pública de valores mobiliários desua emissão. No entanto, as considerações aplicam-se tanto às ofertas iniciais, quanto àquelas realizadas por companhias que já tenham os valores mobiliários de sua emissão admitida à negociação no mercado. Conceito elaborado pelo professor Nelson Eizirik em seu livro. EIZIRIK, 2011, p. 139.

${ }^{59}$ Os passos para realização de mineração de Criptoativos estão exemplificados no Princetonbook da seguinte forma:"Tobe a Bitcoinminer, youhavetojointheBitcoin network andconnecttoother nodes. Once you're connected, there are six tasks to perform:
} 
em que os próprios usuários adquirem os tokens através do próprio sistema.

E como se dá no mercado secundário? Qual a relação das Exchanges nesse procedimento?

1. Listen for transactions. First, you listen for transactions on the network and validate them by checking that signatures are correct and that the outputs being spent haven't been spent before.

2. Maintain block chain and listen for new blocks. You must maintain the block chain. You start by asking other nodes to give you all of the historical block that are already part of the block chain before you joined the network. You then listen for new blocks that are being broadcast to the network. You must validate each block that you receive - by validating each transaction in the block and checking later in this section.

3. Assemble a candidate block. Once you gave an up-to-date copy of the block chain, you can begin building your own blocks. To do this, you group transactions that you heard about into a new block that extends the latest block you know about. You must make sure that each transaction included in your block is valid.

4. Find a nonce that makes your block valid. This step requires the most work and it's where all the real difficulty happens for miners.

5. Hope your block is accepted. Even if you find a block, there's no guarantee that your block will become part of the consensus chain. There's bit of luck here; you have to hope that other miners accept your block and start mining on top of it, instead of some competitor's block.

6. Profit. If all other miners do accept your block, then you profit" At the time of this writing in early 2015 , the block reward is 25 bitcoins which is currently worth over $\$ 6,000$. In addition, if any of the transactions in the block contained transactions fees, the miner collects those too. So far transaction fees have been a modest source of additional income, only about $1 \%$ of block rewards." 


\section{CAPÍTULO 4 - CONCEITUAÇÃO DO I.C.O. COM SUAS SEMELHANÇAS E DIFERENÇAS COM O I.P.O.}

\subsection{DEFINIÇÃO}

De certa forma, o nome dado para a referida oferta pública de moedas foi inspirado no conhecido nome do I.P.O., visto que não restam dúvidas sobre a enorme semelhança da grafia dos nomes em tela. Uma jogada de marketing um tanto quanto perigosa, pois para a concepção de uma oferta pública de ações é necessário passar por alguns requisitos burocráticos, fiscais e regulamentares, e, caso não respeitado, os respectivos órgãos e instituições reguladoras serão acionados para barrar com sua oferta.

Primeiramente, antes de classificar o I.C.O., precisa-se entender seu paradigma. O I.P.O., ou as ofertas públicas de aquisição de ações em âmbito geral, trata-se de uma proposta oferecida a um número indefinido de investidores para realização da compra de ações de determinada espécie ou classe que estão sendo emitidas.

Como conceitua o Modesto Carvalhosa "uma declaração unilateral de vontade, tendo efeitos vinculantes por si mesma, e criando obrigações para o ofertante, mesmo que o contrato cuja realização se almeja não venha a existir" $" 60$.

As O.P.A.s podem ser classificadas de diversas formas dependendo da faculdade outorgada ao ofertante, seja constituída de forma obrigatória ou voluntária.

Nas ofertas públicas obrigatórias, o ofertante é obrigado, por força da lei, a proceder à oferta pública como requisito suspensivo, resolutivo ou

\footnotetext{
${ }^{60}$ CARVAlHOSA, Modesto de Souza Barros. Oferta pública de aquisições de ações. Rio de
} Janeiro: IBMEC, 1979. p. 19. 
prejudicial para concretização de determinada operação. Como está listado na Instrução CVM n ${ }^{\circ}$ 361, e na Lei 6.404/76, há três modalidades de OPA obrigatórias, cada uma portando uma destinação e objeto distinto: (i) OPA para cancelamento de registro de companhia aberta, ou como também é conhecida para "fechamento de capital", exposta no artigo $4^{\circ}, \S 4^{\circ}$, da Lei 6.404/1976; (ii) OPA por aumento de participação acionária, por força do artigo $4^{\circ}, \S 6^{\circ}$ da Lei 6.404/1976; e (iii) OPA por alienação de controle acionário, por força do artigo 254-A da Lei 6.404/1976 ${ }^{61}$.

Há também a possibilidade de realização de OPA em caso de saída da companhia do segmento de Novo Mercado da Bolsa de Valores, com exigência de os acionistas titulares de mais de 1/3 (um terço) das ações em circulação, ou percentual maior definido no estatuto social, deverão aceitar a O.P.A. ou concordar expressamente com a saída do segmento sem efetuar a venda das ações ${ }^{62}$.

É possível ainda estabelecer uma O.P.A. nos casos em que esteja previsto no estatuto social uma cláusula que caso um dos acionistas atinja

\footnotetext{
${ }^{61}$ Como fora listado, os referidos artigos são respectivamente: “Art.4 - Para os efeitos desta Lei, a companhia é aberta ou fechada conforme os valores mobiliários de sua emissão estejam ou não admitidos à negociação no mercado de valores mobiliários (...) $\$ 4^{\circ} \mathrm{O}$ registro de companhia aberta para negociação de ações no mercado somente poderá ser cancelado se a companhia emissora de ações, o acionista controlador ou a sociedade que a controle, direta ou indiretamente, formular oferta pública para adquirir a totalidade das ações em circulação no mercado, por preço justo, ao menos igual ao valor de avaliação da companhia, apurado com base nos critérios adotados de forma isolada ou combinada, de patrimônio líquido contábil, de patrimônio líquido avaliado a preço de mercado, de fluxo de caixa descontado, de comparação por múltiplos, de cotação das ações no mercado de valores mobiliários, ou com base em outro critério aceito pela Comissão de Valores Mobiliários, assegurada a revisão do valor da oferta, em conformidade com o disposto no art. $4^{\circ}-\mathrm{A}(. .) \.$ 6^{\circ} \mathrm{O}$ acionista controlador ou a sociedade controladora que adquirir as ações da companhia aberta sob seu controle que elevem sua participação, direta ou indireta, em determinada espécie ou classe de ações à porcentagem que, segundo normais gerais expedidas pela Comissão de Valores Mobiliários, impeça a liquidez de mercado das ações remanescentes, será obrigado a fazer oferta pública, por preço determinado nos termos do $\S 4^{\circ}$, para aquisição da totalidade das ações remanescentes no mercado.".

"Art. 254-A A alienação, direta ou indireta, do controle de companhia aberta somente poderá ser contratada sob a condição, suspensiva ou resolutiva, de que o adquirente se obrigue a fazer oferta pública de aquisição das ações com direito a voto de propriedade dos demais acionistas da companhia, de modo a lhes assegurar o preço no mínimo igual a $80 \%$ (oitenta por cento) do valor pago por ação com direito a voto, integrante do bloco de controle."

62 Definição retirada do site BM\&FBOVESPA. Segmentos de listagem. Disponível em: <http://www.bmfbovespa.com.br/pt_br/listagem/acoes/segmentos-de-listagem/novo-mercado/>. Acessado em: 22 mai. 2019.
} 
um percentual estipulado de ações, este terá obrigação de fazer uma oferta pública.

E as ofertas voluntárias, por sua vez, são oferecidas a critério exclusivo do emissor, que realiza tal operação com finalidade que escolheu. Há exposto na Lei $n^{\circ}$ 6.404/1976 duas modalidades de ofertas voluntárias: (i) O.P.A. para aquisição de controle de companhia aberta, que trata o artigo 257 da Lei 6.404/1976; e (ii) O.P.A. concorrente, que é formulada por um terceiro que não o ofertante ou pessoa a ele vinculada, e que tenha por objeto ações abrangidas por O.P.A. já apresentada para registro perante a CVM, ou por O.P.A. não sujeita a registro cujo edital já tenha sido publicado $^{63}$, fundamentação exposta no artigo 262 da Lei n ${ }^{\circ} 6.404 / 1976^{64}$.

Caso ocorra uma oferta pública que não tenha sido registrada previamente na CVM, ou sem a divulgação das informações ao público, pode ocasionar em algumas sanções previstas nas esferas administrativa, civil e penal.

$\mathrm{Na}$ esfera administrativa no primeiro momento a CVM, identificando a oferta pública não registrada, considerada fraudulenta ou ilegal, ou esteja se anunciando em condições diversas ao registro, determinará a sua suspensão ou cancelamento ${ }^{65}$.

Ocorrerá na esfera civil a nulidade de subscrição dos valores mobiliários emitidos publicamente sem o prévio registro na CVM ou sem a correta prestação e divulgação das referidas informações requeridas. E, a companhia e seus administradores irão ser responsáveis pelos prejuízos causados aos subscritores ${ }^{66}$.

\footnotetext{
${ }^{63}$ Art. $2^{\circ}$, VI, da Instrução da CVM n ${ }^{\circ} 361$.

${ }^{64}$ Referidos artigos apresentados: Art. 257 - A oferta pública para aquisição de controle de companhia aberta somente poderá ser feita com a participação de instituição financeira que garanta cumprimento das obrigações assumidas pelo ofertante.

Art. 262 A existência de oferta pública em curso não impede oferta concorrente, desde que observadas as normas desta Seção.

${ }^{65}$ EIZIRIK, 2011, p. 175.

${ }^{66}$ Ibid., p. 176.
} 
E por fim, como exposto no artigo $7^{\circ}$ da Lei $n^{o} 7.492 / 1986^{67}$, lei que legisla sobre os crimes contra o sistema financeiro nacional, estabelece a sanção penal contra a conduta de quem emite, oferece ou negocia valores mobiliários sem o devido registro prévio junto à autoridade competente, ou em condições divergentes das que constam no referido registro, ou que estejam irregularmente registrados ${ }^{68}$.

Conceituado o paradigma, resta definir e analisar o cabimento dos I.C.O. nessa esfera jurídica. Primeiro, o que é a referida oferta pública de moedas? Como o professor Francisco Mussnich, juntamente com Felipe Thompson $^{69}$, esclareceram que se trata de uma forma de captação pública de recursos, com pagamentos em criptomoedas (em Bitcoin na maioria dos casos conhecidos), tendo como contrapartida ao investidor a emissão de tokens do referido Criptoativo ofertado.

Como também está conceituado no artigo do Lawrence Lundy, Jamie Burke, e Aron van Ammers ${ }^{70}$ :

\begin{abstract}
A network token presale or initial coin offering (ICO) is an event in a project that uses cryptographic tokens where part of its token pool is exchanged for money, typically Bitcoin, to a community of developers and early adopters. Examples include Ethereum. The DAO, and Mastercoin (now Omni). The terminology is still fluid, as these tokens are also referred to as appcoins or just 'coins'. ICO is now a popular term, in part because it's more marketable than 'token crowdsale' or 'network token presale'. Sometimes the term 'crypto-equity' is also used to describe the tokens provided.
\end{abstract}

\footnotetext{
67 Como disposto no artigo $7^{\circ}$ da Lei $n^{\circ} 7.942 / 1986$ : Art. 7 - Emitir, oferecer ou negociar, de qualquer modo, títulos ou valores mobiliários: I - falsos ou falsificados; II - sem registro prévio de emissão junto à autoridade competente, em condições divergentes das constantes do registro ou irregularmente registrados; III - sem lastro ou garantia suficientes, nos termos da legislação; IV sem autorização prévia da autoridade competente, quando legalmente exigida. Pena - Reclusão, de 2 (dois) a 8 (oito) anos, e multa.

${ }^{68}$ EIZIRIK, 2011, p. 177.

${ }^{69}$ ECOA-PUC-Rio. Palestra ministrada pelo Francisco Mussnich e Filipe Thompson em 20 de dezembro de 2017. Disponível em: 〈https://www.youtube.com/watch?v=TqqSOKtDYvQ>. Acesso em: 13 abr. 2019.

70 LUNDY-BRYAN, Lawrence et al. All You Need to Know About Initial Coin Offerings. Disponível em: <https://courses.edx.org/courses/coursev1:BerkeleyX+CS198.1x+3T2018/courseware/9aab1c6ab2ff46d9a2696895ac71f176/b9f1fc94b86 d42e3a3346efa57e0ff32/2?activate_block_id=blockv1\%3ABerkeleyX\%2BCS198.1x\%2B3T2018\%2Btype\%40vertical\%2Bblock\%40c6fb6211ee604e 1d9e6907231ba9feb2>. Acesso em: 13 abr. 2019.
} 
Originally a token presale was designed to raise capital to pay for expenses related to product development, in more recent examples, funds raised may also be used for a mix of functions including but not limited to legal, sales or marketing. The key benefits to the creators of a network using a token presale are to jumpstart the initiative by providing early liquidity to participants and to incentivise developers. Typically details of the crowdsale will be provided including how the collection of funds will occur, the coin distribution, the escrow used, the rate of the native token compared to Bitcoin or other cryptocurrencies, and how the tokens will be produced and used.

A CVM, por sua vez, já se manifestou algumas vezes a respeito do tema. Em um FAQ da CVM publicado em 16 de novembro de 2017 71 , a douta instituição proferiu que:

\section{O que são Initial Coin Offerings?}

r. Podem-se compreender os ICOs como captações públicas de recursos, tendo como contrapartida a emissão de ativos virtuais, também conhecidos como tokens ou coins, em favor do público investidor. Tais ativos virtuais, por sua vez, a depender do contexto econômico de sua emissão e dos direitos conferidos aos investidores, podem representar valores mobiliários, nos termos do art. $2^{\circ}$ da Lei $6.385 / 76$.

Os ICOs vêm sendo utilizados como uma estratégia inovadora de captação de recursos por parte de empresas ou projetos em estado nascente ou de crescimento, muitos ainda em estado pré-operacional, o que enseja um componente de risco por si só.

A inovação associada aos ICOs é oriunda de uma sequência de fatores. Primeiro, por utilizar-se de meios exclusivamente digitais, essa forma de captação facilita a captação de recursos de investidores a partir de qualquer localidade, mediante a transferência de moedas virtuais ou moedas fiduciárias, com maior facilidade e agilidade quando comparado às vias tradicionais.

Segundo, a "digitalização" da cadeia de processos operacionais costuma valer-se de criptografia, programação lógica, protocolos de rede de computadores descentralizados e tecnologias de registro distribuído ("distributed ledger tecnology - DLT"), o que em tese possibilita maior velocidade e precisão de registros.

${ }^{71}$ COMISSÃO DE VALORES MOBILIÁRIOS. Initial Coin Offerings (ICOs). Disponível em: <http://www.cvm.gov.br/noticias/arquivos/2017/20171116-1.html>. Acesso em: 16 mai. 2019. 
E, em um comunicado mais recente, a CVM definiu o ponto chave da questão da necessidade dos ICO's serem fiscalizados pela referida autoridade reguladora:

O que determina se uma operação de ICO estará ou não sujeita à regulamentação do mercado de valores mobiliários é a natureza dos ativos virtuais emitidos na operação. Se os direitos caracterizam o ativo como valor mobiliário, a operação, os emissores e demais agentes envolvidos estarão obrigados a cumprir a legislação e a regulamentação da CVM.

As ofertas de ativos virtuais que se enquadrem na definição de valor mobiliário e estejam em desconformidade com a regulamentação serão tidas como irregulares e, como tais, estarão sujeitas às sanções e penalidades aplicáveis.

A CVM alerta que, até a presente data, não foi registrada nem dispensada de registro nenhuma oferta de tokens cujos direitos os caracterizam como valores mobiliários $^{72}$.

Em suma, a CVM pontua a necessidade do objeto, do token a ser emitido pelo I.C.O. em se enquadrar ou não na definição de valor mobiliário para poder ser regulado pela instituição. Não sendo necessário realizar o registro do agente emissor nem do I.C.O. em si, se o token ofertado for das outras categorias apresentadas neste trabalho, como por exemplo o utility token.

Além da proximidade do nome e a maneira como é ofertado, outra semelhança entre o I.C.O. e o I.P.O. se dá na maneira em que o agente emissor introduz sua oferta e fornece as informações relevantes para os investidores em potencial.

Ao se referir ao I.P.O., e demais ofertas públicas de aquisição de ações, retrata-se a utilização do "prospecto", seja preliminar ou definitivo. Trata-se de um conjunto de informações relativas ao agente emissor, cujo conteúdo provém do formulário de referência, dispostas em um documento atualizado periodicamente pela companhia, e relativa à própria oferta, sendo uma fonte de informação indispensável para a tomada de decisão dos

\footnotetext{
${ }^{72}$ COMISSÃO DE VALORES MOBILIÁRIOS. Criptoativos. Série Alertas, Maio 2018, p. 4.
} 
investidores $^{73}$, como está disposta sua necessidade pela Instrução CVM no 400, podendo citar a definição exposta no artigo 38 da referida Instrução:

Art. 38 - Prospecto é o documento elaborado pelo ofertante em conjunto com a instituição líder da distribuição, obrigatório nas ofertas públicas de distribuição de que trata esta Instrução, e que contém informação completa, precisa, verdadeira, atual, clara, objetiva e necessária, em linguagem acessível, de modo que os investidores possam formar criteriosamente a sua decisão de investimento.

Agora, no caso do I.C.O., trata-se de um documento de conceito semelhante que é chamado de "whitepaper". Preliminarmente tem a mesma função ao se comparar com um prospecto em uma oferta pública de ações. Nele estão dispostas as informações do produto, do token a ser emitido, e, na maioria do caso, há certos detalhamentos da sua funcionalidade, da sua plataforma e solução de problemas e casos que o uso do referido produto fornece.

Dessa forma, ao comparar com as adequações exigidas na Instrução da CVM n 400, há uma série de fatores que estariam faltando para o "whitepaper" poder se enquadrar como um documento válido de informação para os investidores, como por exemplo os fatores de risco, o gerenciamento de risco e controles internos, projeções, destinação de recursos, montante que pretende captar, condições específicas das ofertas, como está expresso no Artigo 39 da referida Instrução ${ }^{74}$.

\footnotetext{
73 COMISSÃO DE VALORES MOBILIÁRIOS. Portal do Investidor. Oferta pública de distribuição primária e secundária. Disponível em:

<http://www.investidor.gov.br/menu/Menu_Investidor/ofertas/ofertas_publicas.html>. Acesso em: 17 mai. 2019.

${ }^{74}$ Como consta exposto no artigo 39 da Instrução da CVM n 400: Art. 39 - O Prospecto deverá, de maneira que não omita os fatos de relevo, nem contenha informações que possam induzir em erro os investidores, conter os dados e informações sobre: I - a oferta; II - os valores mobiliários objeto da oferta e os direitos que lhes são inerentes; III - o ofertante; IV - a companhia emissora e sua situação patrimonial, econômica e financeira; V - terceiros garantidores de obrigações relacionadas com os valores mobiliários objeto da oferta; e VI - terceiros que venham a ser destinatários dos recursos captados com a oferta. $\S 2^{\circ}$ - A CVM poderá exigir do ofertante e da emissora, inclusive com vistas à inclusão no Prospecto, as informações adicionais que julgar adequadas, além de advertências e considerações que entender cabíveis para a análise e compreensão do Prospecto pelos investidores. $\S 3^{\circ}$ - No caso de ofertas públicas que envolvam a emissão de valores mobiliários para os quais não estejam previstos procedimentos, informações e documentos específicos, a CVM poderá, a pedido dos interessados, estabelecer o conteúdo para o respectivo Prospecto.
} 
Assim, torna-se claro as semelhanças e diferenças entre os dois dispositivos. Que mesmo possuindo pontos em comum, há diversos aspectos exigidos pelos órgãos reguladores competentes para que o I.C.O. seja considerado uma oferta pública de ações.

Dentro dessa discussão, há também movimentos para alterar tal nomenclatura, defendendo o uso do termo T.A.O. (tokenized asset offering). Uma forma mais favorável de oferta de tais Criptoativos, incluindo investidores institucionais e gestores de fundo, proporcionando uma maior transparência ${ }^{75}$.

Contudo, referindo-se aos Criptoativos de maneira mais abrangente, seja qual for a forma de sua oferta, encontra-se sua caracterização muito mais pelas maneiras em que eles estão dispostos digitalmente, como "ativos digitais tokenizados", do que com a finalidade distante da esfera do mercado de capitais, voltando-se, assim, somente para o conceito de bens, de patrimônios. Visto que o uso deste software possui inúmeras possibilidades de destinação. O que impossibilita a formação de uma definição em abstrato, sendo necessária uma análise casuística do Criptoativo emitido, já que seu conceito está inerentemente ligado a sua destinação.

Com isso, o Criptoativo é mais facilmente comparado com um mercado de compra e venda de obras de arte, de bens fungíveis que correspondem a um valor volúvel no patrimônio do titular do que estar inserido em um dos mercados financeiros. Com a utilização da permuta

\footnotetext{
${ }^{75}$ Definição tirada a partir dos seguintes links:

KERKMANN, Jens. What is a Tokenized Asset Offering (TAO). Disponível em: <https://blockchainwelt.de/tokenized-asset-offering-tao/>. Acesso em: 18 mai. 2019.

PALLOTA, Christopher; MOLINARI, Vicent. Goodbye ICOs, Hello TAOs? How tokens Will change in 2018. Disponível em: <https://www.coindesk.com/goodbye-icos-hello-taos-tokens-willchange-2018>. Acesso em: 18 mai. 2019.

MACY, Scot. WhatisAssetTokenization?. Disponível em: <https://medium.com/security-tokenoffering/what-is-asset-tokenization-2f0536e3e81c>. Acesso em: 18 mai. 2019.

BLOCKCHAIN APP FACTORY. Tokenized Assets Offering - Legally Compliant Asset-Backed Tokens! Disponível em: <https://www.blockchainappfactory.com/tokenized-assetoffering\#utm_source=Medium\&utm_medium=Blog\&utm_campaign=vignesh $>$. Acesso em: 18 mai. 2019.
} 
para realização de compra e venda de bens e serviços através do uso dos tokens. 


\title{
CAPÍTULO 5 - ENTIDADES REGULADORAS E FISCALIZADORAS DO BRASIL
}

\subsection{Comissão de Valores Mobiliários}

\subsubsection{Atuação}

A fim de entender a discussão dos Criptoativos inseridos no meio das instituiçõos e órgãos reguladores do mercado de capitais, e dos demais que estejam inseridos, primeiramente é preciso entender as características das entidades que regem as regulações e fiscalizações. Primeiramente irá ser trabalhado a Comissão de Valores Mobiliários.

A CVM, como é definida pela Professora Norma Parente ${ }^{76}$ :

\begin{abstract}
A CVM é a entidade integrante da administração pública indireta responsável pela regulação e fiscalização do mercado de capitais brasileiro. Foi instituída pela Lei 6.385, de 07.12.1976 (Lei da CVM), e possui natureza jurídica de autarquia federal especial, vinculada ao Ministério da Fazenda. Como observado acima, essa vinculação não significa subordinação hierárquica, mas sim sujeição ao cotrole ministerial no que tange ao cumprimento das finalidades que justificaram a criação da CVM.
\end{abstract}

Nesse sentido, a CVM tem como mandato principal o estímulo à formação de poupança e ao investimento em valores mobiliários, a promoção do desenvolvimento e a eficiência do mercado, bem como a proteção dos investidores contra fraudes e práticas irregulares.

Também tem a função de fiscalizar o mercado de capitais, nos termos previstos pela Lei 6.385/1976, mas compete ao Banco Central do Brasil a fiscalização do mercado financeiro e de capitais não incluídos na competência prevista na referida lei.

Para que a CVM pudesse exercer suas funções de maneira independente e cumprir com o seu mandato legal, a Lei da CVM conferiu-lhe as seguintes características: (i) personalidade jurídica e patrimônio próprios; (ii) autoridade administrativa independente; (iii) ausência de subordinação hierárquica; (iv) mandato fixo e estabilidade de seus dirigentes; e (v) autonomia financeira e orçamentária.

\footnotetext{
${ }^{76}$ PARENTE, 2016, p. 90.
} 
Dessa forma, caberia a CVM a tarefa de regular e fiscalizar os Criptoativos que teriam características de valores mobiliários. Contudo, antes de criar um "sandbox"77 do caso em questão, é necessário gerar uma massa crítica sobre o assunto, uma vez que " a extraordinária rapidez com que se desenrolam os fatos da vida econômica e financeira dificilmente pode ser acompanhada pela edição de normas reguladoras"'78.

Em se tratando de sandbox, a CVM já se manifestou sobre o tema no Relatório Semestral Julho - Dezembro de $2017^{79}$ na seguinte forma:

\begin{abstract}
A respeito do sandbox há duas considerações centrais: 1) prós e contras de um sandbox e 2) real necessidade de um sandbox considerando as dispensas já contempladas nas Instruções CVM.
\end{abstract}

Quanto ao primeiro aspecto, os prós e contras de um sandbox, a tônica comum é considera-lo uma panaceia, uma solução para todos os problemas relacionados a fintech em geral e a blockchain em particular.

Trata-se, sem dúvida, de uma abordagem progressista adotada por alguns reguladores, com potencial de fomento à inovação e de aproximação entre reguladores e regulados. No entanto, para que um programa de sandbox seja bem sucedido, não basta sua criação através de dispositivos legais. Há que existir real disponibilidade de pessoal qualificado, de infraestrutura tecnológica e de apetite por inovação por parte dos reguladores, de modo que os ambientes de testes pretendidos possam, de fato, gerar conhecimento e aprimorar o regime regulatório aplicável.

(...) Quanto ao segundo ponto, as áreas técnicas se posicionaram no sentido de que não haveria real necessidade de um sandbox dadas as dispensas já contempladas nas Instruções CVM. Empreendedores e projetos que pretendam desempenhar atividades regulamentadas pela CVM poderiam, portanto, formular

\footnotetext{
77 O Sandbox é um termo apropriado da computação. A ideia, em tal contexto, é bem semelhante ao de criar uma máquina virtual (virtualização), e assim proteger o restante do sistema de potenciais danos causados em decorrência da execução de determinadas aplicações no ambiente do Sandbox. Ou seja, trata-se de forma bastante eficaz de testar sistemas considerados não seguros, mas sem isso comprometer o sistema operacional da máquina. Conceito visto no artigo: FEIGELSON, Bruno. Sandbox: o futuro da regulação. No Brasil, o instituto vem ganhando força. Disponível em: <https://www.jota.info/paywall?redirect_to=//www.jota.info/opiniao-eanalise/colunas/regulacao-e-novas-tecnologias/sandbox-o-futuro-da-regulacao-15012018>. Acesso em: 20 mai. 2019.

${ }_{78}$ ABRÃO, 2018, p. 297.

79 COMISSÃO DE VALORES MOBILIÁRIOS. Supervisão Baseada em Risco. Relatório Semestral. Julho, Dezembro 2017. Disponível em:

<http://www.cvm.gov.br/export/sites/cvm/menu/acesso_informacao/planos/sbr/Relatorio_Semestr al_julhodezembro_2017.pdf $>$. Acesso em: 20 mai. 2019.
} 
pedidos justificados de dispensa à CVM para ajustar as regras postas à realidade das inovações(...).

Dentre os casos centrais de dispensas já previstas que poderiam ser pleiteadas, foram mencionadas as dispensas da Instrução CVM n ${ }^{\circ} 461 / 07$, que disciplina os mercados regulamentados de valores mobiliários.

Ao estabelecer as regras aplicáveis às entidades administradoras de mercado organizados de valores mobiliários, o art. $9^{\circ}, \S 4^{\circ}$ dessa Instrução prevê que o Colegiado da CVM poderá dispensar a observância de requisitos de estrutura, organização e funcionamento de entidade administradora, desde tais requisitos não sejam compatíveis com a estrutura ou a natureza do mercado a ser administrado pela entidade, ou as finalidades visadas com a imposição de tais requisitos sejam alcançados por mecanismos alternativos adotados pela entidade.

Uma dispensa desta espécie poderia ser pleiteada por uma Exchange de moedas virtuais que pretendesse listar em seus ambientes de negociação tokens, moedas ou ativos digitais que tenham características de valores mobiliários. Não se trata de uma situação trivial, seria necessário um trabalho conjunto intenso do demandante e da CVM para ajustar as exigências da Instrução à realidade das exchanges de moedas virtuais, até mesmo porque algumas infraestruturas de mercado consideradas atualmente indispensáveis ao mercado de capitais (e.g. sistema de liquidação, compensação e custódia) podem se tornar obsoletas ou desnecessárias no contexto das tecnologias de registro distribuído (Distributed Ledger Technologies, ou DLT).

No mesmo relatório, a CVM retrata a situação de regulamentação das questões do I.C.O.s e do mercado de moedas virtuais no seguinte modo:

(c) Negociações secundárias de tokens emitidos em ICOs.

Foram revisitadas as orientações publicadas pela CVM nos casos de negociação secundária de tokens que apresentassem características de valores mobiliários, enfatizando a obrigatoriedade de cumprimento de regras aplicáveis a emissores de valores mobiliários e à negociação secundária em mercados regulamentadores de valores mobiliários.

(d) Criação de regulamentação específica para os agentes de mercado de moedas virtuais.

Informou-se ao consulente que não havia projeto em andamento na CVM destinado a criar regulamentação específica para os agentes do mercado de moedas virtuais, mas que tanto a CVM como o Banco Central do Brasil estavam acompanhando de perto o desenvolvimento desse mercado. 
Assim, percebe-se que a CVM não planeja, por enquanto, criar uma regulamentação e nem estabelecer o uso de sandbox sobre os Criptoativos, já que ao primeiro momento estão analisando o desenrolar da questão a fím de criar um melhor entendimento sobre o tema. Pois, como se trata de algo muito novo, elaborar uma regulamentação voltada a essas questões poderia extinguir e/ou reduzir o desenvolvimento dessa área.Tal tese se manteve nos relatórios semestrais subsequentes.

Mesmo com a criação de sandbox, que já é um método de regulação mais maleável, seria difícil estabelecer normas que impedissem o desenvolvimento do produto, visto que falta contato dos órgãos reguladores com o tema em debate.

No Brasil ocorreram poucos casos e manifestações das autoridades regulamentadoras sobre o tema, o que fornece uma certa insegurança tanto para os investidores, quanto para os empreendedores e para as próprias autoridades.

Um dos poucos casos que aconteceram sobre tal questão dentro da CVM foi sobre o NiobiumCoin. Tal criptomoeda tinha como objetivo ser adquirido somente por meio de Bitcoins ou "Ethereuns" e não há qualquer direito de remuneração aos seus adquirentes, ainda que haja expectativa de lucro. Os titulares desse ativo poderão utiliza-lo somente para pagar serviços contratados na plataforma de negociação de criptomoedas da Bolsa de Moedas Digitais Empresariais de São Paulo (Bomesp) ${ }^{80}$, quando ela for desenvolvida e implementada ${ }^{81}$.

\footnotetext{
${ }^{80}$ Bomesp trata-se de um tipo de "Bolsa de Valores" de criptomoedas, tal entidade funciona como um marketplace de moedas digitais, exclusivamente emitidas pelo mercado corporativo. Tal empresa utiliza da emissão de criptomoedas, através dos I.C.O.s de diversos criptoativos, tendo como "moeda base" de troca a NiobiumCoin. Tal definição foi tirada do artigo: MIOZZO, Júlia. Como funcionam os ICOs da Bomesp, primeira bolsa de criptomoedas empresariais no Brasil. Disponível em: <https://www.infomoney.com.br/negocios/inovacao/noticia/7330885/comofuncionam-icos-bomesp-primeira-bolsa-criptomoedas-empresariais-brasil>. Acesso em: 20 mai. 2019.

Disponível em: 〈https://www.bomesp.org/quem-somos>. Acesso em: 20 mai. 2019.

${ }^{81}$ Tal definição está no artigo da DE GOBBI, Thais. Colegiado da CVM confirma decisão sobre o NiobiumCoin. Disponível em: <https://www.machadomeyer.com.br/pt/inteligencia-
} 


\author{
O caso em tela está caracterizado no Processo SEI \\ 19957.010938/2017-13 - Caracterização de I.C.O. como oferta de valor \\ mobiliário $^{82}$ :
}

Trata-se de relato apresentado pela Superintendência de Registro de Valores Mobiliários -SRE a respeito de eventual caracterização da criptomoeda ou token denominada Niobium Coin ("Niobium") como valor mobiliário e a consequente atração da competência da CVM em relação à sua pretendida oferta inicial de distribuição (Initial Coin Offering - ICO).

Inicialmente, a área técnica instaurou processo para verificar se a ICO da Niobium, divulgada nos websites https://niobiumcoin.io/ e http://bomesp.org/, relativa às atividades da denominada Bolsa de Moedas Digitais Empresariais de São Paulo - BOMESP, representaria uma oferta pública de valores mobiliários.

Em sua análise, a SRE concluiu que a Niobium não poderia ser caracterizada como valor mobiliário nos termos do art. $2^{\circ}$, IX, da Lei $\mathrm{n}^{\circ} 6.385 / 76$, notadamente em razão de não haver remuneração, participação ou parceria oferecidas aos investidores, conforme o Memorando n ${ }^{\circ}$ 92/2017-CVM/SRE/GER-3.

Adicionalmente, a SRE realizou consulta à Procuradoria Federal Especializada junto à CVM - PFE/CVM. Em conclusão, o parecer jurídico seguiu em linha com a manifestação da área técnica, a saber: "corrobora-se o entendimento da SRE, (...) no sentido de que o Niobium constitui um utilitytoken e, portanto, não possui a natureza jurídica de valor mobiliário na feição de Contrato de Investimento Coletivo. Face ao exposto, sua oferta pública não atrai a competência da CVM de sorte a gerar a edição de uma stop order, cabendo ao público investidor avaliar os riscos acentuados de aquisição de um ativo que não encontra correspondência no $\mathrm{PIB}$, carecendo de regulamentação quer por parte da CVM, quer pelo Banco Central do Brasil - BACEN, nos termos do Comunicado $\mathrm{N}^{\circ} 31.379$, de 16 de novembro de 2017 e da Nota divulgada pela CVM em 11.10.2017”.

Em reunião de 09.01.2018, a SRE apresentou ao Colegiado suas conclusões sobre o tema. Iniciada a discussão, o Colegiado requereu a realização de diligências adicionais, visando ao aprofundamento da análise. Em nova manifestação, a SRE prestou os esclarecimentos solicitados pelo Colegiado e manteve o posicionamento no sentido de que o Niobium não poderia ser caracterizado como valor mobiliário.

O Colegiado acompanhou a manifestação da área técnica, consubstanciada no Memorando $\mathrm{n}^{\mathrm{o}}$ 19/2017-CVM/SER, complementando pelo Memorando $\mathrm{n}^{\mathrm{o}}$ 7/2018-CVM/SRE/GER-3, no sentido de que a criptomoeda ou utility token

juridica/publicacoes-ij/bancario-seguros-e-financeiro-ij/colegiado-da-cvm-confirma-decisaosobre-o-niobium-coin>. Acesso em: 20 mai. 2019.

${ }^{82}$ BRASIL. SRE. Reg. $n^{\circ}$ 0888/18. Caracterização de ICO como oferta de valor mobiliário PROC. SEI 19957.010938/2017-13. Disponível em:

<http://www.cvm.gov.br/decisoes/2018/20180130_R1.html>. Acesso em: 20 mai. 2019. 
Niobium Coin, nos estritos termos em que foi apresentada à CVM até esta data, não se caracterizada como valor mobiliário, razão pela qual a CVM não teria competência em relação à sua pretendida oferta inicial de distribuição (Initial Coin Offering - ICO).

No entanto, o Colegiado ressaltou que essa decisão circunscreve-se à análise da Niobium Coin, e em nada impacta a atuação desta Autarquia em relação a ofertas que envolvam produtos que, independentemente de sua denominação, sejam caracterizados como valores mobiliários. O Colegiado ressaltou, por fim, que plataformas de negociação constituídas para negociar, ainda que de forma não exclusiva, valores mobiliários devem verificar se estão sujeitas à legislação brasileira e à regulação editada pela CVM. (grifou-se)

Nos referidos Memorandos $n^{\circ}$ 19/2017 - CVM/SRE e $n^{\circ} 7 / 2018$ CVM/SRE/GER- $3^{83}$, constata o enquadramento do Niobium da seguinte forma:

1. O presente processo foi instaurado a fim de verificar se a "Initial Coin Offering" ("ICO") da criptomoeda denominada NiobiumCoin ("Niobium"), relativa às atividades da denominada Bolsa de Moedas Digitais Empresariais de São Paulo - BOMESP ("Bomesp"), representava uma oferta pública de valores mobiliários e, desta forma, estaria sob a competência da CVM. 2. Após a análise do caso (descrita no Memorando $n^{\circ}$ 92/2017-CVM/SRE/GER-3 - doc. SEI ${ }^{\circ}$ 0405609), inclusive tendo sido obtida manifestação da pessoa responsável pelo ICO, a SRE entendeu que o Niobium não poderia ser caracterizada como valor mobiliário, afastando a competência da CVM em relação a sua oferta. 3 . Adicionalmente, foi solicitada a manifestação da Procuradoria Federal Especializada da CVM sobre a questão. A PFE, através do Parecer $n$. 00151/2017/GJU - 2/PFE-CVM/PGF/AGU e dos Despachos n. 00190/2017/GJU - 2/PFE-CVM/PGF/AGU e n. 00708/2017/PFE - CVM/PFECVM/PGF/AGU (doc. SEI $n^{\circ}$ 0413729), corroborou o entendimento da SRE, "no sentido de que o Niobium constitui um utility token e, portanto, não possui a natureza jurídica de valor mobiliário na feição de Contrato de Investimento Coletivo" e "sua oferta pública não atrai a competência da CVM de sorte a gerar a edição de uma stop order". 4. Sem prejuízo do exposto, tendo em vista (i) a crescente adoção de estruturas de ICO no mundo todo e a intenção de sua realização no Brasil, (ii) o fato de que vários ICOs envolvem utility tokens, bem como (iii) o caráter institucional da questão (discussão sobre a eventual competência da CVM em relação a ICOs de utility tokens), sugiro o encaminhamento do presente processo ao Colegiado, para dar ciência dos entendimentos aqui exarados e, caso seus membros entendam pertinente, proporcionar a oportunidade de discussão sobre o tema.

\footnotetext{
${ }^{83}$ RAWET, Dov. Memorando $n^{\circ}$ 19/2017 - CVM/SRE. Disponível em: <http://www.cvm.gov.br/export/sites/cvm/decisoes/anexos/2018/20180130/088818_Manifestacao SRE.pdf $>$. Acesso em: 20 mai. 2019.

CAMARGO, Rodrigo de S. V. et al. Memorando $n^{\circ}$ 7/2018. CVM/SRE/GER-3. Disponível em: <http://www.cvm.gov.br/export/sites/cvm/decisoes/anexos/2018/20180130/088818_Manifestacao SRE.pdf $>$. Acesso em: 20 mai. 2019.
} 
representantes do FinTech Hub apresentaram algumas considerações sobre o caso concreto, as quais podem ser segmentadas em duas vertentes: i. foram citadas supostas divergências entre as informações colhidas no processo e outras disponíveis ao público em redes sociais mantidas em nome da BOMESP e Niobium Foundation e ii. interpretação do conceito de valor mobiliário previsto no inciso IX do art. $2^{\circ}$ da Lei 6385/76. 5. Diante da eventual inconsistência das informações constantes no processo, as quais subsidiaram as manifestações da SRE bem como da PFE a respeito da não caracterização do Niobium enquanto valor mobiliário, o Colegiado retirou de pauta a apreciação do presente processo, solicitando diligências adicionais. 6. A SRE procedeu novamente à verificação das páginas de Facebook e Youtube relacionadas à BOMESP e Niobium Foundation bem como dos apontamentos obtidos junto ao representante do FinTech Hub, citados na reunião do Colegiado, em especial: a) Vídeo divulgado no Facebook da Niobium Foundation em 06.12.2017 no qual o representante da BOMESP afirma que o Niobium seria classificada como uma "Gold Coin"; b) Post Facebook da Niobium Foundation em 10.11.17 citando regras de governança definidas no "smartcontract" da BOMESP e c) Post Facebook da Niobium Foundation em 20.10 .17 citando recebimento de "dividendos [...] distribuídos com inteligência aos seus investidores de acordo com suas apostas". 7. Cabe pontuar que, especificamente em relação aos dois últimos tópicos, verificou-se que em uma leitura contextualizada dos mesmos, juntamente à manifestação da BOMESP (doc. SEI $n^{\circ}$ 0405480), não prosperam as alegadas divergências informacionais. Isto porque: i. a referência a dividendos associa-se à remuneração que poderá ser obtida em algumas das "Colorfull Coins" cujos ICOs, no futuro, os desenvolvedores esperam que sejam realizados através da BOMESP; ao passo em que ii. as regras de governança dizem respeito aos parâmetros estabelecidos em smartcontracts registrados na rede blockchain "Ethereum" os quais governarão as funcionalidades e a operação da BOMESP, caracterizada como uma Organização autônoma descentralizada ou DAO. 8. Não obstante tal constatação, novo Ofício foi encaminhado à BOMESP solicitando pontualmente manifestação em relação

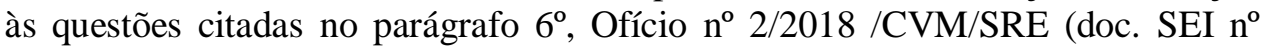
0418417), ainda em 09/01/2018. 9. Em 11/01/2018 foi apresentada a manifestação (doc. SEI $n^{\circ}$ 0420849) em atenção ao Ofício citado, da qual destacam-se os seguintes trechos: [...] apesar de ter utilizado o vocábulo governança, o fez de forma atécnica e equivocada [...] A real intenção da frase foi informar que a BOMESP terá uma reserva de Niobiuns em sua posse, a ser utilizada como Utility Token na sua plataforma. E esse o sentido que o documento dá ao termo governança ainda que tal termo destoe do significado usualmente aplicado a ele, principalmente no âmbito do direito societário e do mercado de capitais. [...] o fato de poder ser classificada, sob esse angulo, como uma "goldcoin", não faz com que deixe de ter as características que a identifiquem como um Utility Token conforme, inclusive, é peremptoriamente e imediatamente afirmado em sequência: "... ela vai ser uma moeda de utilidade dentro da bolsa. Assim, o conceito (fluído) de "goldtoken" não se limita a Tokens que possam ser consideradas, ainda que em tese, valores mobiliários ou equiparados. A efetiva analise deve se pautar - - como ja inclusive analisado pela área técnica - na presença dos requisitos legais para tanto. E, conforme já anteriormente esclarecido, ao adquirente do Niobium não e prometido nenhum ganho, lucro ou participação; mas apenas a aquisição de um ativo que poderá ter uma utilidade específica quando da implementação futura da BOMESP. Nesse ponto, trata-se de infeliz manutenção, por parte da equipede marketing, ao misturar, equivocadamente, as possíveis funcionalidades que os smartcontracts 
podem conferir a uma criptomoeda, como a própria Niobium. Entretanto, mais uma vez, é importante nos limitarmos ao que esta explicito no White Paper documento que efetivamente regula a emissão em questão. O Niobium não conferira qualquer remuneração aos seus detentores, a qualquer título, incluindo a título de dividendos. 10. Tendo em vista as apurações realizadas, acima descritas, entendemos conveniente o retorno do presente processo ao Colegiado, com relato pela SRE, sendo certo que o debate sobre possíveis interpretações divergentes daquela manifestada no âmbito deste processo pela área técnica, corroborada pela PFE, é pertinente àquele fórum. 11. Cabe entretanto, consignar no presente memorando algumas considerações sobre a possibilidade de que a obtenção de lucro, advindo da expectativa de valorização dos Niobiums, seja caracterizada como o "direito de participação, de parceria ou de remuneração, inclusive resultante de prestação de serviços, cujos rendimentos advêm do esforço do empreendedor ou de terceiros", conforme previsto no inciso IX do art. $2^{\circ}$ da Lei $\mathrm{n}^{\mathrm{o}}$ 6385/76. 12. Notadamente citam-se aqui os aspectos do instrumento relacionados: i. ao limite da quantidade emitida destes tokens; bem como ii. ao fato de que tais tokens serão utilizados em uma plataforma que será desenvolvida a partir dos recursos levantados no seu ICO, pelos desenvolvedores do projeto, acarretando que seu valor de uso decorrerá do bom andamento do projeto. Tais aspectos em conjunto poderiam sugerir a interpretação de que o instrumento Niobium conferiria ao seu detentor o direito à remuneração advinda do esforço do empreendedor, materializada na expectativa de valorização destes. 13. Ainda que esta seja uma compreensão possível, a qual inclusive encontra respaldo na interpretação dada pela SEC no âmbito da conceituação de Security no recente caso da Munchee Inc. ${ }^{84}$, é importante observar que esta perspectiva foi contemplada na análise conduzida pela Procuradoria Federal Especializada da CVM. Com efeito, afirmou a PFE em seu parecer que o conceito de security, em nosso ordenamento jurídico, foi positivado, adquirindo contornos legais que limitam a sua configuração, de modo que, embora haja expectativa de lucro, o instrumento em tela em princípio não se enquadra na definição de CIC, à luz do previsto no art. $2^{\circ}$, IX, da Lei 6.385/76.

Portanto, como se constatou, o único processo e contato que as autoridades reguladoras e fiscais tiveram com Criptoativos, acabou não sendo enquadrado dentro do escopo da sua atuação.

Houve mais um caso relevante a respeito de Criptoativos, em que a CVM deu um stop order em um projeto de "mineração" de Bitcoins. Nesse caso, não se refere a um experimento de oferta pública de Criptoativos no Brasil, mas sim de uma tentativa de captação de investimento para compras de participação de um grupo de investimento no qual tem como objetivo realizar um aluguel de computadores que "minerariam" os Criptoativos.

\footnotetext{
${ }^{84}$ Trata-se de um caso similar à análise do Niobium Coin pela CVM, só que a SEC entendeu de maneira diferente da mostrada no caso em tela. Tal discussão irá ser abordada posteriormente nesse trabalho.
} 
Tal questão trata-se de um contrato de investimento coletivo que fornece direito de participação, uma parceria, uma remuneração para os investidores. Por se comportar como uma oferta pública de valores mobiliários sem registro ou dispensa de registro na CVM, a autarquia determinou a suspensão do referido procedimento ${ }^{85}$.

Dessa maneira como a oferta pública de Criptoativos pode ser enquadrada? Como não há uma Instrução ou lei específica regulando tal produto, eles terão que ser enquadrados num primeiro momento em uma norma já estabelecida. Atualmente há três Instruções que mais se aproximam de tal questão.

A primeira, mais facilmente identificada e possivelmente a que melhor enquadraria os casos de I.C.O.s, é a Instrução da CVM n 400, que aborda a regral geral de ofertas públicas, a que alerta para a necessidade de material publicitário, registro do emissor e da oferta, regras de conduta a ser tomadas pelo emissor, entre outras coisas. O maior contraste seria a imposição de um intermediário para estabelecer a aplicação da oferta, já que na concepção dos Criptoativos é justamente cortar tais gastos. Contudo, cabe salientar o caput do artigo $4^{\circ}$ da referida instrução ${ }^{86}$, que seria possível que a CVM, respeitada as devidas proporções, dispensasse o registro ou alguns requisitos das ofertas iniciais de Criptoativos que acontecerem no Brasil, já que se trata de um tema inovador e não há maiores conhecimento sobre sua aplicação.

Em seguida há a possibilidade de enquadrar o I.C.O. na Instrução da $\mathrm{CVM} \mathrm{n}^{\circ} 476$, que aborda sobre as ofertas com esforços restritos. Devido ao risco das operações, poderia juntar a necessidade de investidores qualificados retratados na referida Instrução. Contudo, tal instrução

\footnotetext{
${ }^{85}$ Conforme consta na Deliberação da CVM n ${ }^{\circ} 785$, de 19 de dezembro de 2017.

${ }^{86} \mathrm{Art}$. $4^{\circ}$ - Considerando as características da oferta pública de distribuição de valores mobiliários, a CVM poderá, a seu critério e sempre observados o interesse público, a adequada informação e a proteção ao investidor, dispensar o registro ou alguns dos requisitos, inclusive divulgações, prazos e procedimentos previstos nesta Instrução.
} 
estabelece diversas limitações para a oferta (como por exemplo, o número de investidores) e possui um rol exaustivo e exclusivo para qual é aplicado.

Por último, há o possível enquadramento na Instrução da CVM n ${ }^{\circ}$ 588 que aborda sobre as ofertas de crowdfunding, como foi, por exemplo, o caso da Kria mencionado anteriormente neste trabalho, que tem como vantagem ser uma opção menos custosa para o emissor, pois permite a divulgação de informações em métodos menos elaborados, já que não há a obrigação do prospecto, por exemplo. Contudo, tal instrução estabelece limitações de receitas de emissores e da oferta, o que é uma dificuldade bastante significativa para um bem com um valor tão volúvel quanto os Criptoativos. Só há um ponto chave que impede a realização dos I.C.O.s por essa Instrução que é a questão do mercado secundário, que está expresso na norma a vedação de transferência do bem por investidores ${ }^{87}$.

\subsection{Banco Central do Brasil}

\subsubsection{Atuação}

Próximo agente regulador a ser analisado trata-se do Banco Central, órgão presente tanto no mercado de capitais, quanto na regulação e fiscalização da política monetária nacional, que expõe questões relevantes e que se relacionam para construção do conceito e das normas que regem e regerão as chamadas criptomoedas.

O Banco Central é definido por Nelson Abrão como ${ }^{88}$.

O Banco Central do Brasil é uma autarquia federal, com personalidade jurídica e patrimônio próprios, administrado por uma diretoria de cinco membros, sendo um presidente, escolhidos pelo Conselho Monetário Nacional. De modo geral, cabe ao Banco Central cumprir as prescrições legais e as normas expedidas pelo Conselho Monetário Nacional no que diz respeito à política financeira.

\footnotetext{
87 Art. 28 - Na condução de suas atividades, as plataformas eletrônicas de investimento participativo, seus sócios, administradores e funcionários não podem: [...] X - realizar atividades de intermediação secundária de valores mobiliários;

${ }^{88}$ ABRÃO, 2018, p. 71.
} 
Privativamente, compete-lhe emitir papel-moeda e moeda metálica nas condições e limites autorizados pelo Conselho Monetário Nacional; executar os serviços do meio circulante; [...] E, em caráter não privativo (outras instituições públicas também poderão fazê-lo), cabe ao Banco Central: entender-se, em nome do Governo, com as instituições financeiras estrangeiras e internacionais; [...] exercer permanentemente vigilância nos mercados financeiros e de capitais sobre empresas que, direta ou indiretamente, interfiram nesses mercados e em relação às modalidades ou processos operacionais que utilizem $(\operatorname{art.~11})^{89}$.

\section{Em novembro de 2017, o Banco Central estabeleceu duas frontes de} comunicação sobre os criptoativos, que na época ainda eram chamados de moedas digitais. A primeira comunicação foi através do FAQ, que teve como base normativa a Lei $12.865 / 2013^{90}$, que elaborou o conceito e definiu o posicionamento que iria adotar frente a essa questão:

\footnotetext{
${ }^{89}$ Artigo 11 da Lei 4.595/1964: Art. 11 - Compete ainda ao Banco Central da República do Brasil: I - Entender-se, em nome do Governo Brasileiro, com as instituições financeiras estrangeiras e internacionais; II - Promover, como agente do Governo Federal, a colocação de empréstimos internos ou externos, podendo, também, encarregar-se dos respectivos serviços; III - Atuar no sentido do funcionamento regular do mercado cambial, da estabilidade relativa das taxas de câmbio e do equilíbrio no balanço de pagamentos, podendo para esse fim comprar e vender ouro e moeda estrangeira, bem como realizar operações de crédito no exterior, inclusive as referentes aos Direitos Especiais de Saque, e separar os mercados de câmbio financeiro e comercial; IV - Efetuar compra e venda de títulos de sociedades de economia mista e empresas do Estado; V - Emitir títulos de responsabilidade própria, de acordo com as condições estabelecidas pelo Conselho Monetário Nacional; VI - Regular a execução dos serviços de compensação de cheques e outros papéis; VII - Exercer permanente vigilância nos mercados financeiros e de capitais sobre empresas que, direta ou indiretamente, interfiram nesses mercados e em relação às modalidades ou processos operacionais que utilizem; VIII - Prover, sob controle do Conselho Monetário Nacional, os serviços de sua Secretaria.
}

${ }^{90}$ A Lei 12.865/2013 estabelece, entre outras coisas, competências impostas ao Banco Central ilustradas em seus artigos $9^{\circ}$ e $10^{\circ}$ da seguinte forma: Art. 9 - Compete ao Banco Central do Brasil, conforme diretrizes estabelecidas pelo Conselho Monetário Nacional: I - disciplinar os arranjos de pagamento; II - disciplinar a constituição, o funcionamento e a fiscalização das instituições de pagamento, bem como a descontinuidade na prestação de seus serviços; III - limitar o objeto social de instituições de pagamento; IV - autorizar a instituição de arranjos de pagamento no País; V - autorizar constituição, funcionamento, transferência de controle, fusão, cisão e incorporação de instituição de pagamento, inclusive quando envolver participação de pessoa física ou jurídica não residente; VI - estabelecer condições e autorizar a posse e o exercício de cargos em órgãos estatutários e contratuais em instituição de pagamento; VII - exercer vigilância sobre os arranjos de pagamento e aplicar as sanções cabíveis; VIII - supervisionar as instituições de pagamento e aplicar as sanções cabíveis; IX - adotar medidas preventivas, com o objetivo de assegurar solidez, eficiência e regular funcionamento dos arranjos de pagamento e das instituições de pagamento, podendo, inclusive: a) estabelecer limites operacionais mínimos; b) fixar regras de operação, de gerenciamento de riscos, de controles internos e de governança, inclusive quanto ao controle societário e aos mecanismos para assegurar a autonomia deliberativa dos órgãos de direção e de controle; e c) limitar ou suspender a venda de produtos, a prestação de serviços de pagamento e a utilização de modalidades operacionais; X - adotar medidas para promover competição, inclusão financeira e transparência na prestação de serviços de pagamentos; XI cancelar, de ofício ou a pedido, as autorizações de que tratam os incisos IV, V e VI do caput ; XII coordenar e controlar os arranjos de pagamento e as atividades das instituições de pagamento; XIII - disciplinar a cobrança de tarifas, comissões e qualquer outra forma de remuneração referentes a serviços de pagamento, inclusive entre integrantes do mesmo arranjo de pagamento; e XIV - 


\section{1) O que são "moedas virtuais"?}

As chamadas "moedas virtuais" ou "moedas criptográficas" são representações digitais de valor que não são emitidas por Banco Central ou outra autoridade monetária. O seu valor decorre da confiança depositada nas suas regras de funcionamento e na cadeia de participantes.

\section{2) O Banco Central do Brasil regula as "moedas virtuais"?}

Não. As "moedas virtuais" não são emitidas, garantidas ou reguladas pelo Banco Central. Possuem forma, denominação e valor próprios, ou seja, não se trata de moedas oficiais, a exemplo do real.

As "moedas virtuais" não se confundem com a "moeda eletrônica" prevista na legislação. Moedas eletrônicas se caracterizam como recursos em reais mantidos em meio eletrônico que permitem ao usuário realizar pagamentos.

\section{3) O Banco Central do Brasil autoriza o funcionamento das empresas que negociam "moedas virtuais" e/ou guardam chaves, senhas ou outras informações cadastrais dos usuários, empresas conhecidas como "exchanges"?}

Não. Essas empresas não são reguladas, autorizadas ou supervisionadas pelo Banco Central. Não há legislação ou regulamentação específica sobre o tema no Brasil.

\footnotetext{
dispor sobre as formas de aplicação dos recursos registrados em conta de pagamento. $\S 1^{\circ} \mathrm{O}$ Banco Central do Brasil, respeitadas as diretrizes estabelecidas pelo Conselho Monetário Nacional, disciplinará as hipóteses de dispensa da autorização de que tratam os incisos IV, V e VI do caput. $\S 2^{\circ} \mathrm{O}$ Banco Central do Brasil, respeitadas as diretrizes estabelecidas pelo Conselho Monetário Nacional, poderá dispor sobre critérios de interoperabilidade ao arranjo de pagamento ou entre arranjos de pagamento distintos. $\S 3^{\circ}$ No exercício das atividades previstas nos incisos VII e VIII do caput, o Banco Central do Brasil poderá exigir do instituidor de arranjo de pagamento e da instituição de pagamento a exibição de documentos e livros de escrituração e o acesso, inclusive em tempo real, aos dados armazenados em sistemas eletrônicos, considerando-se a negativa de atendimento como embaraço à fiscalização, sujeita às sanções aplicáveis na forma do art. 11 . $4^{\circ}$ O Banco Central do Brasil poderá submeter a consulta pública as minutas de atos normativos a serem editados no exercício das competências previstas neste artigo. $\S 5^{\circ}$ As competências do Conselho Monetário Nacional e do Banco Central do Brasil previstas neste artigo não afetam as atribuições legais do Sistema Brasileiro de Defesa da Concorrência, nem as dos outros órgãos ou entidades responsáveis pela regulação e supervisão setorial. $\S 6^{\circ} \mathrm{O}$ Banco Central do Brasil, respeitadas as diretrizes estabelecidas pelo Conselho Monetário Nacional, definirá as hipóteses que poderão provocar o cancelamento de que trata o inciso XI do capute os atos processuais necessários. Art. 10. O Banco Central do Brasil poderá, respeitadas as diretrizes estabelecidas pelo Conselho Monetário Nacional, estabelecer requisitos para a terceirização de atividades conexas às atividades fins pelos participantes dos arranjos de pagamento e para a atuação de terceiros como agentes de instituições de pagamento. $1^{\circ} \mathrm{O}$ instituidor do arranjo de pagamento e a instituição de pagamento respondem administrativamente pela atuação dos terceiros que contratarem na forma do caput. $\S 2^{\circ}$ Não se aplica o disposto no caput caso a entidade não participe de nenhuma atividade do arranjo de pagamento e atue exclusivamente no fornecimento de infraestrutura, como os serviços de telecomunicações.
} 
O cidadão que decidir utilizar os serviços prestados por essas empresas deve estar ciente dos riscos de eventuais fraudes ou outras condutas de negócio inadequadas, que podem resultar em perdas patrimoniais.

4) É possível realizar compras de bens ou serviços no Brasil utilizando "moedas virtuais"?

A compra e venda de bens ou de serviços depende de acordo entre as partes, inclusive quanto à forma de pagamento. No caso de utilização de "moedas virtuais", as partes assumem todo o risco associado.

5) Qual o risco para o cidadão se as moedas virtuais forem utilizadas para atividades ilícitas?

Se utilizada em atividades ilícitas, o cidadão pode estar sujeito à investigação por autoridades públicas.

6) As "moedas virtuais" podem ser utilizadas como investimento?

A compra e a guarda de "moedas virtuais" estão sujeitas aos riscos de perda de todo o capital investido, além da variação de seu preço. $\mathrm{O}$ cidadão que investir em "moedas virtuais" deve também estar ciente dos riscos de fraudes.

7) É permitido realizar transferência internacional utilizando "moedas virtuais"?

Não. Transferências internacionais devem ser feitas por instituições autorizadas pelo Banco Central a operar no mercado de câmbio, que devem observar as normas cambiais ${ }^{91}$.

Em seguida o Banco Central fornece o Comunicado ${ }^{\circ} 31.379$ de 16 de novembro de 2017 que dispõe o seguinte:

COMUNICADO N 31.379, DE 16 DE NOVEMBRO DE 2017

Alerta sobre os riscos decorrentes de operações de guarda e negociação das denominadas moedas virtuais.

\footnotetext{
${ }^{91}$ BANCO CENTRAL DO BRASIL. Moedas Virtuais. Disponível em: <https://www.bcb.gov.br/acessoinformacao/legado?url=https:\%2F\%2Fwww.bcb.gov.br\%2Fpre\% 2Fbc_atende\%2Fport\%2Fmoedasvirtuais.asp\%3Fidpai\%3DFAQCIDADAO>. Acesso em: 23 mai. 2019.
} 
Considerando o crescente interesse dos agentes econômicos (sociedade e instituições) nas denominadas moedas virtuais, o Banco Central do Brasil alerta que estas não são emitidas nem garantidas por qualquer autoridade monetária, por isso não têm garantia de conversão para moedas soberanas, e tampouco são lastreadas em ativo real de qualquer espécie, ficando todo o risco com os detentores. Seu valor decorre exclusivamente da confiança conferida pelos indivíduos ao seu emissor.

2. A compra e a guarda das denominadas moedas virtuais com finalidade especulativa estão sujeitas a riscos imponderáveis, incluindo, nesse caso, a possibilidade de perda de todo o capital investido, além da típica variação de seu preço. $\mathrm{O}$ armazenamento das moedas virtuais também apresenta o risco de o detentor desses ativos sofrer perdas patrimoniais.

3. Destaca-se que as moedas virtuais, se utilizadas em atividades ilícitas, podem expor seus detentores a investigações conduzidas pelas autoridades públicas visando a apurar as responsabilidades penais e administrativas.

4. As empresas que negociam ou guardam as chamadas moedas virtuais em nome dos usuários, pessoas naturais ou jurídicas, não são reguladas, autorizadas ou supervisionadas pelo Banco Central do Brasil. Não há, no arcabouço legal e regulatório relacionado com o Sistema Financeiro Nacional, dispositivo específico sobre moedas virtuais. O Banco Central do Brasil, particularmente, não regula nem supervisiona operações com moedas virtuais.

5. A denominada moeda virtual não se confunde com a definição de moeda eletrônica de que trata a Lei $\mathrm{n}^{\mathrm{o}} 12.865$, de 9 de outubro de 2013, e sua regulamentação por meio de atos normativos editados pelo Banco Central do Brasil, conforme diretrizes do Conselho Monetário Nacional. Nos termos da definição constante nesse arcabouço regulatório consideram-se moeda eletrônica "os recursos em reais armazenados em dispositivo ou sistema eletrônico que permitem ao usuário final efetuar transação de pagamento". Moeda eletrônica, portanto, é um modo de expressão de créditos denominados em reais. Por sua vez, as chamadas moedas virtuais não são referenciadas em reais ou em outras moedas estabelecidas por governos soberanos.

6. É importante ressaltar que as operações com moedas virtuais e com outros instrumentos conexos que impliquem transferências internacionais referenciadas em moedas estrangeiras não afastam a obrigatoriedade de se observar as normas cambiais, em especial a realização de transações exclusivamente por meio de instituições autorizadas pelo Banco Central do Brasil a operar no mercado de câmbio.

7. Embora as moedas virtuais tenham sido tema de debate internacional e de manifestações de autoridades monetárias e de outras autoridades públicas, não foi identificada, até a presente data, pelos organismos internacionais, a necessidade de regulamentação desses ativos. No Brasil, por enquanto, não se observam riscos relevantes para o Sistema Financeiro Nacional. Contudo, o Banco Central do Brasil permanece atento à evolução do uso das moedas virtuais, bem como 
acompanha as discussões nos foros internacionais sobre a matéria para fins de adoção de eventuais medidas, se for o caso, observadas as atribuições dos órgãos e das entidades competentes.

8. Por fim, o Banco Central do Brasil afirma seu compromisso de apoiar as inovações financeiras, inclusive as baseadas em novas tecnologias que tornem o sistema financeiro mais seguro e eficiente ${ }^{92}$.

Assim, o Banco Central estabelece, de forma semelhante a CVM, uma posição de não vedar ou legislar inicialmente sobre os Criptoativos. Ambas as instituições tomaram a decisão de no primeiro momento adquirirem uma melhor informação e conhecimento da questão a ser discutida antes de elaborar normas e regulamentos voltados diretamente a esse novo conceito que surgia na época.

\subsection{Receita Federal}

\subsubsection{Atuação}

Por fim, paralelamente a toda essa discussão de classificação entre valores mobiliários e moeda, de competência da CVM ou do Bacen, a Receita Federal estabeleceu a posição vanguardista e decidiu a questão no ponto de vista tributário.

Disposto na Instrução Normativa da Receita Federal $n^{\circ} 1.888$ de 03 de maio de 2019, foi instituído a obrigatoriedade de prestação de informações relativas às operações realizadas com Criptoativos à Secretaria Especial da Receita Federal do Brasil. Lá está estabelecido que as exchanges, e as demais formas de transferência de Criptoativos, têm até

\footnotetext{
${ }^{92}$ BANCO CENTRAL DO BRASIL. Comunicado $n^{\circ}$ 31.379. 16 nov. 2017. Disponível em: $<$ https://www.bcb.gov.br/estabilidadefinanceira/exibenormativo?tipo=Comunicado\&numero=313 79>. Acesso em: 23 mai. 2019.
} 
agosto de 2019 para se adequarem às normas estipuladas na Instrução e apresentarem as informações pendentes de tributação ${ }^{93}$.

Em tal instrução há algumas definições importantes para compreender o entendimento que tal órgão regulador obteve antes de elaborar a respectiva instrução normativa. Primeiro:

Art. $5^{\circ}[\ldots]$ I - criptoativo: a representação digital de valor denominada em sua própria unidade de conta, cujo preço pode ser expresso em moeda soberana local ou estrangeira, transacionando eletronicamente com a utilização de criptografia e de tecnologia de registros distribuídos, que pode ser utilizado como forma de investimento, instrumento de transferência de valores ou acesso a serviços, e que não constitui moeda de curso legal ${ }^{94}$.

Dessa forma, a partir do que foi exposto, percebe-se que juntamente com a CVM, a Receita Federal compreende no seu escopo de análise os tipos de Criptoativos mais comuns, os Securities Tokens, os Utility Tokens e os Criptocurrencies. Contudo, o órgão especifica a necessidade de que tais tokens tenham representação em valor de moeda local, o Real, ou estrangeira, mais comumente utilizado é o dólar americano, dessa forma, conscientemente ou não, a Receita excluiu da sua análise os Criptoativos que detenham como método de valoração outros Criptoativos, na grande parte dos casos a "moeda" de comparação é o Bitcoin.

Em seguida, no inciso seguinte do mesmo artigo $5^{\circ}$, há a seguinte definição:

II - exchange de criptoativo: a pessoa jurídica, ainda que não financeira, que oferece serviços referentes a operações realizadas com criptoativo, inclusive intermediação, negociação ou custódia, e que pode aceitar quaisquer meios de pagamento, inclusive outros criptoativos.

Parágrafo único. Incluem-se no conceito de intermediação de operações realizadas com criptoativos, a disponibilização de ambientes para a realização das

93 RECEITA FEDERAL DO BRASIL. Instrução Normativa RFB $n^{\circ}$ 1.888. 03 mai. 2019. Disponível em:

<http://normas.receita.fazenda.gov.br/sijut2consulta/link.action?visao=anotado\&idAto=100592> . Acesso em: 27 mai. 2019.

94 Ibid., Acesso em: 27 mai. 2019. 
operações de compra e venda de criptoativo realizadas entre os próprios usuários de seus serviços ${ }^{95}$.

Ao comparar com as referências dispostas nesse trabalho, a Receita Federal estabeleceu um conceito abrangente de Exchange, próximo ao que já havia sido disposto nas leis 4.494/64, 4.728/76, e 7.492/86. Estabelecendo como parâmetro as instituições financeiras, ou as distribuidoras e emissoras de valores mobiliários, que trabalhem com a transferência de Criptoativos, seja de oferta primária ou secundária.

Os parâmetros dispostos na instrução para serem enquadradas dentro da esfera normativa da Receita Federal tem que ter como valor mensal das operações, isolado ou conjuntamente, a quantia de $\mathrm{R} \$ 30.000,00$ (trinta mil reais) como disposto no trecho:

Art. $6^{\circ}$ Fica obrigada à prestação das informações a que se refere o art. $1^{\circ}$ : I - a exchange de criptoativos domiciliada para fins tributários no Brasil; II - a pessoa física ou jurídica residente ou domiciliada no Brasil quando:

a) as operações forem realizadas em exchange domiciliada no exterior; ou b) as operações não forem realizadas em exchange.

$\S 1^{\circ}$ No caso previsto no inciso II do caput, as informações deverão ser prestadas sempre que o valor mensal das operações, isolado ou conjuntamente, ultrapassar $\mathrm{R} \$ 30.000,00$ (trinta mil reais).

$\S 2^{\circ} \mathrm{A}$ obrigatoriedade de prestar informações aplica-se à pessoa física ou jurídica que realizar quaisquer das operações com criptoativos a seguir:

I - compra e venda;

II - permuta;

III - doação;

IV - transferência de criptoativo para a exchange;

$\mathrm{V}$ - retirada de criptoativo para a exchange;

VI - cessão temporária (aluguel);

VII - dação em pagamento;

VIII - emissão; e

IX - outras operações que impliquem em transferência de criptoativos ${ }^{96}$.

Como já foi comentada nesse trabalho, tal valorização é um tanto quanto flutuante, graças a volatilidade existente na precificação dos Criptoativos. Também, cabe notar a vasta lista de operações existentes, já que até o momento não foi estipulado o conceito jurídico próprio para

\footnotetext{
${ }^{95}$ RECEITA FEDERAL DO BRASIL. Instrução Normativa RFB $n^{\circ}$ 1.888. Acesso em: 27 mai. 2019.

${ }^{96}$ Ibid., Acesso em: 27 mai. 2019.
} 
designar o que são os Criptoativos, assim, a Instrução Normativa está acionando qualquer medida de transferência para se enquadrar no referido artigo.

Assim sendo, nota-se que as instituições reguladoras do Brasil ainda estão em processo de estudo antes de definir uma norma e conceito próprio para esse novo ativo digital. Como não há uma expectativa de uma criação de uma norma mais específica para o tema, os Criptoativos terão que se enquadrar nos termos já existentes na regulação. Até o momento, a última movimentação a respeito de tal tema foi a aprovação pela Comissão de Ciência, Tecnologia, Inovação, Comunicação e Informática (CCT) do requerimento do senador Flávio Arns, do partido Rede - PR, para realização de uma audiência pública com a Comissão de Assuntos Econômicos (CAE), com os representantes do Bacen, da CVM, da Receita Federal, da Associação Brasileira de Criptoeconomia ${ }^{97}$ e da Associação Brasileira de Criptomoedas e Blockchain ${ }^{98}$, contudo, tal audiência não tem data definida ${ }^{99}$.

\footnotetext{
${ }^{97}$ Também chamada de ABCripto, trata-se de uma colaboração estratégica entre organizações e indivíduos no ramo de uma nova economia, que inclui criptoativos, criptomoedas e tokens. Possuem como objetivo a união dos players para interlocução com o poder público. Texto oriundo do próprio site da Associação. ABCRIPTO. Disponível em: <https://www.abcripto.com.br/>. Acesso em: 28 mai. 2019.

${ }_{98}$ Também chamada de $\mathrm{ABCB}$, trata-se da primeira associação do setor de criptomoedas e blockchain no Brasil, com o objetivo passar informação para a sociedade, debater soluções com as autoridades e criar um marco regulatório para este novo setor da economia. Possui como presidente o Fernando Furlan, professor de direito e economia em Brasília e membro do grupo consultor de especialistas das Nações Unidas (UNCTAD) em programas de defesa da concorrência e do consumidor. Texto oriundo do próprio site da Associação. ABCRIPTO. Disponível em: <http://abcb.in/>. Acesso em: 28 mai. 2019.

99 BRASIL. Senado Federal. CCT vai debater regulamentação das bitcoins. Disponível em: $<$ https://www12.senado.leg.br/noticias/materias/2019/05/15/cct-vai-debater-regulamentacao-dasbitcoins>. Acesso em: 28 mai. 2019.
} 


\section{CAPÍTULO 6 - DIRETRIZES DE INSTITUIÇÕES REGULADORAS INTERNACIONAIS}

\subsection{Securities and Exchange Commission}

\subsubsection{Atuação}

Após a discussão anterior sobre as regulações presentes nas autarquias reguladoras no Brasil, compete a este capítulo introduzir e questionar as normas estipuladas nos agentes reguladores estrangeiros.

Primeiramente, pelo grau de proximidade das leis societárias e relativas ao mercado de capitais ao comparamos com a legislação brasileira, este trabalho irá tratar sobre as questões já reguladas pelas leis norte americanas, mais especificamente a agência federal de regulação dos valores mobiliários, a Securities and Exchange Commission, abreviada simplesmente como SEC.

Num primeiro momento, é importante ressaltar a definição de valores mobiliários, as securities, disposta no Investment Company Act of 1940:

(36) "Security" means any note, stock, treasury stock, security future, bond, debenture, evidence of indebtedness, certificate of interest or participation in any profit-sharing agreement, collateral-trust certificate, preorganization certificate or subscription, transferable share, investment contract, voting-trust certificate, certificate of deposit for a security, fractional undivided interest in oil, gas, or other mineral rights, any put, call, straddle, option, or privilege on any security (including a certificate of deposit) or on any group or index of securities (including any interest therein or based on the value thereof), or any put, call, straddle, option, or privilege entered into on a national securities exchange relating to foreign currency, or, ingeneral, any interest or instrument commonly known as a "security", or any certificate of interest or participation in, temporary or interim certificate for, receipt for, guarantee of, orwarrant or right to subscribe to or purchase, any of the foregoing ${ }^{100}$.

${ }^{100}$ SECURITIES AND EXCHANGE COMMISSION. Investment Company Act of 1940. Section 2. General Definitions. Article 36. 
Assim como foi visto na definição de valor mobiliário no Brasil, os Estados Unidos optaram pela criação de um rol exemplificativo do que seria caracterizado como security.

A fim de comparação, como leciona o professor Leães, as securities possuem cinco características para serem definidas:

(1) todo investimento em dinheiro ou bens suscetíveis de avaliação monetária, (2) realizado pelo investidor em razão de uma captação pública de recursos, (3) de modo a fornecer capital de risco a um empreendimento, (4) em que ele, o investidor, não tem ingerência direta, (5) mas do qual espera obter algum ganho ou benefício futuro ${ }^{101}$.

Dessa forma, constata-se a aproximação dos dois ordenamentos jurídicos. Contudo, há de se notar como cada um regula os casos constituídos de oferta de Criptoativos.

Nos Estados Unidos, como foi mencionado anteriormente, houve um caso de um I.C.O. da MUN token, uma Utility Token, que foi classificada como security pela SEC. Houve uma situação semelhante no Brasil que não foi concebido o mesmo entendimento pela CVM (tal qual ficou disposto no referido caso da Niobium Coin no capítulo anterior).

\subsubsection{Caso Munchee}

Munchee Inc. é uma companhia de Delaware com sede em São Francisco, Califórnia, que criou um aplicativo para o iPhone que seus usuários podem avaliar pratos e restaurantes cadastrados no sistema, e forneceu um "ecossistema", um "marketplace”, no qual a companhia e terceiros pudessem comprar e vender bens e serviços usando os tokens a serem emitidos na plataforma ${ }^{102}$. Em novembro de 2017, a companhia

\footnotetext{
${ }^{101}$ LEÃES, Luís Gastão Paes de Barros. O conceito de "security" no direito norte americano e o conceito análogo no direito brasileiro. Revista de direito mercantil, industrial, econômico e financeiro, v. 14, 1976. p. 48.

${ }_{102}$ Conforme consta no artigo da U.S. Securities and Exchanges Commission. Company Halts ICO After SEC Raises Registration Concerns. Disponível em: <https://www.sec.gov/news/pressrelease/2017-227>. Acesso em: 31 mai. 2019.
} 
disponibilizou um sistema de tokens digitais, chamados de "MUN" ou "MUN token", emitidos dentro de uma estrutura de blockchain ou distributed ledger. Munchee planejou realizar uma oferta de MUN tokens que levantaria uma quantia aproximada de quinze milhões de dólares, como se encontra disposto no processo administrativo da SEC n ${ }^{\circ} 3-18304^{103}$ :

4. By Fall 2017, Munchee had developed a plan to improve the Munchee App during 2018 and 2019 that included raising capital through the creation of the MUN token and incorporating the token into the Munchee App. The MUN is a token issued on the Ethereum blockchain. Munchee created 500 million MUN tokens and stated that no additional tokens could be created.

5. On or about October 1, 2017, Munchee announced it would be launching an "initial coin offering" or "ICO" 104 to offer MUN tokens to the general public. Munchee posted the MUN White Paper that described MUN tokens, the offering process, how Munchee would use the offering proceeds to develop its business, the way in which MUN tokens would increase in value, and the ability for MUN token holders to trade MUN tokens on secondary markets. Munchee posted information about the offering and the MUN White Paper through posts on the Munchee Web Pages, including on a blog, Facebook, Twitter, BitcoinTalk, and the Munchee Website.

6. MUN tokens were to be available for purchase by individuals in the United States and worldwide through websites and social media pages including, but not limited to, the Munchee Web Pages.

7. Pursuant to the MUN White Paper, Munchee sought to raise about $\$ 15$ million in Ether by selling 225 million MUN tokens out of the 500 million total MUN tokens created by the company. Purchasers of MUN tokens in the earlier stages of the offering were offered discounts of $15 \%$ and $10 \%$ on the offering price. Munchee said it would keep the remaining 275 million MUN tokens and use those MUN tokens to support its business, including by paying rewards in the

\footnotetext{
103 Conforme consta no ORDER INSTITUTING CEASE-ANDDESIST PROCEEDINGS PURSUANT TO SECTION 8A OF THE SECURITIES ACT OF 1933, MAKING FINDINGS, AND IMPOSING A CEASE-AND-DESIST ORDER. 11 dez. 2017. Disponível em: <https://www.sec.gov/litigation/admin/2017/33-10445.pdf>. Acesso em: 01 jun. 2019.

104 No referido processo administrativo, a SEC definiu I.C.O. da seguinte forma: An "initial coin offering" or "ICO" is a recently developed form of fundraising event in which an entity offers participants a unique digital "coin" or "token" in exchange for consideration (most commonly Bitcoin, Ether, or fiat currency). The tokens are issued and distributed on a "blockchain" or cryptographically-secured ledger. Tokens often are also listed and traded on online platforms, typically called virtual currency exchanges, and they usually trade for other digital assets or fiat currencies. Often, tokens are listed and tradeable immediately after they are issued. Issuers often release a "white paper" describing the particular project they seek to fund and the terms of the ICO. Issuers often pay others to promote the offering, including through social media channels such as message boards, online videos, blogs, Twitter, and Facebook. There are websites and social media feeds dedicated to discussions about ICOs and the offer, sale and trading of coins and tokens.
} 
Munchee App with MUN tokens, paying its employees and advisors with MUN tokens, and "facilitating advertising transactions in the future." In the MUN White Paper and elsewhere, Munchee said that it would spend $75 \%$ of the offering proceeds to hire people for its development team and to market and promote the Munchee App, use 15\% "for maintenance and to ensure the smooth operation of the MUN token ecosystem" and use 10\% for "legals to make sure Munchee is compliant in all countries." Munchee described a timeline that provided for various development milestones in 2018 and 2019, including the development of a smart contract on the Ethereum blockchain to integrate "in-app" use of the MUN token and setting up in-app wallets for end-users.

8. The MUN White Paper referenced the DAO Report and stated that Munchee had done a "Howey analysis" and that "as currently designed, the sale of MUN utility tokens does not pose a significant risk of implicating federal securities laws." The MUN White Paper, however, did not set forth any such analysis.

Conforme foi alegado, antes de propor tal oferta de tokens, a Munchee diz ter feito uma análise, a partir do teste Howey, para ver se o objeto da operação se enquadrava como security. Conforme foi descrito no relato da companhia, tal Criptoativo se enquadra na categoria de Utility Token, visto que é um meio de troca de bens e serviços dentro de uma plataforma, de um sistema constituído no aplicativo. Como foi relatado pela CVM no caso da Niobium, tal tipo de Criptoativo não se enquadra nos parâmetros de classificação para valor mobiliário no Brasil.

Contudo, a SEC formou um entendimento diferente no caso em tela. $\mathrm{Na}$ instituição norte americana foi exposto como relevante a questão da valorização do token e a expectativa dos usuários "investidores" em captar um lucro futuro em cima disso, com o provimento da valorização vindo de esforços de terceiros, no caso a companhia Munchee e seus agentes, como consta no já referido processo administrativo da SEC:

10. While Munchee told potential purchasers that they would be able to use MUN tokens to buy goods or services in the future after Munchee created an "ecosystem," no one was able to buy any good or service with MUN throughout the relevant period.

11. On the Munchee Website, in the MUN White Paper and elsewhere, Munchee described the "ecosystem" that it would create, stating that it would pay users in MUN tokens for writing food reviews and would sell both advertising to restaurants and "in-app" purchases to app users in exchange for MUN tokens. 
Munchee also said it would work with restaurant owners so diners could buy food with MUN tokens and so that restaurant owners could reward app users - perhaps those who visited the restaurant or reviewed their meal - in MUN tokens. As a result, MUN tokens would increase in value. [...]

12. In the MUN White Paper, on the Munchee Website and elsewhere, Munchee and its agents further emphasized that the company would run its business in ways that would cause MUN tokens to rise in value. First, Munchee described a "tier" plan in which the amount it would pay for a Munchee App review would depend on the amount of the author's holdings of MUN tokens. For example, a "Diamond Level" holder having at least 300 MUN tokens would be paid more for a review than a "Gold Level" holder having only 200 MUN tokens. Also, Munchee said it could or would "burn" MUN tokens in the future when restaurants pay for advertising with MUN tokens, thereby taking MUN tokens out of circulation. $[\ldots]$

13. Munchee intended for MUN tokens to trade on a secondary market. In the MUN White Paper, Munchee stated that it would work to ensure that MUN holders would be able to sell their MUN tokens on secondary markets, saying that "Munchee will ensure that MUN token is available on a number of exchanges in varying jurisdictions to ensure that this is an option for all token-holders." Munchee represented that MUN tokens would be available for trading on at least one U.S.-based exchange within 30 days of the conclusion of the offering. It also stated that Munchee would buy or sell MUN tokens using its retained holdings in order to ensure there was a liquid secondary market in MUN tokens. [...]

14. Purchasers reasonably would have viewed the MUN token offering as an opportunity to profit. Purchasers had a reasonable expectation that they would obtain a future profit from buying MUN tokens if Munchee were successful in its entrepreneurial and managerial efforts to develop its business. Purchasers would reasonably believe they could profit by holding or trading MUN tokens, whether or not they ever used the Munchee App or otherwise participated in the MUN "ecosystem," based on Munchee's statements in its MUN White Paper and other materials. Munchee primed purchasers' reasonable expectations of profit through statements on blogs, podcasts, and Facebook that talked about profits.

15. For example, Munchee published a blog post on October 30, 2017 that was titled "7 Reasons You Need To Join The Munchee Token Generation Event." Reason 4 listed on the post was "As more users get on the platform, the more valuable your MUN tokens will become" and then went on to describe how MUN purchasers could "watch[] their value increase over time" and could count on the "burning" of MUN tokens to raise the value of remaining MUN tokens.

16. Similarly, on or about October 23, 2017, one of Munchee's founders described the opportunity on a podcast about the MUN offering: So they [users] will create more quality content to attract more restaurants onto the platform. So the more restaurants we have, the more quality content Munchee has, the value of the MUN token will go up - it's like an underlying incentive for users to actually contribute and actually build the community. [...] 
18. Munchee and its agents targeted the marketing of the MUN tokens offering to people with an interest in tokens or other digital assets that have in recent years created profits for early investors in ICOs. This marketing did not use the Munchee App or otherwise specifically target current users of the Munchee App to promote how purchasing MUN tokens might let them qualify for higher tiers and bigger payments on future reviews. Nor did Munchee advertise the offering of MUN tokens in restaurant industry media to reach restaurant owners and promote how MUN tokens might let them advertise in the future. Instead, Munchee and its agents promoted the MUN token offering in forums aimed at people interested in investing in Bitcoin and other digital assets, including on BitcoinTalk.org, a message board where people discuss investing in digital assets. These forums are available and attract viewers worldwide, even though the Munchee App was only available in the United States.

19. For example, one of Munchee's founders chose to appear and promote the MUN token offering on the podcast discussed above where the host talks with guests about blockchains and digital assets, emphasizing the financial value of "cryptocurrency." On that podcast, the Munchee founder talked about making money purchasing digital assets, including her own profits investing in Ether and other digital assets.

20. Similarly, Munchee offered to provide MUN tokens to people who published promotional videos, articles or blog posts in forums such as BitcoinTalk.org or otherwise helped Munchee promote the MUN token offering. More than 300 people promoted the MUN token offering through social media and by translating MUN token offering documents into multiple languages so that Munchee could reach potential investors in South Korea, Russia, and other countries where the Munchee App was unavailable. [...]

21. Purchasers would reasonably have had the expectation that Munchee and its agents would expend significant efforts to develop an application and "ecosystem" that would increase the value of their MUN tokens.

22. Munchee highlighted the credentials, abilities and management skills of its agents and employees. For example, in the MUN White Paper and elsewhere, Munchee highlighted that its founders had worked at prominent technology companies and highlighted their skills running businesses and creating software.

23. As discussed above, Munchee said in the MUN White Paper that the value of MUN tokens would depend on the company's ability to change the Munchee App and create a valuable "ecosystem" that would inspire users to create new reviews, inspire restaurants to obtain MUN tokens to reward diners and pay Munchee for advertising, and inspire users to obtain MUN tokens to buy meals and to attain higher status within the Munchee App. Munchee said that it and its agents would undertake that work during 2018 and 2019.

24. Potential purchasers would have had a reasonable understanding that their future profit depended on Munchee creating a MUN "ecosystem." For example, on or about October 25, 2017, a person posted a video onYouTube to describe the 
MUN token offering. The person's YouTube channel has approximately 15,000 followers and was created by a self-proclaimed "[c]ryptocurrency enthusiast" who believed "[t]he early investor catches the bitcoin."

Assim, ao se deparar com uma possibilidade de lucro com o mercado secundário dos Criptoativos, e que essa valorização do "ecossistema" foi fornecida através de esforços de terceiros, a SEC entendeu que dessa forma há a constituição dos requisitos necessários para que o token seja classificado como security. Com isso, caso a Munchee Inc. mantivesse a sua "oferta pública" da maneira que estava exercendo até o momento, sofreria as sanções legais previstas.

Por fim, a SEC proferiu a seguinte análise jurídica:

28. Under Section 2(a)(1) of the Securities Act, a security includes "an investment contract." See 15 U.S.C. § 77b. An investment contract is an investment of money in a common enterprise with a reasonable expectation of profits to be derived from the entrepreneurial or managerial efforts of others. See SEC v. Edwards, 540 U.S. 389, 393 (2004); SEC v. W.J. Howey Co., 328 U.S. 293, 301 (1946); see also United Housing Found., Inc. v. Forman, 421 U.S. 837, 852-53 (1975) (The "touchstone" of an investment contract "is the presence of an investment in a common venture premised on a reasonable expectation of profits to be derived from the entrepreneurial or managerial efforts of others."). This definition embodies a "flexible rather than a static principle, one that is capable of adaptation to meet the countless and variable schemes devised by those who seek the use of the money of others on the promise of profits." Howey, 328 U.S. at 299 (emphasis added). The test "permits the fulfillment of the statutory purpose of compelling full and fair disclosure relative to the issuance of 'the many types of instruments that in our commercial world fall within the ordinary concept of a security." Id. In analyzing whether something is a security, "form should be disregarded for substance," Tcherepnin v. Knight, 389 U.S. 332, 336 (1967), "and the emphasis should be on economic realities underlying a transaction, and not on the name appended thereto." Forman, 421 U.S. at 849.

29. As the Commission discussed in the DAO Report, tokens, coins or other digital assets issued on a blockchain may be securities under the federal securities laws, and, if they are securities, issuers and others who offer or sell them in the United States must register the offering and sale with the Commission or qualify for an exemption from registration.

\section{A. The MUN Tokens Were Securities}

30. As described above, the MUN tokens were securities as defined by Section 2(a)(1) of the Securities Act because they were investment contracts. 
31. Munchee offered and sold MUN tokens in a general solicitation that included potential investors in the United States. Investors paid Ether or Bitcoin to purchase their MUN tokens. Such investment is the type of contribution of value that can create an investment contract.

32. MUN token purchasers had a reasonable expectation of profits from their investment in the Munchee enterprise. The proceeds of the MUN token offering were intended to be used by Munchee to build an "ecosystem" that would create demand for MUN tokens and make MUN tokens more valuable. Munchee was to revise the Munchee App so that people could buy and sell services using MUN tokens and was to recruit "partners" such as restaurants willing to sell meals for MUN tokens. The investors reasonably expected they would profit from any rise in the value of MUN tokens created by the revised Munchee App and by Munchee's ability to create an "ecosystem" - for example, the system described in the offering where restaurants would want to use MUN tokens to buy advertising from Munchee or to pay rewards to app users, and where app users would want to use MUN tokens to pay for restaurant meals and would want to write reviews to obtain MUN tokens. In addition, Munchee highlighted that it would ensure a secondary trading market for MUN tokens would be available shortly after the completion of the offering and prior to the creation of the ecosystem. Like many other instruments, the MUN token did not promise investors any dividend or other periodic payment. Rather, as indicated by Munchee and as would have reasonably been understood by investors, investors could expect to profit from the appreciation of value of MUN tokens resulting from Munchee's efforts.

33. Investors' profits were to be derived from the significant entrepreneurial and managerial efforts of others - specifically Munchee and its agents - who were to revise the Munchee App, create the "ecosystem" that would increase the value of MUN (through both an increased demand for MUN tokens by users and Munchee's specific efforts to cause appreciation in value, such as by burning MUN tokens), and support secondary markets. Investors had little choice but to rely on Munchee and its expertise. At the time of the offering and sale of MUN tokens, no other person could make changes to the Munchee App or was working to create an "ecosystem" to create demand for MUN tokens.

34. Investors' expectations were primed by Munchee's marketing of the MUN token offering. To market the MUN token offering, Munchee and its agents created the Munchee Website and the MUN White Paper and then posted on message boards, social media and other outlets. They described how Munchee would revise the Munchee App and how the new "ecosystem" would create demand for MUN tokens. They likened MUN to prior ICOs and digital assets that had created profits for investors, and they specifically marketed to people interested in those assets - and those profits - rather than to people who, for example, might have wanted MUN tokens to buy advertising or increase their "tier" as a reviewer on the Munchee App. Because of the conduct and marketing materials of Munchee and its agents, investors would have had a reasonable belief that Munchee and its agents could be relied on to provide the significant entrepreneurial and managerial efforts required to make MUN tokens a success. 
35. Even if MUN tokens had a practical use at the time of the offering, it would not preclude the token from being a security. Determining whether a transaction involves a security does not turn on labelling - such as characterizing an ICO as involving a "utility token" - but instead requires an assessment of "the economic realities underlying a transaction." Forman, 421 U.S. at 849. All of the relevant facts and circumstances are considered in making that determination. See Forman, 421 U.S. at 849 (purchases of "stock" solely for purpose of obtaining housing not purchase of "investment contract"); see also SEC v. C.M. Joiner Leasing Corp., 320 U.S. 344, 352-53 (1943) (indicating the "test . . . is what character the instrument is given in commerce by the terms of the offer, the plan of distribution, and the economic inducements held out to the prospect").

\section{B. Munchee Offered And Sold MUN Tokens In Violation Of The Securities Act}

36. As described above, Munchee offered and sold securities to the general public, including potential investors in the United States, and actually sold securities to about 40 investors. No registration statements were filed or in effect for the MUN token offers and sales and no exemptions from registration were available.

37. As a result of the conduct described above, Munchee violated Section 5(a) of the Securities Act, which states that unless a registration statement is in effect as to a security, it shall be unlawful for any person, directly or indirectly, to make use of any means or instruments of transportation or communication in interstate commerce or of the mails to sell such security through the use or medium of any prospectus or otherwise; or to carry or cause to be carried through the mails or in interstate commerce, by any means or instruments of transportation, any such security for the purpose of sale or for delivery after sale.

38. Also as a result of the conduct described above, Munchee violated Section 5(c) of the Securities Act, which states that it shall be unlawful for any person, directly or indirectly, to make use of any means or instruments of transportation or communication in interstate commerce or of the mails to offer to sell or offer to buy through the use or medium of any prospectus or otherwise any security, unless a registration statement has been filed as to such security.

Em outras palavras, a SEC entendeu que os MUN tokens, e os demais Criptoativos de atuação semelhante, fossem contratos de investimento coletivo devido aos métodos utilizados de divulgação do produto, e à criação do ecossistema estabelecido pelo aplicativo que forneceu um aumento da demanda do token. Assim, possibilitou uma valorização do ativo e proporcionou uma expectativa de lucro para os investidores. 
Em consequência, foi emitido uma cease-and-desist order para impedir a consolidação da operação a ser realizada pela Munchee Inc. Determinou-se, dessa forma, um marco no setor dos Criptoativos já que a comissão anunciou que os aspectos intrínsecos aos tokens não são o bastante para fugir à aplicação das leis reguladoras dos mercados de capitais dos Estados Unidos ${ }^{105}$.

Com isso, a SEC estabelece, num primeiro momento, uma adequação do conceito de security para as emissões de Criptoativos. Posição, como foi dito anteriormente, diferente do já comentado pela CVM, inclusive como consta na apresentação ${ }^{106}$ do Superintendente de Registro de Valores Mobiliários Dov Rawet na Semana de Educação Financeira realizada na CVM, a autarquia brasileira não considera os Utility Tokens como valor mobiliário.

\subsection{Malta Financial Services Authority}

\subsubsection{Atuação}

O próximo ordenamento jurídico a ser comparado é o da instituição de valores mobiliários maltês. Malta foi a primeira jurisdição a elaborar uma orientação direta a questão do Initial Coin Offering, regulamentando os requerimentos necessários para constituir tal operação.

Diferente das autoridades reguladoras citadas até então, em 2018 Malta foi a pioneira em questão da criação de normas e regulamentos para nortearem as relações jurídicas e econômicas envolvendo os Criptoativos.

\footnotetext{
105 ANDRADE, Raphael. Tokens e valores mobiliários: uma nova perspectiva de abordagem. Disponível em: <https://www.conjur.com.br/2018-abr-01/raphael-andrade-tokens-valoresmobiliarios-perspectiva>. Acesso em: 02 jun. 2019.

106 RAWET, Dov. A Visão da CVM sobre ICOs. Disponível em: <https://www.investidor.gov.br/portaldoinvestidor/export/sites/portaldoinvestidor/SemanaENEF/2 018/180516_RJ_CVM_ICOs_DovRawet.pdf>. Acesso em: 02 jun. 2019.
} 
Primeiramente foi elaborado o Malta Digital Innovation Authority $A c t^{107}$, lei que providencia a criação da Malta Digital Innovation Authority (também chamado de $\underline{\text { MDIA) }}$ para apoiar o desenvolvimento e implementação dos princípios orientadores na referida lei e para promover princípios consistentes para o desenvolvimento de inovações tecnológicas. Com esse ponta pé inicial, Malta certificou a atuação de tecnologias como Blockchain e o software da plataforma DLT, e garantiu segurança jurídica e técnica aos usuários e os desenvolvedores, o que incentivou o próprio crescimento desses setores no país ${ }^{108}$.

Em seguida foi promulgado a Innovative Technology Arrangements and Services Act ${ }^{109}$ (ou simplesmente 'ITAS Act'), lei que estabelece a regulamentação dos dispositivos tecnológicos e os serviços de tecnologia mencionados na lei, com a MDIA sendo a instituição designada para regular tais setores.

A ITAS Act estabelece os critérios de definição e requisitos de registro para os acordos de tecnologia inovadora, serviços de tecnologia inovadores e pessoas que prestam serviços de tecnologia inovadora, todos os quais são regulados pela MDIA. A Lei fornece ainda fiscalização e certificação de software e designs usados na concepção e entrega de DLT, smartcontracts, tokens exchanges, bem como outras tecnologias similares ${ }^{110}$.

Por fim, foi promulgada a Virtual Financial Assets Act ('VFA' Act $)^{111}$, lei com a finalidade de regular a esfera jurídica das Ofertas Iniciais de Ativos Financeiros e Virtuais e dos Ativos Financeiros Virtuais, bem

\footnotetext{
${ }^{107}$ Lei de Malta. Disponível em:

<http://justiceservices.gov.mt/DownloadDocument.aspx?app=lp\&itemid=29080\&l=1>. Acesso em: 04 junho 2019.

${ }^{108}$ Conforme disposto no artigo do MALTA, Ico Launch. Disponível em:

<https://icomalta.com/ico-regulation/>. Acesso em: 04 jun. 2019.

${ }^{109}$ Lei de Malta. Disponível em:

<http://justiceservices.gov.mt/DownloadDocument.aspx?app=lp\&itemid=29078>. Acesso em: 04 jun. 2019.

${ }^{110}$ MALTA. Acesso em: 04 jun. 2019.

${ }^{111}$ Lei de Malta. Acesso em: 04 jun. 2019.
} 
como para estabelecer disposições sobre assuntos auxiliares ou incidentais relacionados a eles.

A lei estabelece um marco regulatório para governar entidades que trabalham direta ou indiretamente com Ativos Financeiros Virtuais, tais como I.C.O., tokens exchanges, provedores de wallets $^{112}$, corretoras, gestores de carteiras e consultores de investimento. A VFA também define uma série de requerimentos e orientações para I.C.O. e Security Token Offering whitepapers que deverão ser entregues à Malta Financial Services Authority ('MFSA'). A VFA determina que a emissão de tokens deverá apontar um agente, que será aprovado pela MFSA, como autoridade competente para monitorar e reportar a oferta de tokens.

A partir dessas três leis, Malta conseguiu criar um ambiente favorável para o desenvolvimento dos sistemas blockchain e dos Criptoativos. Enquanto outras jurisdições acabam apenas enquadrando requisitos de valor mobiliário nos whitepapers e tokens emitidos, Malta analisa o software e a tecnologia do objeto em si.

Assim, há uma forma diferente de regular o I.C.O., primeiramente a instituição reguladora avalia a tecnologia explicada nos whitepapers dos operadores interessados em se instalar no país, e assim, determina se a empresa é qualificada para possuir uma licença a partir da qualidade do código de programação do whitepaper $^{113}$.

\footnotetext{
112 Conforme disposto no curso Bitcoin and Cryptocurrencies, da BerkeleyX: CS198.1x: "wallets are simply a method of storing and accessing your private key, which then allows you to spend the corresponding bitcoin. Most wallet software will also store, send, receive, and list transactions for you, since it's easy for software to do this but not necessarily for humans. It would be infeasible to manually keep track of all blockchain activity involving you. To take care of this, wallet software will store all relevant information about the blockchain on your behalf." Em outras palavras, wallet é um Sistema de armazenamento de dados e informações pessoais (comparando é como se fosse a conta em um determinado banco) e para realizar as transferências de criptoativos utiliza-se a private key (que no caso seria a senha de acesso da conta). Disponível em: $<$ https://courses.edx.org/courses/course-

v1:BerkeleyX+CS198.1x+3T2018/courseware/9cab5d7414b9409bb0db0632b2e1ecb7/a1598d46f 5cb493980292552e4e52698/1?activate_block_id=block-

v1\%3ABerkeleyX\%2BCS198.1x\%2B3T2018\%2Btype\%40vertical\%2Bblock\%40d027096eaed24 a738b0992a8811de32d>. Acesso em: 05 jun. 2019.

${ }^{113}$ MALTA. Acesso em: 04 jun. 2019.
} 
Com isso, há um afastamento de uma análise financeira e a elaboração de uma legislação regulatória flexível, visto que sua formação normativa é baseada na análise técnica do produto, o que fez com que Malta fosse conhecida como "Blockchain island".

\subsection{China Securities Regulatory Commission}

\subsubsection{Atuação}

Por último encontra-se a jurisdição regulatória chinesa. A China foi palco de grandes investimentos em I.C.O.s e em "mineração" de Criptoativos. Grande parte veio por causa da concentração de um sistema de hardware chamado de Application Specific Integrated Circuits (ou 'ASIC' $)^{114}$ que possibilitou na China a concentração de $50-90 \%$ do valor global de transferência de Criptoativos, no período entre 2014 e $2016^{115}$.

Inicialmente os agentes reguladores nem sequer reconheciam os tokens como moeda ou como método de pagamento. Em uma circular datada de 3 de dezembro de 2013, o Governo chinês definiu as criptomoedas como uma commodity virtual e permitiu que os cidadãos participassem livremente das negociações on-line, mas alertou sobre os riscos existentes em tais operações. Além disso, as instituições financeiras e de pagamento foram proibidas de realizar qualquer negócio relacionado a Bitcoin, e o People's Bank of China exigiu que todas as entidades sob sua

\footnotetext{
114 Conforme disposto no curso Bitcoin and Cryptocurrencies, da BerkeleyX: CS198.1x, ASICs são um hardware que só possuem em seu sistema operacional a capacidade para resolver os códigos dos Criptoativos, e realiza tal função em um tempo incomparável com os demais computadores. Disponível em: <https://courses.edx.org/courses/course-

v1:BerkeleyX+CS198.1x+3T2018/courseware/9cab5d7414b9409bb0db0632b2e1ecb7/3f242fbbb4 36458da56dc2bff6a2a9ba/14?activate_block_id=block-

v1\%3ABerkeleyX\%2BCS198.1x\%2B3T2018\%2Btype\%40vertical\%2Bblock\%40d51b881439f04 97198d28a18c5107b31>. Acesso em: 05 jun. 2019.

${ }^{115}$ Conforme o exposto no artigo. LEGALICO. People's Republic of China - 中华人民共和国. Disponível em: <https://www.legalico.io/china/>. Acesso em: 05 jun. 2019.
} 
administração "fizessem um esforço para evitar riscos de lavagem de dinheiro que possam surgir do Bitcoin" $" 116$.

Além das negociações on-line, as commodities também são negociáveis como objeto no mercado de derivativos ou contratos futuros, como por exemplo a $\mathrm{CME}^{117}$, que lançou contratos futuros de Bitcoin ${ }^{118}$ na sua bolsa. No entanto, nunca foi possível constituir um mercado de futuro para as "commodities virtuais" na China, visto que todas as negociações de futuros devem ser aprovadas pela Securities Regulatory Commission ('SRC'). Contudo a autoridade não reconheceu os Criptoativos como aptos em atuar no mercado futuro e impediu a sua negociação ${ }^{119}$.

Até o momento, a regulação em relação aos Criptoativos não era rígida, já que não estava sendo disciplinada por nenhum ente regulatório chinês, o que possibilitou o rápido desenvolvimento das operações com essa nova tecnologia no país. Contudo, em 2017 foi emitida uma nova circular, e essa por sua vez estabeleceu a proibição de todas as plataformas de transação de I.C.O. e afirmou que qualquer plataforma que desobedecesse seria desativada pelo Ministério da Indústria e da Tecnologia de Informação $(\text { 'MIIT') })^{120}$.

Em relação a Lei de Valores Mobiliários, a circular de 2017 estabeleceu uma repressão aos I.C.O.s os caracterizou como uma forma de emissão ilegal de títulos e de captação de fundos. Algo semelhante já havia sido estabelecido em 2016 quando a SRC, junto com outros agentes

\footnotetext{
116 Conforme disponível no Notice on Guarding Against the Risks of Bitcoins, issued jointly by PBoC, MIIT, BRC, SRC and IRC. 3 December 2013, Yin Fa [2013] no. 289, p. 1-5.

${ }_{117}$ Bolsa de Chicago (Chicago Mercantile Exchange).

118 Conforme disposto no site do CME Group. CME GROUP. Disponível em: <https://www.cmegroup.com/trading/equity-index/us-index/bitcoin.html〉. Acesso em: 05 jun. 2019.

119 Conforme disposto no artigo: LEGALICO. People's Republic of China - 中华人民共和国. Acesso em: 05 jun. 2019.

${ }^{120}$ Conforme disponível no Announcement on Guarding Against the Risks of Financing by Initial Coin Offerings, issued jointly by PBoC, MIIT, BRC, SRC, IRC, State Administration of Industry and Commerce ("AIC"), and Cyberspace Administration of China ("CAC"). 4 September 2017.
} 
reguladores, emitiu uma proibição de captação on-line de fundos, o que afetou também sistemas como crowdfunding que atuavam no país ${ }^{121}$.

121 Conforme disposto no aritgo Implementation Plan for the Special Rectification on Risks in Equity Crowdfunding. Zheng Jian Fa. [2016] no. 29, April 14, 2016. 


\section{CONCLUSÃO}

A partir das diversas esferas jurídicas apresentadas, percebe-se que o tema da regulação dos Criptoativos está sendo tratado de diferentes formas. São evidentes as preocupações dos entes estatais referente às aplicações ilícitas dos Criptoativos, visto que se trata de uma forma, até o momento, não regulada e que o atraiu inúmeras operações de lavagem de dinheiro, pirâmides, esquemas "Ponzi"122, esquemas "pump\&dump"123 e demais fraudes.

Fora os riscos cibernéticos, já que as movimentações de Bitcoin, e outras criptomoedas, atraíram a atuação de hackers que atacaram diversas exchanges e demais sistemas de armazenamento de Criptoativos. Ademais há ainda a questão do risco da liquidez dos tokens, visto que tais ativos digitais possuem uma alta volatilidade, o que pode provocar perdas expressivas da quantia aplicada pelos usuários.

Pela análise das jurisdições brasileiras e norte americanas, até o momento, os Criptoativos não estão totalmente inseridos num conceito jurídico já pré estabelecido. Há certas formas de adequações nas aplicações das Instruções e nos precedentes conforme as funcionalidades apresentadas pelos tokens. Contudo, existem alguns "desencaixes" na forma como estão sendo regulados no momento, visto que as presentes normas não preveem a atuação desta tecnologia tão recente.

Em complementação, nota-se também os casos das regulamentações de Malta e da China, cada uma diametralmente oposta a outra. Tais normas não auxiliam a consolidação normativa e jurisprudencial do ativo, visto que uma é fortemente impeditiva e a outra é amplamente permissiva. Não

\footnotetext{
${ }^{122}$ Os sistemas "Ponzi" se caracterizam, em geral, como uma forma de divulgação de informações falsas sobre um determinado projeto ou serviço, oferta de ganhos exagerados ou garantidos, ou ainda um sistema de remuneração alimentado pela entrada de novos participantes. A referida classificação está disposta no Alerta da CVM de maio de 2018.

${ }^{123} \mathrm{O}$ sistema "pump\&dump" trata-se de um esquema de manipulação realizado através de informações falsas e estratégias de marketing, com o intuito de inflar os preços para vender os determinados ativos. Conforme classificação apresentada no Alerta da CVM de maio de 2018.
} 
incentivando, dessa forma, a criação de uma massa crítica para elaboração de uma norma adequada para regular tal produto, pois ambas tomaram medidas extremistas em relação a tal discussão.

O objetivo deste trabalho é promover um debate mais aprofundado sobre essa nova tecnologia que pretende atualizar aplicações utilizadas cotidianamente pela sociedade. Entende-se que a regulamentação dos Criptoativos só irá alcançar um resultado apropriado após a análise casuística dos objetos apresentados e enfim ser estabelecido uma legislação específica sobre o tema. 


\section{REFERÊNCIAS BIBLIOGRÁFICAS}

ABCRIPTO. Disponível em: <http://abcb.in/>. Acesso em: 28 mai. 2019. mai. 2019.

Disponível em: <https://www.abcripto.com.br/>. Acesso em: 28

ABRÃO, Nelson. Direito Bancário. $17^{\mathrm{a}}$ ed. São Paulo: Saraiva Educação, 2018.

ANDRADE, Raphael. Tokens e valores mobiliários: uma nova perspectiva de abordagem. Disponível em: <https://www.conjur.com.br/2018-abr01/raphael-andrade-tokens-valores-mobiliarios-perspectiva>. Acesso em: 02 jun. 2019.

Announcement on Guarding Against the Risks of Financing by Initial Coin Offerings, issued jointly by PBoC, MIIT, BRC, SRC, IRC, State Administration of Industry and Commerce ("AIC"), and Cyberspace Administration of China ("CAC"). 4 September 2017.

BANCO CENTRAL DO BRASIL. Comunicado $n^{\circ}$ 31.379. 16 nov. 2017. Disponível em:

<https://www.bcb.gov.br/estabilidadefinanceira/exibenormativo?tipo=Com unicado\&numero=31379>. Acesso em: 23 mai. 2019.

BANCO CENTRAL DO BRASIL. $F A Q$ - Câmbio - Mercado de câmbio definições. Disponível em:

<www.bcb.gov.br/acessoinformacao/legado?url=https:\%2F\%2Fwww.bcb.g ov.br\%2Fpre\%2Fbc_atende\%2Fport\%2Fmerccam.asp>. Acesso em: 10 abr. 2019.

BANCO CENTRAL DO BRASIL. Moedas Virtuais. Disponível em: <https://www.bcb.gov.br/acessoinformacao/legado?url=https:\%2F\%2Fww w.bcb.gov.br\%2Fpre\%2Fbc_atende\%2Fport\%2Fmoedasvirtuais.asp $\% 3$ Fid pai\%3DFAQCIDADAO>. Acesso em: 23 mai. 2019.

BARROSI-FILHO, M; SZTAJN, R. Natureza Jurídica da Moeda e Desafios da Moeda Virtual. Justitia, São Paulo, v. 204/205/206, p. 251-268, Jan./Dec. 2013-2014-2015.

BLOCKCHAIN APP FACTORY. Tokenized Assets Offering - Legally Compliant Asset-Backed Tokens! Disponível em:

$<$ https://www.blockchainappfactory.com/tokenized-asset- 
offering\#utm_source=Medium\&utm_medium=Blog\&utm_campaign=vigne sh>. Acesso em: 18 mai. 2019.

BM\&FBOVESPA. Segmentos de listagem. Disponível em: $<$ http://www.bmfbovespa.com.br/pt_br/listagem/acoes/segmentos-delistagem/novo-mercado/>. Acessado em: 22 mai. 2019.

BRASIL. RE 478.410. Rel. Min. Eros Grau, Tribunal Pleno, DJe 14/5/2010.

BRASIL. Lei no 6.385, de 7 de dezembro de 1976. Disponível em: <http://www.planalto.gov.br/ccivil_03/leis/16385.htm>. Acesso em: 05 junho. 2019.

BRASIL. Senado Federal. CCT vai debater regulamentação das bitcoins. Disponível em:

<https://www12.senado.leg.br/noticias/materias/2019/05/15/cct-vaidebater-regulamentacao-das-bitcoins>. Acesso em: 28 mai. 2019.

BRASIL. SRE. Reg. $n^{\circ}$ 0888/18. Caracterização de ICO como oferta de valor mobiliário - PROC. SEI 19957.010938/2017-13. Disponível em: <http://www.cvm.gov.br/decisoes/2018/20180130_R1.html>. Acesso em: 20 mai. 2019.

CAMARGO, Rodrigo de S. V. et al. Memorando $n^{\circ} 7 / 2018$. CVM/SRE/GER-3. Disponível em:

<http://www.cvm.gov.br/export/sites/cvm/decisoes/anexos/2018/20180130/ 088818_ManifestacaoSRE.pdf>. Acesso em: 20 mai. 2019.

CARVALHOSA, Modesto de Souza Barros. Oferta pública de aquisições de ações. Rio de Janeiro: IBMEC, 1979.

CLAYTON, Chairman Jay. Statement on Cryptocurrencies and Initial Coin Offerings. Disponível em: <https://www.sec.gov/news/publicstatement/statement-clayton-2017-12-11>. Acesso em: 19 mar. 2019.

CME GROUP. Disponível em: <https://www.cmegroup.com/trading/equity-index/us-index/bitcoin.html>. Acesso em: 05 jun. 2019.

COIN CRUNCH. Guide to Crypto Token Types. Disponível em: <https://hackernoon.com/guide-to-crypto-token-types-6ce04edaba72>. Acesso em: 19 março 2019 
COINTIMES. O primeiro Security Token Offering do Brasil. Disponível em: $\quad<$ https://cointimes.com.br/o-primeiro-security-token-offering-dobrasil/>. Acesso em: 26 mar. 2019.

COMISSÃO DE VALORES MOBILIÁRIOS. Deliberação da $n^{\circ} 785.19$ dez. 2017.

COMISSÃO DE VALORES MOBILIÁRIOS. História do Mercado de Capitais. Disponível em:

<https://www.investidor.gov.br/menu/Menu_Academico/O_Mercado_de_v alores_mobiliarios_brasileiro/Historia_Mercado-Capitais.html>. Acesso em: 06 jun. 2019.

COMISSÃO DE VALORES MOBILIÁRIOS. Initial Coin Offerings (ICOs). Disponível em: <http://www.cvm.gov.br/noticias/arquivos/2017/20171116-1.html>. Acesso em: 16 mai. 2019.

COMISSÃO DE VALORES MOBILIÁRIOS. O mercado de valores mobiliários brasileiro. $3^{\mathrm{a}}$ ed. Rio de Janeiro, 2014.

COMISSÃO DE VALORES MOBILIÁRIOS. Oferta pública de distribuição primária e secundária. Portal do Investidor. Disponível em: $<$ http://www.investidor.gov.br/menu/Menu_Investidor/ofertas/ofertas_publi cas.html>. Acesso em: 17 mai. 2019.

COMISSÃO DE VALORES MOBILIÁRIOS. Relatório Semestral JaneiroJunho 2018. Disponível em:

<http://www.cvm.gov.br/export/sites/cvm/menu/acesso_informacao/planos/ sbr/Relatorio_semestral_janeirojunho_2018.pdf>. Acesso em: 26 mar. 2019.

COMISSÃO DE VALORES MOBILIÁRIOS. Supervisão Baseada em Risco. Relatório Semestral. Julho, Dezembro 2017. Disponível em: <http://www.cvm.gov.br/export/sites/cvm/menu/acesso_informacao/planos/ sbr/Relatorio_Semestral_julhodezembro_2017.pdf>. Acesso em: 20 mai. 2019.

Conforme consta no artigo da U.S. Securities and Exchanges Commission. Company Halts ICO After SEC Raises Registration Concerns. Disponível em: 〈https://www.sec.gov/news/press-release/2017-227>. Acesso em: 31 mai. 2019.

CORNELL LAW SCHOOL. U.S. Supreme Court. Securities and Exchange Comission v. W. J. Howey CO. et al. Disponível em: 
<https://www.law.cornell.edu/supremecourt/text/328/293>. Acesso em: 2 abr. 2019.

Cryptography is a method of protecting information and communications through the use of codes so that only those for whom the information is intended can read and process it. The pre-fix "crypt" means "hidden" or "vault" and the suffix "graphy" stands for "writing.". Disponível em: $<$ https://searchsecurity.techtarget.com/definition/cryptography>. Acesso em: 06 jun. 2019.

Curso de Bitcoin and Cryptocurrencies da BerkeleyX: CS198.1. Disponível em: <https://courses.edx.org/courses/course-

v1:BerkeleyX+CS198.1x+3T2018/courseware/9aab1c6ab2ff46d9a2696895 ac71f176/97414bbf2199433799b8e87aa60fc8b0/1?activate_block_id=bloc $\mathrm{k}-$

v1\%3ABerkeleyX\%2BCS198.1x\%2B3T2018\%2Btype\%40vertical\%2Bblo ck\%4017b784dd3caf4ac6908ca14a3f193f59>. Acesso em: 06 jun. 2019.

COMISSÃO DE VALORES MOBILIÁRIOS. Criptoativos. Série Alertas, Maio 2018.

DALE, Oliver. What is the Howey Test \& How Does it Relate to ICOs \& Cryptocurrency? Disponível em: <https://blockonomi.com/howey-test/>. Acesso em: 3 abr. 2019.

DE GOBBI, Thais. Colegiado da CVM confirma decisão sobre o NiobiumCoin. Disponível em:

$<$ https://www.machadomeyer.com.br/pt/inteligencia-juridica/publicacoesij/bancario-seguros-e-financeiro-ij/colegiado-da-cvm-confirma-decisaosobre-o-niobium-coin>. Acesso em: 20 mai. 2019.

DEPARTAMENTO FEDERAL DE FINANÇAS DA SUÍÇA. Disponível em: <https://www.efd.admin.ch/efd/en/home/themen/wirtschaft-waehrung--finanzplatz/finanzmarktpolitik/financial-market-infrastructureact--fmia-.html>. Acesso em: 22 mai. 2019.

Disponível em: <https://courses.edx.org/courses/coursev1:BerkeleyX+CS198.1x+3T2018/courseware/9cab5d7414b9409bb0db063 2b2e1ecb7/a1598d46f5cb493980292552e4e52698/1 ?activate_block_id=blo ck-

v1\%3ABerkeleyX\%2BCS198.1x\%2B3T2018\%2Btype\%40vertical\%2Bblo ck\%40d027096eaed24a738b0992a8811de32d>. Acesso em: 05 jun. 2019.

Disponível em: <https://www.bomesp.org/quem-somos>. Acesso em: 20 mai. 2019. 
Disponível em: <https://www.niobiumcoin.io/>. Acesso em: 21 mai. 2019.

ECOA-PUC-Rio. Palestra ministrada pelo Francisco Mussnich e Filipe Thompson em 20 de dezembro de 2017. Disponível em:

<https://www.youtube.com/watch?v=TqqSOKtDYvQ>. Acesso em: 13 abr. 2019.

EIZIRIK, Nelson et al. Mercado de Capitais - regime jurídico. $3^{\mathrm{a}}$ ed. rev. e amp., Rio de Janeiro: Renovar, 2011.

Ethereum\& Smart Contracts: Enabling a Decentralized Future. Bitcoin and Cryptocurrencies. Disponível em:

$<$ https://courses.edx.org/courses/coursev1:BerkeleyX+CS198.1x+3T2018/courseware/ff59f66fd88246d992d5d001 dd4820a8/8244efc217974454ba060eced4b1d83c/3?activate_block_id=bloc $\mathrm{k}-$

v1\%3ABerkeleyX\%2BCS198.1x\%2B3T2018\%2Btype\%40vertical\%2Bblo ck\%40496d2eb3deb2472aaaac0e4421a862dd>. Acesso em: 20 mar. 2019.

ETHEREUM. What is Ethereum? Disponível em:

<https://www.ethereum.org/beginners/>. Acesso em: 21 mar. 2019.

Exchanges de criptomoedas: o que é e como escolher?. Mercado Bitcoin. Disponível em: <https://blog.mercadobitcoin.com.br/exchange-decriptomoedas-o-que-\%C3\%A9-e-como-escolher-f06d8c41e0b7>. Acesso em: 11 abr. 2019.

FEIGELSON, Bruno. Sandbox: o futuro da regulação. No Brasil, o instituto vem ganhando força. Disponível em:

<https://www.jota.info/paywall?redirect_to=//www.jota.info/opiniao-eanalise/colunas/regulacao-e-novas-tecnologias/sandbox-o-futuro-daregulacao-15012018>. Acesso em: 20 mai. 2019.

GYMREWARDS. Disponível em: <https://www.gymrewards.io/>. Acesso em: 1 abr. 2019.

HENRIQUE, Matheus. $O$ que são as securities tokens e porque o mercado está tão interessado nelas?. Disponível em:

<https://guiadobitcoin.com.br/que-sao-security-tokens/>. Acesso em: 24 mar. 2019.

HERTOG, Johan Den. General Theories of Regulation. In: BOUDEWIJN BOUCKAERT, Gerrit de Geest (Eds.). Enciclopedia of Law and Economics, v. 3. Cheltenham: Edward Elgar Publishing Limited, 2001. 
HUGON, Paul. Introdução à Análise e às políticas Monetárias e à Moeda no Brasil. São Paulo: Pioneira, 1967.

ICOSCORING. Types of tokens. The four mistakes beginner cryptoinvestors make. Disponível em: <https://medium.com/swlh/types-of-tokensthe-four-mistakes-beginner-crypto-investors-make-a76b53be5406>. Acesso em: 19 mar. 2019.

Implementation Plan for the Special Rectification on Risks in Equity Crowdfunding. Zheng Jian Fa. [2016] no. 29, April 14, 2016.

KERKMANN, Jens. What is a Tokenized Asset Offering (TAO). Disponível em: 〈https://blockchainwelt.de/tokenized-asset-offering-tao/>. Acesso em: 18 mai. 2019.

KHATWANI, Sudhir. A look at the top 5 Securities Tokens Issuance Plataforms. Disponível em: <https://coinsutra.com/security-tokensplatform/>. Acesso em: 24 mar. 2019.

KRIA. Disponível em: <https://www.kria.vc/startups/kria>. Acesso em: 26 mar. 2019.

LAMY FILHO, Alfredo; PEDREIRA, José Luiz Bulhões. Direito das Companhias. v. I. Rio de Janeiro: Forense, 2009.

LEÃES, Luís Gastão Paes de Barros. O conceito de "security" no direito norte americano e o conceito análogo no direito brasileiro. Revista de direito mercantil, industrial, econômico e financeiro, v. 14, 1974.

LEGALICO. People's Republic of China - 中华人民共和国. Disponível em: <https://www.legalico.io/china/>. Acesso em: 05 jun. 2019.

Lei de Malta. Disponível em:

<http://justiceservices.gov.mt/DownloadDocument.aspx?app=lp\&itemid=2 9080\&l=1>. Acesso em: 04 junho 2019.

LUNDY-BRYAN, Lawrence et al. All You Need to Know About Initial Coin Offerings. Disponível em: <https://courses.edx.org/courses/coursev1:BerkeleyX+CS198.1x+3T2018/courseware/9aab1c6ab2ff46d9a2696895 ac71f176/b9f1fc94b86d42e3a3346efa57e0ff32/2?activate_block_id=blockv1\%3ABerkeleyX\%2BCS198.1x\%2B3T2018\%2Btype\%40vertical\%2Bblo ck\%40c6fb6211ee604e1d9e6907231ba9feb2>. Acesso em: 13 abr. 2019. 
MACY, Scot. WhatisAssetTokenization? Disponível em: $<$ https://medium.com/security-token-offering/what-is-asset-tokenization2f0536e3e81c>. Acesso em: 18 mai. 2019.

MALTA, Ico Launch. Disponível em: <https://icomalta.com/icoregulation/>. Acesso em: 04 jun. 2019.

MASTERTHECRYPTO. Moedas, Tokens \&Altcoins: Qual é a diferença? Disponível em: <https://masterthecrypto.com/differences-betweencryptocurrency-coins-and-tokens/?lang=pt $>$. Acesso em: 17 mar. 2019.

MATTOS FILHO, Ary Oswaldo. O conceito de valor mobiliário. RAERevista de administração de empresas, $\mathrm{n}^{\circ}$ 2, 1985.

MEDIAPEDIA. The Various types of Crypto Tokens. Disponível em: $<$ https://medium.com/@ medipedia/the-various-types-of-crypto-tokens26bab8f6622c>. Acesso em: 19 mar. 2019.

MIOZZO, Júlia. Como funcionam os ICOs da Bomesp, primeira bolsa de criptomoedas empresariais no Brasil. Disponível em:

<https://www.infomoney.com.br/negocios/inovacao/noticia/7330885/comofuncionam-icos-bomesp-primeira-bolsa-criptomoedas-empresariais-brasil>. Acesso em: 20 mai. 2019.

NAKAMOTO, Satoshi. Bitcoin: A Peer-to-Peer Eletronic Cash System. Disponível em: 〈www.bitcoin.org〉. Acesso em: 09 abr. 2019.

Notice on Guarding Against the Risks of Bitcoins, issued jointly by PBoC, MIIT, BRC, SRC and IRC. 3 December 2013, Yin Fa [2013] no. 289.

OMISSÃO DE VALORES MOBILIÁRIOS. O mercado de valores mobiliários brasileiro. $3^{\mathrm{a}}$ ed. Rio de Janeiro, 2014.

ORDER INSTITUTING CEASE-ANDDESIST PROCEEDINGS PURSUANT TO SECTION 8A OF THE SECURITIES ACT OF 1933, MAKING FINDINGS, AND IMPOSING A CEASE-AND-DESIST ORDER. 11 dez. 2017. Disponível em:

<https://www.sec.gov/litigation/admin/2017/33-10445.pdf>. Acesso em: 01 jun. 2019.

PALLOTA, Christopher; MOLINARI, Vicent. Goodbye ICOs, Hello TAOs? How tokens Will change in 2018. Disponível em: $<$ https://www.coindesk.com/goodbye-icos-hello-taos-tokens-will-change2018>. Acesso em: 18 mai. 2019. 
PARENTE, Norma Jossen. Mercado de Capitais. In: CARVALHOSA, Modesto. (Coord.). Coleção tratado de direito empresarial. v. 6. São Paulo: Editora Revista dos Tribunais, 2016.

PEREIRA, Caio Mário da Silva. Instituições de direito civil: introdução ao direito civil: teoria geral de direito civil. rev. e atual. MORAES, Maria Celina Bodin de. 32a ed. Rio de Janeiro: Forense, 2019.

PETRAM, Lodewijk. The World's First Stock Exchange: How the Amsterdam Market for Duscht East India Company Shares Became a Modern Securities Market, 1602-1200. RICHARDS, Lynne. (Trad.). ISBN 9780231163781. Columbia University Press, 2014.

PINHEIRO, Armando Castelar et al. Direito e economia: diálogos. Rio de Janeiro: FGV Editora, 2019.

POLYMATH. Disponível em: 〈https://polymath.network/>. Acesso em: 24 mar. 2019.

RAWET, Dov. A Visão da CVM sobre ICOs. Disponível em: $<$ https://www.investidor.gov.br/portaldoinvestidor/export/sites/portaldoinve stidor/SemanaENEF/2018/180516_RJ_CVM_ICOs_DovRawet.pdf >.

Acesso em: 02 jun. 2019.

Memorando $n^{\circ}$ 19/2017 - CVM/SRE. Disponível em:

<http://www.cvm.gov.br/export/sites/cvm/decisoes/anexos/2018/20180130/ 088818_ManifestacaoSRE.pdf>. Acesso em: 20 mai. 2019.

RECEITA FEDERAL DO BRASIL. Instrução Normativa RFB $n^{\circ} 1.888$. 03 mai. 2019. Disponível em:

$<$ http://normas.receita.fazenda.gov.br/sijut2consulta/link.action?visao=anot ado\&idAto=100592>. Acesso em: 27 mai. 2019.

REVOREDO, Tatiana Trícia de Paiva. Criptomoedas: cenário global e tendências. Disponível em:

<https://www.jota.info/paywall?redirect_to=//www.jota.info/opiniao-e analise/artigos/criptomoedas-cenario-global-e-tendencias-25102017>. Acesso em: 06 jun. 2019.

SCOTT, Doug. Sweet Appoints Crypto Expert Max Keiser to Economic Advisory Role. Disponível em: <https://brands.sweet.io/2018/06/11/maxkeiser-joins-sweet/>. Acesso em: 1 abr. 2019. 
SECURITIES AND EXCHANGE COMMISSION. Investment Company Act of 1940. Section 2. General Definitions. Article 36.

SUPERINTENDENCIA NACIONAL DE CRIPTOACTIVOS Y ACTIVIDADES CONEXAS. Petro. Hacia la revolucion digital económica. Disponível em: <https://petro.gob.ve/files/petro-whitepaper.pdf>. Acesso em: 29 mar. 2019.

TAUHATA, Sérgio. BTG Pactual lança criptoativo lastreado em imóveis. Disponível em: <https://www.valor.com.br/financas/6130683/btg-pactuallanca-criptoativo-lastreado-em-imoveis>. Acesso em: 22 mai. 2019.

U.S. SUPREME COURT. SEC v. Howey Co., 328 U.S. 293 (1946). Disponível em: <https://supreme.justia.com/cases/federal/us/328/293/\#F1>. Acesso em: 2 abr. 2019.

UMPIERES, Rodrigo Tolotti. Real Madrid se torna o primeiro time de futebol do mundo a aceitar Bitcoin. Disponível em:

<https://www.infomoney.com.br/mercados/bitcoin/noticia/7189013/realmadrid-torna-primeiro-time-futebol-mundo-aceitar-bitcoin>. Acesso em: 04 abr. 2019.

VENÂNCIO FILHO, Alberto et al. Lei das S.A. em seus 40 anos. $1^{\mathrm{a}}$ ed. Rio de Janeiro: Forense, 2017.

WILMOTH, Josiah. 3 Types of ICO Tokens. Disponível em: <https://strategiccoin.com/3-types-ico-tokens/>. Acesso em: 19 mar. 2019.

The Difference Between Utility Tokens and Equity Tokens. Disponível em: <https://strategiccoin.com/difference-utility-tokens-equitytokens/>. Acesso em: 19 mar. 2019. 